\title{
Redução dimensional de dados de alta dimensão e poucas amostras usando Projection Pursuit
}

\author{
Soledad Espezua Llerena
}

Tese apresentada à Escola de Engenharia de São Carlos da Universidade de São Paulo, como parte dos requisitos para obtenção do título de Doutora em Ciências, Programa de Engenharia Elétrica

ORIENTADOR: Prof. Dr. Carlos Dias Maciel ÁREA DE CONCENTRAÇÃO: Sistemas Dinâmicos 
AUTORIZO A REPRODUÇÃO TOTAL OU PARCIAL DESTE TRABALHO

POR QUALQUER MEIO CONVENCIONAL OU ELETRONICO, PARA FINS

DE ESTUDO E PESQUISA, DESDE QUE CITADA A FONTE.

Espezua Llerena, Soledad

Redução dimensional de dados de alta dimensão e poucas amostras usando Projection Pursuit / Soledad Espezua Llerena; orientador Carlos Dias Maciel. São Carlos, 2013.

Tese (Doutorado) - Programa de Pós-Graduação em Engenharia Elétrica e Área de Concentração em Sistemas Dinâmicos -- Escola de Engenharia de São Carlos da Universidade de São Paulo, 2013.

1. Redução dimensional. 2. Classificação. 3. Projection Pursuit. 4. Dados de microarranjo. I. Título. 


\section{FOLHA DE JULGAMENTO}

Candidata: Bacharel SOLEDAD ESPEZUA LLERENA.

Título da tese: "Redução dimensional de dados de alta dimensão e poucas amostras usando Projection Pursuit".

Data da defesa: 30/07/2013

\section{Comissão Julgadora:}

Prof. Associado Carlos Dias Maciel (Orientador)

(Escola de Engenharia de São Carlos/EESC)

Prof. Associado Alexandre Cláudio Botazzo Delbem

(Instituto de Matemática e Computação/ICMC)

Prof. Titular André Carlos Ponce de Leon Ferreira de Carvalho APNSADS (Instituto de Matemática e Computação/ICMC)

Prof. Dr. Estevam Rafael Hruschka Júnior (Universidade Federal de São Carlos/UFSCar)

Prof. Dr. Ailton Akira Shinoda

(Universidade Estadual Paulista "Júlio de Mesquita Filho"/UNESP- Ilha Solteira)
Resultado:

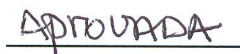

APROVADA APROVADA

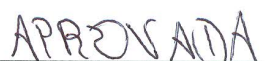

Coordenador do Programa de Pós-Graduação em Engenharia Elétrica e Presidente da Comissão de Pós-Graduação:

Prof. Titular Denis Vinicius Coury 
Dedicatória

A meu esposo Edwin e a meu filho Gabriel por seu grande amor e compreensão. 


\section{Agradecimentos}

Agradeço ao meu orientador prof. Dr. Carlos Dias Maciel, pelo apoio, confiança e oportunidade, elementos essenciais para a realização deste trabalho.

A meu esposo Edwin, grande companheiro e amigo de todas as horas. Pelas longas e longas horas de discussões teóricas, seu carinho, determinação, abnegação à família e sua forma optimista de enfrentar as dificuldades da vida, foram incentivos determinantes para eu chegar até aqui. Por estar sempre nos momentos mais difíceis dando-me seu auxilio e força, por tudo o compartilhado e felicidade que sempre me deu e espero continue assim a vida toda.

A meu filho Gabriel, pequenino da mamãe (nascido durante este trabalho). O tempo de nossa convivência "roubado" pela tese só fez fortalecer a vontade de estar junto de você para compensar o tempo não dedicado.

Agradeço aos meus pais Hugo e Soledad, fontes de inspiração e carinho, por acreditarem em mim e sempre me apoiarem nas decisões tomadas. Aos meus irmãos, César, suporte não só emocional também cúmplice de vida, fonte de alegria inesgotável e Eva Katia, que com sua nobreza só me faz lembrar que na vida podemos ser melhores pessoas. As minhas queridas tias Lourdes e Isabel por seu grande carinho brindado e apoio incondicional.

Agradeço também aos meus amigos corintianos Regina Pimenta e Adilson Barros que sempre estiveram no meu lado compartilhando as coisas simples e alegres da vida. Ao meu grande amigo Renato que foi quase um irmão e foi muito importante neste período, pela compreensão e sustento em tudo momento.

Um agradecimento especial aos meus ex-companheros de laboratório, Alan, Lianet, Amilcar, Anderson e Eugenia pelas gratas horas vivenciadas e algumas sofridas, pelo acolhimento, abertura e disponibilidade em me ajudar sempre.

Também agradeço a todos meus demais queridos amigos que têm me acompanhado neste trajeto e com os quais compartilhei grandes momentos de alegria, bom humor e descontração durante este doutorado: Sandra Patricia, Aymer, Jaime Alberto, Pilar Anzola, Jesús Garcia, Jesús Villalba, Julian Villamarin, Felipe, Marcia, Josephine Bukola, Estephen, Maritza, Victor, Guido, Roxana, Paty, Norvil, Cecilia, Henry, Waldo, Shermila, Frizy, Erick, Indara e Orieta.

A CAPES/PEC-PG, pelo fundamental suporte financeiro dispensado à execução desta pesquisa e ao Programa de Engenharia Elétrica que me aceitou e ajudou em esta jornada. 
Finalmente, agradeço de coração a todas as pessoas que torceram ou intercederam por mim, mesmo que de forma anônima ou discreta, a todos vocês,

Muito Obrigada. 
"And in the end it's not the years in your life that count. It is the life in your years". Abraham Lincolm 


\section{Conteúdo}

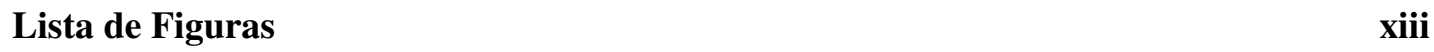

$\begin{array}{ll}\text { Lista de Tabelas } & \text { xv }\end{array}$

$\begin{array}{ll}\text { Lista de Símbolos } & \text { xvii }\end{array}$

$\begin{array}{lll}\text { Lista de Siglas } & \text { xix }\end{array}$

Resumo $\quad$ xxiii

$\begin{array}{ll}\text { Abstract } & \mathbf{x x v}\end{array}$

1 Introdução 1

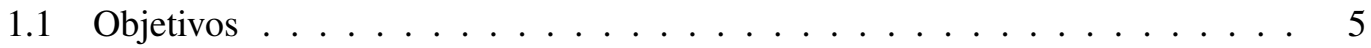

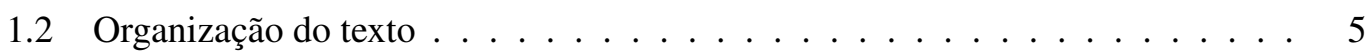

2 Redução dimensional de dados $\quad 7$

2.1 Notação . . . . . . . . . . . . . . . . . . . . . . . 7

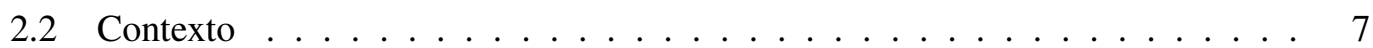

2.3 Seleção de atributos . . . . . . . . . . . . . . . . . . . . 9

2.4 Extração de atributos . . . . . . . . . . . . . . . . . . . . . 13

Considerações Finais . . . . . . . . . . . . . . . . . . . . . . 15

3 Projection Pursuit $\quad 17$

3.1 Projeção dimensional . . . . . . . . . . . . . . . . . . . . . 17

3.2 Projection Pursuit $(\mathrm{PP}) \ldots \ldots \ldots \ldots$. . . . . . . . . . . . . 18

3.3 Índices de projeção . . . . . . . . . . . . . . . . . . . . . . . . . . . . 19

3.3.1 Índices para análise não supervisionada . . . . . . . . . . . . 20

3.3.2 Índices para análise supervisionada . . . . . . . . . . . . . . . 23

3.4 Otimização em Projection Pursuit . . . . . . . . . . . . . . . . . . . . . . 25

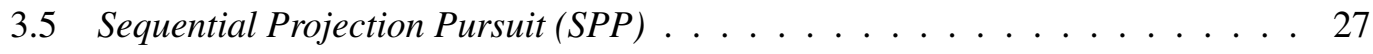


Considerações Finais . . . . . . . . . . . . . . . . . . . . . . . . 27

4 Redução de dimensão com Projection Pursuit 29

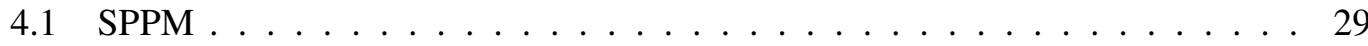

4.1.1 Projection Pusuit Genetic Algorithm (PPGA) . . . . . . . . . . . . . . 33

4.2 Block-SPPM . . . . . . . . . . . . . . . . . . 40

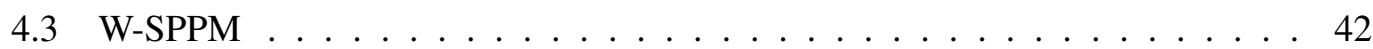

5 Avaliação Experimental 45

5.1 Avaliação de operadores de cruzamento para PPGA . . . . . . . . . . . . . . . 45

5.1.1 Resultados em convergência . . . . . . . . . . . . . . . . . . . 47

5.1 .2 Resultados em número fixo de gerações . . . . . . . . . . . . 52

5.1 .3 Discussão . . . . . . . . . . . . . . . . . . . . . . 52

5.2 Avaliação de PPGA contra outros algoritmos de otimização para SPPM . . . . 56 5.2 .1 Discussão . . . . . . . . . . . . . . . . . . . . . . . . . 57

5.3 Avaliação de Block-SPPM . . . . . . . . . . . . . . . . . . . 58

5.4 Avaliação de W-SPPM . . . . . . . . . . . . . . . . . . . . . . . 67

5.5 Comparação entre Block-SPPM e W-SPPM . . . . . . . . . . . . . . . . . 78

5.6 Melhoramento do tempo de processamento de W-SPPM . . . . . . . . . 80

6 Conclusões $\quad 83$

6.1 Trabalhos futuros . . . . . . . . . . . . . . . . . . 85

6.2 Produção bibliográfica . . . . . . . . . . . . . . . . . . . 86

Apêndice A - Obtenção de dados de microarranjo $\quad 87$

Apêndice B - Algoritmo Candidate Projection Set 90

$\begin{array}{ll}\text { Bibliografia } & 93\end{array}$ 


\section{Lista de Figuras}

FIGURA 2.1 Classificação de técnicas para redução da dimensão . . . . . . . . . . . 10

FIGURA 2.2 Esquema tradicional para seleção de atributos . . . . . . . . . . . . 11

FIGURA 3.1 Exemplo de projeção de um objeto sobre dois planos $\ldots$. . . . . . . 18

FIGURA 3.2 Esquema de busca no índice Qui-Quadrado . . . . . . . . . . . . . 22

FIGURA 4.1 Esquema do algoritmo Sequential Projection Pursuit Modified (SPPM) 31

FIGURA 4.2 Exemplo de geração dos indivíduos filhos nos operadores CX1 e CX2 35

FIGURA 4.3 Exemplo da geração dos filhos no operador CX3 $\ldots \ldots$. . . . . . . 36

FIGURA 4.4 Exemplo da geração dos filhos no CX $4 \ldots \ldots$. . . . . . . . . . . 36

FIGURA 4.5 Exemplo de geração dos filhos nos operadores CX5 e CX6 . . . . . . 38

FIGURA 4.6 Exemplo de geração dos filhos nos operadores CX7 e CX8 . . . . . . 39

FIGURA 4.7 Esquema de Block-SPPM . . . . . . . . . . . . . 41

FIGURA 4.8 Fluxograma de W-SPPM $\ldots \ldots \ldots \ldots$

FIGURA 5.1 Esquema de avaliação do desempenho dos operadores de cruzamento sobre PPGA . . . . . . . . . . . . . . . . . . . 47

FIGURA 5.2 Resultados da aptidão média e o número de gerações para alcançar a

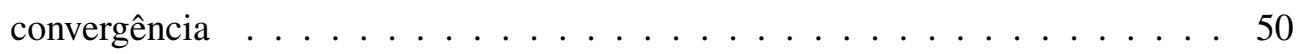

FIGURA 5.3 Resultados do número de gerações para alcançar a convergência usando dois tamanhos de torneio $\ldots \ldots \ldots \ldots \ldots \ldots \ldots$ 
FIGURA 5.4 Resultados da aptidão média e da evolução da população em número fixo de gerações . . . . . . . . . . . . . . . . . . . . . . . . 5 54

FIGURA 5.5 Comparação de desempenho de PPGA versus RSSA e PSO . . . . . 58

FIGURA 5.6 Esquema de avaliação da acurácia de classificação para os classificadores LDA e KNN . . . . . . . . . . . . . . . . . . . . . . . . . 61

FIGURA 5.7 Resultados de classificação com o banco de dados Colon para o método Block-SPMM . . . . . . . . . . . . . . . . . . . . . 63

FIGURA 5.8 Resultados de classificação com o banco de dados MLL para o método Block-SPMM . . . . . . . . . . . . . . . . . . . . . . . . . 64

FIGURA 5.9 Resultados de classificação com o banco de dados SRBCT para o método Block-SPMM . . . . . . . . . . . . . . . . . . . . . . . . 65

FIGURA 5.10 Resultados médios de tempo de processamento para Block-SPMM e outros métodos de redução dimensional . . . . . . . . . . . . . . . . . 67

FIGURA 5.11 Esquema dos experimentos para avaliar o desempenho de W-SPPM . 69

FIGURA 5.12 Acurácias médias (sobre 8 repetições) obtidas com W-SPPM e o classificador LDA . . . . . . . . . . . . . . . . . . . . . . . . 73

FIGURA 5.13 Resultados da média dos ranking sobre os classificadores LDA e KNN com o método W-SPPM . . . . . . . . . . . . . . . . 75

FIGURA 5.14 Resultados médios do tempo de processamento nos experimentos sobre o método W-SPPM . . . . . . . . . . . . . . . . . . . 76

FIGURA 5.15 Comparação de acurácias de classificação dos métodos Block-SPPM e W-SPPM sobre o banco Colon . . . . . . . . . . . . . . . . . . . . . . . . 79

FIGURA 5.16 Comparação de acurácias de classificação dos métodos Block-SPPM e W-SPPM sobre o banco MLL . . . . . . . . . . . . . . . . . . . . . . . . . . 79

FIGURA 5.17 Comparação de acurácias de classificação dos métodos Block-SPPM e W-SPPM sobre o banco SRBC . . . . . . . . . . . . . . . . . . . . . 80

FIGURA A.1 Exemplo de geração de dados de expressão gênica . . . . . . . . . 89 


\section{Lista de Tabelas}

TABELA 2.1 Formato assumido para conjuntos de dados $\ldots \ldots \ldots$. . . . . 8

TABELA 3.1 Índices para análise não supervisionada . . . . . . . . . . . 25

TABELA 3.2 Índices para análise supervisionada $\ldots \ldots \ldots . \ldots . \ldots 25$

TABELA 5.1 Algoritmos de redução dimensional avaliados junto com Block-SPPM 60

TABELA 5.2 Influência da população inicial CPS no tempo de processamento de

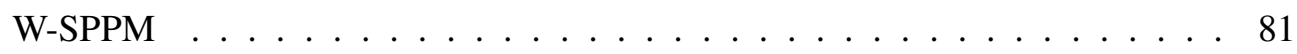

TABELA 5.3 Influência da população inicial CPS na acurácia de classificação de W-SPPM com classificador LDA . . . . . . . . . . . . . . . . . 81 


\section{Lista de Símbolos}

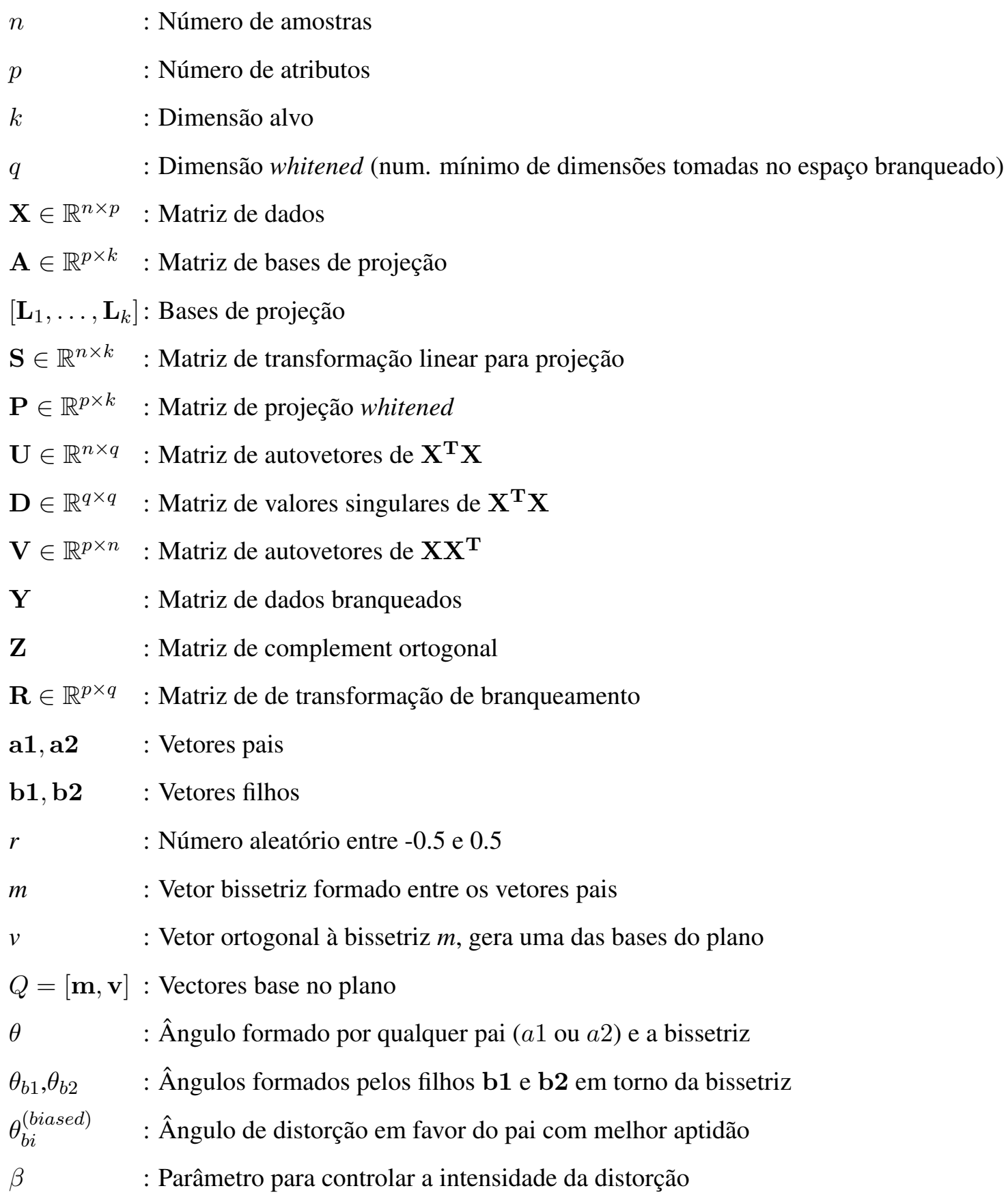


urand $[a, b]$ : Número aleatório gerado seguindo uma distribuição uniforme

$\mathbf{a}_{\text {best }} \quad$ : Pai com o melhor aptidão

$\mathbf{a}_{\text {worst }} \quad$ : Pai com pior aptidão 


\section{Lista de Siglas}

AG Algoritmo Genético

Block-SPPM Block Sequential Projection Pursuit Modified

CBF Consistency-Based Filter

CCA Curvilinear Component Analysis

CDA Curvilinear Distance Analysis

CFS Correlation-based Feature Selection

CPS Candidate Projection Set

CP Componentes Principais

CX1 Operador de cruzamento aritmético interno

CX2 Operador de cruzamento aritmético interno-externo

CX3 Operador de cruzamento de um-ponto

CX4 Operador de cruzamento multiponto

CX5 Operador de cruzamento hiper-cônico interno

CX6 Operador de cruzamento hiper-cônico interno-externo

CX7 Operador de cruzamento interno guiado pela aptidão

CX8 Operador de cruzamento interno-externo guiado pela aptidão

EPP Exploratory Projection Pursuit

FA Factor Analysis 
FCBF Fast Correlation-Based Filter

GEO Gene Expression Omnibus

GNLM Geodesic Non Linear mapping

GTM Generative topographic mapping

ICA Independent Component Analysis

KPCA Kernel PCA

KNN K-Nearest Network

LDA Linear Discriminant Analysis

LE Laplacian Eigenmaps

LLE Locally Linear Embedding

LOO Leave-One-Out

MB Markov Blanket

MDS Multidimensional Scaling

NCA Neighborhood Components Analysis

NMDS Non Linear MDS

PCA Principal Component Analysis

PP Projection Pursuit

PPEA Projection Pursuit Exploratory Analysis

PPGA Projection Pursuit Genetic Algoritm

PSO Particle Swarm Optimization

RSSA Random Scan Sampling Algorithm

RELIEF-F Relief-F Algorithm

SA Simulated Annealing 
SOM Self-Organizing Maps

SPP Sequential Projection Pursuit

SPPM Sequential Projection Pursuit Modified

SVD Singular Value Decomposition

SVM Support Vector Machine

TGA Taguchi-genetic algorithm

T-testM Modified t-test

W-SPPM Whitened Sequential Projection Pursuit Modified 


\section{Resumo}

Espezua Llerena, Soledad. Redução dimensional de dados de alta dimensão e poucas amostras usando Projection Pursuit. 2013. 107 f. Tese de doutorado. Escola de Engenharia de São Carlos, Universidade de São Paulo, São Carlos, 2013.

Reduzir a dimensão de bancos de dados é um passo importante em processos de reconhecimento de padrões e aprendizagem de máquina. Projection Pursuit (PP) tem emergido como uma técnica relevante para tal fim, a qual busca projeções dos dados em espaços de baixa dimensão onde estruturas interessantes sejam reveladas. Apesar do relativo sucesso de PP em vários problemas de redução dimensional, a literatura mostra uma aplicação limitada da mesma em bancos de dados com elevada quantidade de atributos e poucas amostras, tais como os gerados em biologia molecular. Nesta tese, estudam-se formas de aproveitar o potencial de PP em problemas de alta dimensão e poucas amostras a fim de facilitar a posterior construção de classificadores. Entre as principais contribuições deste trabalho tem-se: i) Sequential Projection Pursuit Modified (SPPM), um método de busca sequencial de espaços de projeção baseado em Algoritmo Genético (AG) e operadores de cruzamento especializados; ii) Block Sequential Projection Pursuit Modified (Block-SPPM) e Whitened Sequential Projection Pursuit Modified (W-SPPM), duas estratégias de aplicação de SPPM em problemas com mais atributos do que amostras, sendo a primeira baseada e particionamento de atributos e a segunda baseada em pré-compactação dos dados. Avaliações experimentais sobre bancos de dados públicos de expressão gênica mostraram a eficácia das propostas em melhorar a acurácia de algoritmos de classificação populares em relação a vários outros métodos de redução dimensional, tanto de seleção quanto de extração de atributos, encontrando-se que W-SPPM oferece o melhor compromisso entre acurácia e custo computacional.

Palavras-chaves: Redução dimensional, Classificação, Projection pursuit, Dados de Microarranjo. 


\section{Abstract}

Espezua Llerena, Soledad. Dimension reduction of datasets with large dimensionalities and few samples using Projection Pursuit. 2013. 107 p. Thesis Doctoral. Escola de Engenharia de São Carlos, Universidade de São Paulo, São Carlos, 2013.

Reducing the dimension of datasets is an important step in pattern recognition and machine learning processes. PP has emerged as a relevant technique for that purpose. PP aims to find projections of the data in low dimensional spaces where interesting structures are revealed. Despite the success of PP in many dimension reduction problems, the literature shows a limited application of it in dataset with large amounts of features and few samples, such as those obtained in molecular biology. In this work we study ways to take advantage of the potential of PP in order to deal with problems of large dimensionalities and few samples. Among the main contributions of this work are: i) SPPM, an improved method for searching projections, based on a genetic algorithm and specialized crossover operators; and ii) Block-SPPM and W-SPPM, two strategies of applying SPPM in problems with more attributes than samples. The first strategy is based on partitioning the attribute space while the later is based on a precompaction of the data followed by a projection search. Experimental evaluations over public gene-expression datasets showed the efficacy of the proposals in improving the accuracy of popular classifiers with respect to several representative dimension reduction methods, being W-SPPM the strategy with the best compromise between accuracy and computational cost.

Keywords: Dimentionality reduction, Classification, Projection Pursuit, Microarray data. 


\section{Capítulo 1}

\section{Introdução}

Nas últimas décadas temos assistido um acelerado desenvolvimento e aprimoramento de tecnologias de aquisição de dados em várias áreas científicas e industriais (Johnstone e Titterington, 2009). Isto tem levado ao surgimento de tecnologias de elevado rendimento, as quais têm a capacidade de gerar conjuntos de dados cujos números de atributos medidos $(p)$ são ordens de magnitude maiores que o número de observações ou amostras $(n)$, os assim chamados dados de alta dimensão e poucas amostras (do inglês large $p$ small $n$ data). Um exemplo representativo desses desenvolvimentos tecnológicos é a tecnologia de microarranjo (Russell et al., 2008), a qual tem possibilitado a medição simultânea e econômica dos níveis de expressão de milhares de genes, levando assim a avanços significativos na compreensão das bases biomoleculares de doenças severas como o câncer e, consequentemente, à melhoria de tratamentos e possíveis curas (Golub et al., 1999; Segal et al., 2005).

Apesar da relativa facilidade em coletar bancos de dados de alta dimensão e poucas amostras em diversas áreas do conhecimento, a análise e interpretação dos mesmos provou ser uma tarefa desafiadora (Jimenez e Landgrebe, 1999; Clarke et al., 2008; Johnstone e Titterington, 2009). A origem dessa dificuldade reside no fenômeno conhecido como "a maldição da dimensionalidade" (Korn et al., 2001), inerente a esse tipo de dados. Tal fenômeno estabelece que à medida que se aumenta a razão entre a dimensão dos dados (número de atributos) e o numero de amostras, o espaço onde elas estão representados torna-se cada vez mais vazio e os pontos de dados tendem a ser equidistantes. Isto gera efeitos negativos na maioria de técnicas de reconhecimento de padrões e do aprendizado de máquina, especialmente aqueles baseados em distâncias, tendo-se geralmente instabilidade na estimação de modelos, sobre ajuste dos parâmetros e tendência a convergir frequentemente para modelos ótimos locais. Tais efeitos 
comprometem o poder de generalização dos modelos induzidos e, portanto, a sua utilidade prática (Jimenez e Landgrebe, 1999; Clarke et al., 2008).

Uma abordagem amplamente usada para viabilizar a análise e construção de modelos em dados de alta dimensão e poucas amostras é a redução da dimensão (Clarke et al., 2008). Existem dois paradigmas para esse propósito: seleção de atributos (SA) (Liu e Yu, 2005a; Saeys et al., 2007) e extração de atributos (EA) (Guyon et al., 2006; Burges, 2010). Os métodos de seleção de atributos tentam encontrar subconjuntos reduzidos de atributos entre os atributos originais que sejam relevantes para a análise pretendida. Os métodos de extração de atributos constroem novas representações que podem ser altamente informativas, mediante combinações (lineares ou não lineares) dos atributos originais. SA tem a vantagem de manter a acepção original dos atributos, facilitando assim a interpretação por um experto do domínio (Saeys et al., 2007). No entanto, tem sido apontado que métodos de SA podem não ser tão competitivos quanto os métodos de EA quando o objetivo final é a construção de um sistema de classificação ou regressão (Liu e Motoda, 1998). Uma explicação para isso é que SA está atado ao espaço original de atributos, enquanto que EA não possui tal restrição, proporcionando assim maiores chances de encontrar representações mais compactas e informativas para a tarefa desejada. De fato, visto desde uma perspectiva abrangente, SA é um caso especial de EA, no qual é procurada uma representação que combina linearmente os atributos originais, sendo os coeficientes de combinação valores binários (Liu e Motoda, 1998).

Projection Pursuit (PP) (Friedman e Tukey, 1974; Friedman, 1987) é uma abordagem de EA que tem-se mostrado promissora em contornar o fenômeno da maldição da dimensionalidade. PP reduz a dimensão dos dados mediante a busca de projeções lineares de baixa dimensão onde aspectos "interessantes"dos dados são exibidos. Para tal fim, PP requer: i) uma função objetivo, chamada de índice de projeção, que quantifica o grau de "interessante" de uma projeção dada, e ii) uma estratégia de busca (otimizador) para encontrar as bases do espaço de projeção que maximizam a função índice. A utilidade de PP tem sido mostrada em uma diversidade de aplicações, tais como: detecção de objetivos a partir de imagens hiperespectrais (Malpica et al., 2008; West, 2006; Chiang et al., 2001); análise de polimorfismos em genética (Cui et al., 2005); distribuição de recursos hídricos (Wang e Zhang, 2010); classificação de danos de inundações (Huang e Zhang, 2011; Jin et al., 2003), entre outras.

Uma das principais vantagens de PP, e que explica em parte sua relativa popularidade, é a sua flexibilidade para se adaptar a vários tipos de análises e tarefas. Isto é possível mediante a 
apropriada definição do índice de projeção, a qual encapsula toda a informação relevante para a análise requerida. Assim, por exemplo, PP pode realizar o clássico Principal Component Analysis (PCA) usando como função índice a variância dos dados projetados, enquanto que uma análise supervisionada Linear Discriminant Analysis (LDA) seria possível com a função discriminante de Fisher como função índice (Daszykowski et al., 2007). A literatura de PP tem-se focado fortemente em estudar e propor uma variedade de funções de índices para diversas tarefas, encontrando-se assim índices para realizar análise de agrupamentos (Pena e Prieto, 2001; Bolton e Krzanowski, 2003), para facilitar a classificação de dados (Lee et al., 2005; Demirci et al., 2008; Pires e Branco, 2010; Grochowski e Duch, 2011), para realizar análise de regressão (Ren et al., 2007) e para auxiliar na estimativa de funções de densidade de probabilidade (Aladjem, 2005) (revisões de índices podem ser encontrados em (Lee et al., 2005; Jee, 2009; Rodriguez-Martinez et al., 2010)). Outra vantagem importante de PP é a sua capacidade de projetar dados após a construção do espaço de projeção (capacidade denominada em inglês como out-of-sample mapping), propriedade que resulta útil quando se está construindo uma maquina para estimar ou lidar com situações não observadas.

Apesar das vantagens acima mencionadas, a literatura tem mostrado uma limitada aplicação de PP na analise de bancos de dados de alta dimensão e poucas amostras como aqueles gerados pela tecnologia de microarranjo. Uma explicação para isto pode ser encontrada na elevada dificuldade computacional em encontrar espaços de projeção ótimos para tais situações. Assim por exemplo, a projeção de um banco de dados com $p=10000$ atributos (uma ordem de magnitude realista em bancos de microarranjo) para um espaço visual de dimensão $m=3$ requer a otimização de uma matriz de projeção com $p \times m=30000$ elementos. Evidentemente, o problema se torna ainda mais difícil à medida que o número de atributos ou a dimensão do espaço de projeção (dimensão alvo) é aumentada. Os otimizadores de PP tradicionais, baseados em gradiente ou no procedimento Newton-Raphson (Huber, 1985; Jones e Sibson, 1987; Nason, 1995; Pena e Prieto, 2001), são usualmente inapropriados para esses cenários de muito alta dimensão, dada sua elevada suscetibilidade de cair em ótimos locais irrelevantes (Friedman, 1987) ou a indisponibilidade de gradientes em alguns índices de projeção. Otimizadores mais globais para PP têm sido propostos em anos recentes, incluindo: Algoritmo Genético (AG) (Guo et al., 2000), Simulated Annealing (SA) (Lee et al., 2005), Random Scan Sampling Algorithm (RSSA) (Webb-Robertson et al., 2005) e otimização por enxame de partículas (PSO) (Berro et al., 2010). No entanto, não é claro que tais otimizadores possam lidar adequadamente com dimensionalidades tão altas como aquelas encontradas em bancos de da- 
dos gerados pela tecnologia de microarranjo. A carência de aplicações de PP neste tipo de dados é um indicativo da dificuldade de otimizar índices de projeção nessas situações.

A presente tese estuda estratégias de aplicação de PP a fim de tornar factível sua utilização na redução dimensional de dados de muito alta dimensão e poucas amostras e assim facilitar sua posterior classificação. O estudo é elaborado sobre a ideia base da metodologia Sequential Projection Pursuit (SPP) (Guo et al., 2000), uma forma de PP que constrói o espaço de projeção buscando as suas bases de maneira sequencial (ao invés de abordagens anteriores que otimizam todas as bases de forma simultânea (Friedman, 1987; Posse, 1995b; Nason, 1995)), requerendo assim otimizar somente índices unidimensionais a cada iteração. Já que o otimizador é uma parte crítica de PP, numa primeira etapa foi realizado um estudo sobre um otimizador AG para o ajuste de bases de projeção, o qual foi chamado de Projection Pursuit Genetic Algoritm (PPGA). O estudo envolveu uma análise de desempenho de 8 operadores de cruzamento, 3 existentes na literatura e 5 propostos no presente trabalho. Os resultados desta avaliação apontaram que os operadores hiper-cônicos, aqui propostos, tendem a encontrar projeções de melhor qualidade (aptidão) em relação a operadores de cruzamento canônicos. Estes resultados, junto com desenvolvimentos recentes na literatura de PP, permitiram desenvolver uma versão melhorada de Sequential Projection Pursuit (SPP), o Sequential Projection Pursuit Modified (SPPM), o qual incorpora o melhor operador de cruzamento da avaliação anterior e substitui o procedimento original que evita encontrar bases de projeção repetidas (procedimento chamado de "structure removal"), procedimento que pode induzir distorções na busca de bases (Posse, 1995a). O novo procedimento para evitar repetições nas bases é baseado no método deflation-inflation (Rodriguez-Martinez et al., 2010), o qual não apresenta distorções e facilita o cálculo das bases.

Numa segunda etapa, foram desenvolvidos dois esquemas baseados em SPPM para reduzir a dimensão de bancos de dados de muito alta dimensão e poucas amostras. O primeiro esquema, chamado de Block Sequential Projection Pursuit Modified (Block-SPPM), particiona o conjunto de atributos originais em blocos de tamanho acessível para SPPM, o qual busca subespaços de projeção para cada bloco. Um procedimento para ponderar e combinar os subespaços de projeção encontrados por SPPM foi desenvolvido a fim de montar a matriz de projeção final. O segundo esquema, chamado de Whitened Sequential Projection Pursuit Modified (WSPPM), é baseado numa compactação previa dos dados, seguida por uma aplicação de SPPM nos dados compactados. A compactação é realizada através de uma transformação por bran- 
queamento (conhecida em inglês como whitening transform) Asuncion Vicente et al. (2007), a qual consegue reduzir rapidamente a dimensão dos dados na ordem de $n$. A transformação de branqueamento foi escolhida com base em algumas evidências que apontam que os dados branqueados e purgados de atributos irrelevantes podem ser de grande utilidade para construir modelos acurados (Alter et al., 2000; Wall et al., 2003; Asuncion Vicente et al., 2007). Avaliações experimentais sobre bancos de dados públicos de microarranjo foram conduzidas com os métodos propostos a fim de estimar seu desempenho em facilitar a classificação dos dados. Os resultados mostraram a viabilidade de Block-SPPM e W-SPPM em melhorar a acurácia de classificação em relação a vários métodos representativos de redução dimensional, tanto de seleção quanto de extração de atributos, sendo W-SPPM o método com melhor compromisso entre acurácia e custo computacional.

\subsection{Objetivos}

O objetivo geral do presente trabalho é estudar o potencial da técnica de Projection Pursuit (PP) na redução dimensional de bancos de dados com elevada quantidade de atributos e poucas amostras, tal como os gerados com a tecnologia de microarranjo. Os objetivos específicos são os seguintes:

- Desenvolver métodos eficientes de otimização de índices de projeção em alta dimensão;

- Propor estratégias para tornar viável a aplicação da técnica de PP na redução dimensional de dados de alta dimensão e poucas amostras visando a construção de classificadores acurados;

- Avaliar as propostas quanto a seu potencial em melhorar a acurácia de classificação de dados em relação a métodos existentes.

\subsection{Organização do texto}

Este trabalho está organizado em seis capítulos: O Capítulo 2 apresenta conceitos importantes de redução dimensional e uma revisão dos principais métodos existentes, com foco naqueles que foram descritos para altas dimensionalidades. O Capítulo 3 apresenta os fundamentos teóricos de PP, uma revisão dos principais índices de projeção e o algoritmo SPP, o qual 
constitui a base do presente trabalho. O Capítulo 4 descreve as metodologias propostas para redução dimensional com PP, incluindo Projection Pursuit Genetic Algoritm (PPGA), SPPM, Block-SPPM e W-SPPM. O Capítulo 5 apresenta as avaliações experimentais das metodologias propostas, incluindo a descrição dos dados usados, configurações experimentais, resultados e discussões. Por último, o texto finaliza com o Capítulo 6, apresentando as conclusões e sugestões para futuros trabalhos. 


\section{Capítulo 2}

\section{Redução dimensional de dados}

Neste capítulo é apresentada uma revisão de conceitos e abordagens importantes em redução dimensional. A Seção 2.1 apresenta a notação usada ao longo do texto. A Seção 2.2 apresenta o contexto onde o problema de redução dimensional aparece. Na Seção 2.3 e 2.4 são revistas, respectivamente, as duas maiores abordagens usadas para reduzir a dimensão de dados: seleção de atributos e extração de atributos.

\subsection{Notação}

Ao longo do texto considera-se que os dados $\mathbf{X}$ a analisar estão dispostos em um formato matricial, tal como mostrado na Tabela 2.1. A $i$-ésima amostra é descrita pelo vetor p-dimensional $\mathbf{x}_{i}=\left(x_{i 1}, x_{i 2}, \ldots, x_{i p}\right)$, onde $x_{i j}$ denota o valor medido do atributo $X j$ na respectiva amostra $i$. Adicionalmente, em casos de dados rotulados, a matriz de dados $\mathbf{X}$ tem associada um vetor de etiquetas de classe $C=\left(c_{1}, c_{2}, \ldots, c_{n}\right)$, onde cada amostra $\mathbf{x}_{i}$ está associado a uma etiqueta de classe $c_{i}$, a qual pode assumir um de $g$ estados possíveis (número de classes). O termo 'atributo' é utilizado para nos referir alguma coluna de $\mathbf{X}$, enquanto que o termo 'amostra' é usado para referenciar alguma linha de $\mathbf{X}$.

\subsection{Contexto}

Uma grande parte dos desenvolvimentos teóricos e metodológicos de análise de dados foram estabelecidos no século passado e foram objetivados principalmente para situações onde o 
Tabela 2.1: Formato assumido para conjuntos de dados

\begin{tabular}{c|c|c|c|c|c|}
\cline { 2 - 6 } \multicolumn{1}{c|}{} & \multicolumn{4}{c|}{ Atributos } & Classes \\
\hline \hline Amostras & $X_{1}$ & $X_{2}$ & $\ldots$ & $X_{p}$ & $C$ \\
\hline $\mathbf{x}_{1}$ & $x_{11}$ & $x_{12}$ & $\ldots$ & $x_{1 p}$ & $c_{1}$ \\
\hline $\mathbf{x}_{2}$ & $x_{21}$ & $x_{22}$ & $\ldots$ & $x_{2 p}$ & $c_{2}$ \\
\hline $\mathbf{x}_{3}$ & $x_{31}$ & $x_{32}$ & $\ldots$ & $x_{3 p}$ & $c_{3}$ \\
\hline$\vdots$ & $\vdots$ & $\vdots$ & $\ddots$ & $\vdots$ & $\vdots$ \\
\hline $\mathbf{x}_{n}$ & $x_{n 1}$ & $x_{n 2}$ & $\ldots$ & $x_{n p}$ & $c_{n}$ \\
\hline \hline
\end{tabular}

número de atributos $p$ é inferior ao número de amostras ou observações $n$, cenário conhecido em estatística como "small p, large n". A razão disto foi a pouca disponibilidade na época de tecnologias de aquisição de dados de alto desempenho que gerem grandes quantidades de atributos, assim como limitações em recursos computacionais. Entre os resultados teóricos mais notáveis desses desenvolvimentos está o teorema do limite central (Johnstone e Titterington, 2009), o qual estabelece que quando o número de amostras $n$ aumenta, a distribuição amostral da sua média aproxima-se cada vez mais de uma distribuição normal. Este resultado teve implicações importantes em estatística, permitindo derivar vários estimadores de parâmetros de modelos, porém, sendo somente válidos quando o número de amostras por parâmetro é realmente grande, tal como exige o teorema do limite central.

Nas duas últimas décadas, áreas de pesquisa que lidam com análise de dados, especialmente estatística, aprendizado de máquina, mudaram drasticamente em relação a seus desafios. Isto porque as tecnologias de sensoriamento e aquisição de dados evoluíram dramaticamente. Ao mesmo tempo, o suporte computacional mostrou cada vez maiores capacidades, tanto de processamento quanto de armazenamento. Como consequência, é cada vez mais frequente observar cenários experimentais em que o número de atributos medidos é muito superior ao número de amostras, cenários conhecidos em estatística como "large $p$, small n". Exemplos de áreas onde estes cenários são gerados incluem: análise de imagens, genômica, astronomia, ciências atmosféricas, a web, entre outras (Johnstone e Titterington, 2009).

Um dos principais desafios ao lidar com bancos de dados com mais atributos do que amostras é o fenômeno conhecido como "a maldição da dimensionalidade"(Korn et al., 2001), o qual é inerente nesse tipo de dados. Este fenômeno estabelece que à medida que $p$ cresce em relação a $n$, os pontos de dados tendem a ser equidistantes e seu espaço subjacente torna-se cada vez mais esparso. Isto gera efeitos negativos na maioria de metodologias de análise de dados, como aquelas de reconhecimento de padrões e aprendizagem de máquina que são baseadas 
em distâncias, desde que a informação de distância não serve mais para evidenciar estruturas. Outras consequências relacionadas à maldição da dimensionalidade são: sobre treinamento de modelos e tendência a convergir frequentemente em modelos ótimos locais. Tais efeitos comprometem o poder de generalização dos modelos induzidos e, portanto, a sua utilidade prática (Jimenez e Landgrebe, 1999; Clarke et al., 2008).

Uma forma amplamente utilizada para contornar os efeitos da maldição da dimensionalidade é reduzindo a dimensão dos dados (Clarke et al., 2008). Em termos gerais, reduzir a dimensão de um conjunto de dados $\mathbf{X}$ pode ser definido como o processo de encontrar uma nova representação $\mathbf{S}=\left\{\mathbf{s}_{1} \ldots, \mathbf{s}_{n}\right\}$ para $\mathbf{X}$ (sendo $\mathbf{s}_{i}$ a representação em baixa dimensão $k<p$ da respectiva amostra $\mathbf{x}_{i}$ ), tal que características relevantes para a análise pretendida sejam exibidas em $\mathbf{S}$ (Fodor, 2002). No entanto, encontrar a representação adequada $\mathbf{S}$ é um problema desafiador, o qual é evidenciado pela diversidade de abordagens que podem ser encontradas na literatura para tal propósito. Entre as razões dessa dificuldade estão a falta de conhecimento a priori sobre se os dados originais $\mathbf{X}$ possuem a informação de relevância procurada e também dificuldades computacionais associadas a elevadas quantidades de atributos.

Encontrar uma adequada categorização das diversas abordagens existentes de redução dimensional é uma tarefa difícil dada a natureza multidisciplinar desta área e a transversalidade de muitas abordagens. A Figura 2.1 apresenta uma classificação tradicional e não exaustiva de métodos de redução dimensional (adaptada de (Lee e Verleysen, 2007; Fodor, 2002)). Esta classificação encontra-se com frequência na literatura de aprendizado de máquina e mineração de dados, a qual divide a redução da dimensão em duas grandes categorias: métodos de seleção de atributos e métodos de extração de atributos. Nas seções seguintes são brevemente revisadas estas duas abordagens e seus principais métodos, especialmente aqueles descritas para dados de muito alta dimensão.

\subsection{Seleção de atributos}

As técnicas de seleção de atributos (SA) buscam encontrar um subconjunto de atributos dentro do conjunto de atributos original que contribuam para a análise ou estudo pretendido (por exemplo: classificação, análise de agrupamentos, regressão) (Liu e Motoda, 2007; Guyon et al., 2006). O problema é desafiante, desde que encontrar o conjunto de atributos mais relevante para a análise em questão é um problema combinatório, que na maioria dos casos é 


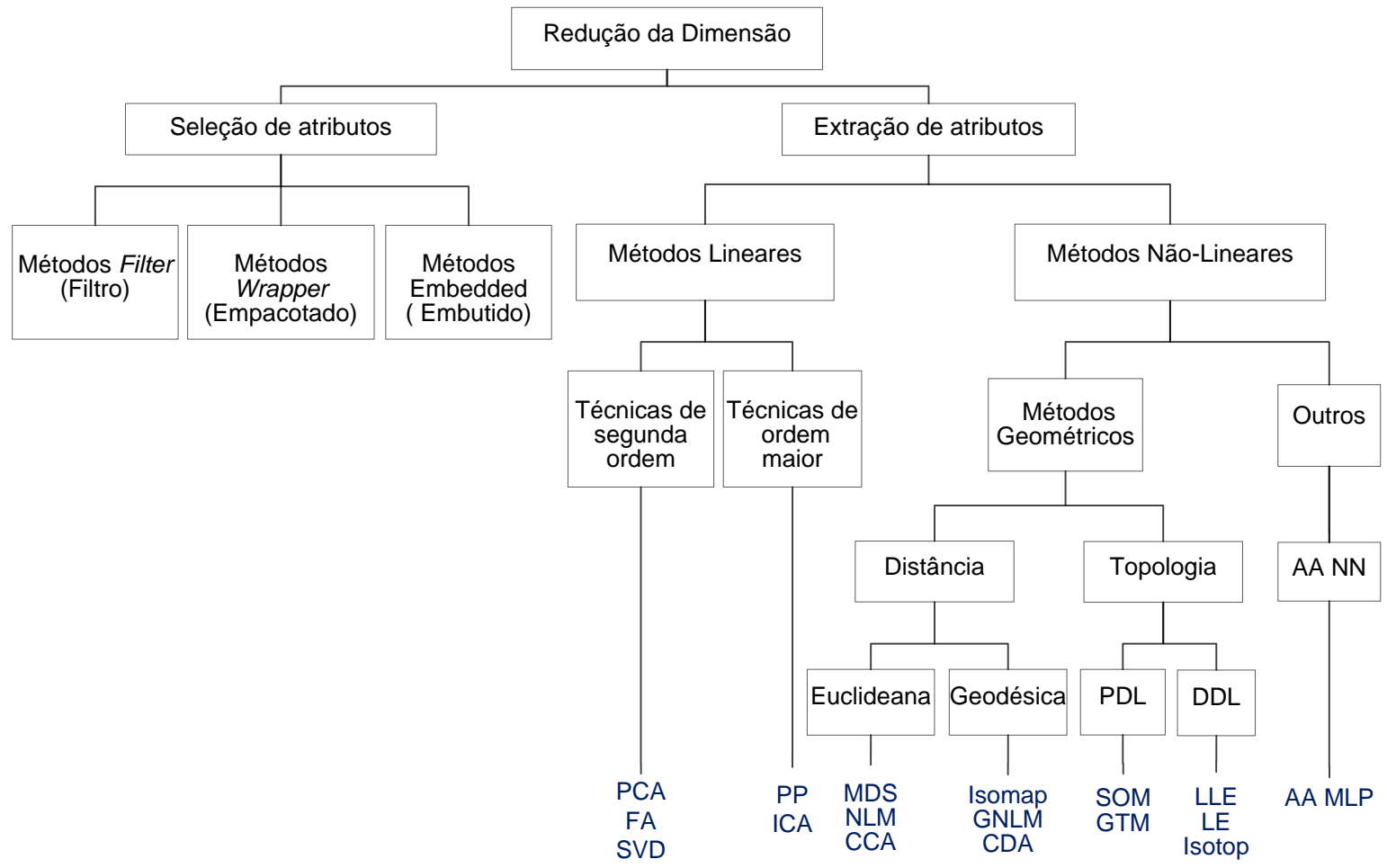

Figura 2.1: Classificação de técnicas para redução da dimensão, adaptada de (Lee e Verleysen, 2007; Fodor, 2002).

intratável com busca exaustiva (Peng et al., 2005; Qu et al., 2005). As vantagens de encontrar um conjunto reduzido de atributos é que ele pode ser diretamente interpretado por um especialista do domínio, ajudando assim a um maior entendimento do fenômeno em estudo. Um exemplo notável de aplicação de SA é encontrado em pesquisas de mapeamento genético de doenças, onde os pesquisadores medem os níveis de expressão de massivas quantidades de genes tentando evidenciar um grupo deles que esteja associado ao estado de uma determinada doença ou fenótipo (Saeys et al., 2007). A Figura 2.2 mostra um esquema tradicional de seleção de atributos (adaptado de (Dash e Liu, 1997)), o qual é formado pelos seguintes componentes:

Busca de subconjuntos de atributos candidatos;

- Avaliação dos subconjuntos por meio de um critério de avaliação (por exemplo, alguma medida de informação ou dependência em relação a uma variável alvo);

- Repetição dos passos anteriores até satisfazer algum critério de parada (por exemplo, um número pré-definido de atributos, um número pré-definido de iterações, se a adição/remoção de atributos ao subconjunto atual não melhora o critério de avaliação); 
- Validação do subconjunto encontrado a fim de estimar sua utilidade na análise pretendida (Duda et al., 2001; Liu e Yu, 2005b).

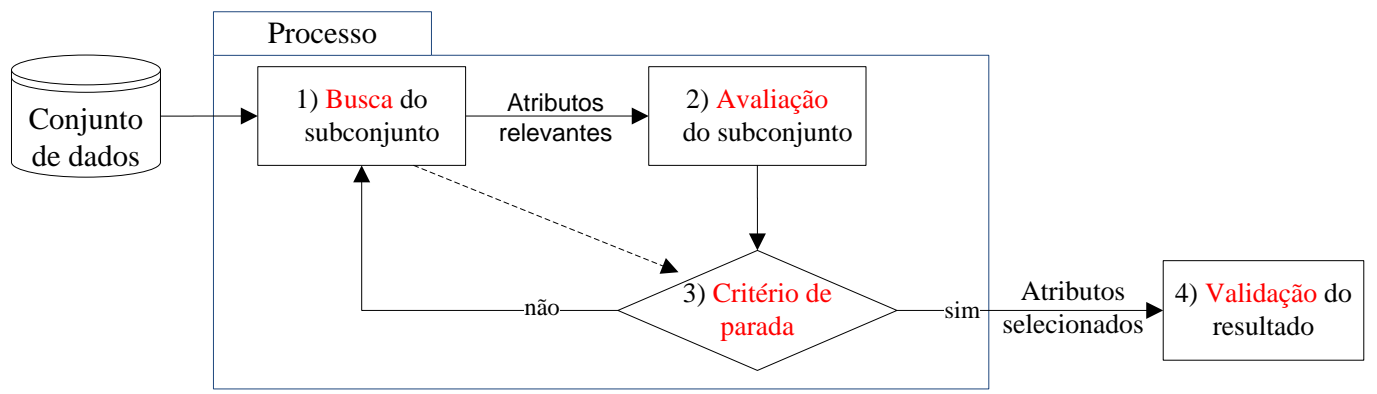

Figura 2.2: Arcabouço tradicional para seleção de atributos (adaptado de (Dash e Liu, 1997)). Quatro etapas formam este esquema: busca de subconjuntos, avaliação de subconjuntos, critério de parada e validação dos subconjuntos resultante.

Os métodos de seleção de atributos diferem principalmente na forma em como eles realizam a busca dos subconjuntos de atributos e nos critérios usados para avaliar a qualidade dos subconjuntos. De forma geral, eles podem ser enquadrados em duas categorias: métodos filtro e métodos wrappers.

Os métodos filtro empregam alguma medida de 'relevância' para pontuar os atributos originais e assim procurar pelo melhor subconjunto, descartando os atributos que não atingem um determinado limiar de relevância. A vantagem dos métodos filtro é que eles são simples, rápidos e escalam facilmente com o número de atributos. No entanto, estes métodos comumente não tomam em consideração as interdependências entre atributos, o qual é muitas vezes importante na construção de modelos (por exemplo, de agrupamento, de classificação ou de regressão) (Saeys et al., 2007; Liu e Yu, 2005b). Entre os métodos filtros mais populares tem-se: método $t$-Test e $t$-Test modificado (Zhou e Wang, 2007), ReliefF (Kononenko, 1994) e Correlation-based Feature Selection (CFS) (Hall, 2000, 1999).

Os métodos wrappers incluem dentro da etapa de busca de atributos o modelo de aprendizagem a ser usado, o qual é encarregado de avaliar os subconjuntos de atributos candidatos. A principal vantagem desta abordagem é sua capacidade de encontrar atributos realmente relevantes para o algoritmo de aprendizado de máquina a ser usado. A desvantagem é seu elevado custo computacional, já que o algoritmo de aprendizado de máquina tem que ser usado toda vez que um subconjunto de atributos é avaliado. Entre os algoritmos mais representativos desta abordagem estão: o C4.5 (Quinlan, 1992), Fast Correlation-Based Filter (FCBF) (Liu e Yu, 2003) e seu predecessor Consistency-Based Filter (CBF) (Dash e Liu, 2003). 
Os métodos filtros e wrappers têm constituído a base de métodos de redução dimensional de dados de alta dimensão (principalmente dados gerados pela tecnologia de microarranjo). Esses métodos encontram-se frequentemente acoplados com avançadas heurísticas de busca.

Por exemplo, Garcia-Nieto e Alba (2012) descreveram um otimizador baseado em Particle Swarm Optimization (PSO) paralelo combinado com um classificador Support Vector Machine (SVM) para seleção de genes relevantes em dados de câncer; Chuang et al. (2011) usaram uma combinação de CFS e Taguchi-genetic algorithm (TGA) na seleção de genes para classificação em onze bancos de expressão gênica de câncer; Kulkarni et al. (2011) apresentaram o sistema DISCIPULUS ${ }^{1}$ que usa um processo de seleção de genes usando atributos ordenados provenientes do teste t-test ou informação mútua acoplado com um classificador AG, mostrando vantagens na predição de câncer de cólon; Lee e Leu (2011) apresentaram um método hibrido que usa um AG de ajuste dinâmico para gerar um número de subconjuntos de genes ordenados para logo aplicar o teste $X^{2}$ para pontuar os subconjuntos a serem usados por um classificador SVM; Debnath e Kurita (2010) usaram um algoritmo evolutivo para selecionar potenciais genes informativos para um classificador SVM; Tan et al. (2008) hibridizaram um AG e um método filtro $t$-Test para selecionar marcadores genéticos que junto com um classificador SVM ajudem na previsão de tumores. Sharma et al. (2012) usaram recentemente um método wrapper que combina a seleção de genes e classificação usando um método de particionamento de atributos, de forma que a busca é focada em pequenos conjuntos de genes que são avaliados por um classificador e em seguida é repetido o procedimento com as partições melhor pontuadas, diminuindo sempre e uma unidade o conjunto de genes até encontrar a configuração de genes ótima.

Além dos métodos filtros e wrappers, a literatura recente de seleção de atributos mostra também um interesse crescente por métodos baseados no cálculo do Markov Blanket (MB) (de Morais e Aussem, 2010). O conceito de MB é frequentemente usado no contexto de Redes Bayesianas (RB) e se refere ao mínimo conjunto de atributos que consegue isolar (fazer condicionalmente independente) a variável classe do resto de atributos, dado o conjunto MB. Trabalhos como os de Zheng e Kwoh (2011),Ram e Chetty (2011),Liu et al. (2010), propõem o uso de MBs para selecionar vários subconjuntos de genes para propósitos de classificação. Zhu et al. (2010) usa um algoritmo memético baseado em MB e dois novos critérios, "full class relevancy" (FCR) e "partial class relevant" (PCR), para estimar a relevância de atributos em

\footnotetext{
${ }^{1}$ http://www.rmltech.com/
} 
situações de mais de duas classes. Han et al. (2010) propuseram um novo método baseado em MB, "Detection of Associations using Markov Blanket"(DASSO-MB), para detectar interações epistáticas em controle de casos de "genome-wide association studies" (GWAS). Os resultados mostraram que o conjunto de marcadores SNP detectados por DASSO-MB têm uma forte associação a doenças e apresenta um menor número de falsos positivos.

\subsection{Extração de atributos}

Diferentemente dos métodos de seleção de atributos, os métodos de extração de atributos tentam reduzir a dimensão dos dados procurando novas representações dos mesmos em espaços de baixa dimensão, onde alguma informação de relevância seja exibida (Guyon et al., 2006; Saeys et al., 2007). Nesta abordagem os atributos originais são combinados (linearmente ou através de funções não lineares) para gerar novos atributos, perdendo-se assim a interpretação dos atributos gerados. Normalmente, um dos objetivos das transformações é que cada atributo gerado mostre um aspecto diferente dos dados (atributos descorrelacionados), pelo que é esperado ter uma redução significativa da dimensionalidade com este tipo de abordagens (Guyon et al., 2006).

De forma geral, os métodos de extração de atributos podem-se dividir em dois grandes grupos: métodos lineares e métodos não lineares (Figura 2.1). Os métodos lineares tentam extrair informações de interesse dos dados procurando projeções lineares dos mesmos em espaços de baixa dimensão onde se facilite a análise pretendida. Entre os métodos mais populares de projeção linear tem-se: PCA (Pearson, 1901), LDA (Duda et al., 2001), Factor Analysis (FA) (Scott, 1992), Singular Value Decomposition (SVD) (Demmel, 1997), PP (Friedman e Tukey, 1974) e Independent Component Analysis (ICA) (Scott, 1992), métodos que tem ganhado popularidade em aplicações como visualização, análise de agrupamentos, classificação, estimativa de funções de densidade e regressão.

Os métodos não lineares de extração de atributos tentam preservar na nova representação alguma medida de distância entre os pontos de dados originais, sem estar limitados à linearidade do mapeamento. Entre os métodos mais populares nesta abordagem tem-se: Multidimensional Scaling (MDS) (Kruskal, 1969), Non Linear MDS (NMDS) (Borg e Groenen, 2005), Curvilinear Component Analysis (CCA) (Demartines e Herault, 1997), Isomap (Silva e Tenenbaum, 2003; Tenenbaum et al., 2000), Geodesic Non Linear mapping (GNLM) (Lee e Verley- 
sen, 2007), Curvilinear Distance Analysis (CDA) (Lee et al., 2004). Têm-se também alguns métodos não lineares que ao invés de conservar distâncias tentam conservar a topologia (vizinhanças dos pontos) do espaço original. Entre as técnicas mais representativas neste tipo de métodos estão: Self-Organizing Maps (SOM) (Kohonen et al., 2001), Generative topographic mapping (GTM) (Bishop e Williams, 1998), Locally Linear Embedding (LLE) (Roweis e Saul, 2000) (Belkin e Niyogi, 2002), Isotop (Lee e Verleysen, 2002).

A adequação dos diversos métodos de extração de atributos para um dado problema depende fortemente da natureza dos dados (Lee e Verleysen, 2007). Assim, métodos de projeção linear são aplicáveis quando se dispõe de valores medidos de atributos; já os métodos que preservam distâncias são mais adequados em situações em que a única informação disponível é alguma informação de distância ou similaridade entre dados (Lee e Verleysen, 2007; Borg e Groenen, 2005; Tenenbaum et al., 2000). Os métodos baseados em topologia são mais bem aproveitados quando as escalas de variação dos dados não são relevantes e sim as vizinhanças locais dos pontos (por exemplo, sistemas de visualização de dados) (van der Maaten et al., 2008; Maimom e Rokach, 2005; Fodor, 2002; Carreira-Perpiñán, 2001).

Entre os métodos de extração de atributos, os métodos de projeção linear são os que mais atenção têm recebido na literatura, dada sua simplicidade, sua frequente convexidade (é possível encontrar uma solução fechada) e o sólido suporte teórico existente (Duda et al., 2001). A metodologia de busca de Projeção (do inglês Projection Pursuit) nasceu justamente como um marco flexível onde podem ser colocados diversos métodos de projeção linear. No Capítulo 3 será descrito em detalhe essa metodologia, dada sua relevância para o presente trabalho.

Em relação à utilização de métodos de extração de atributos na redução dimensional de dados de muito alta dimensão, estes não tem recebido tanta atenção quanto os métodos de seleção de atributos. No entanto, nos últimos anos tem-se observado um interesse crescente por este tipo de abordagens. Por exemplo, Huang e Feng (2012) apresentaram um novo método de aprendizado, o $p$ SELF, que é livre de parâmetros e está baseado no LDA para propósitos de classificação de dados de expressão de tumores no cérebro; Li et al. (2010) usaram um algoritmo baseado em LLE, o LLDE (Local linear Discriminant Embedding), para mapear dados de expressão para análise exploratório e classificação; Lee et al. (2008) compararam métodos lineares (Isomap, LLE, Laplacian Eigenmaps (LE)) e não lineares (PCA, LDA, MDS) com a intenção de determinar quais desses métodos são mais discriminativos no novo espaço de transformação; para tal fim usaram dados de expressão gênica de câncer e classificadores baseados 
em SVM e arvores de decisão $C 4.5$; Zhao e Zhang (2009) apresentaram um método baseado na distância probabilística e em LLE para reduzir a dimensão de cinco dados de microarranjo; Cheng et al. (2011) apresentaram uma metodologia baseado em LLE embutido como kernel no processo de redução dimensional (chamado de KVDA, kernel-view discriminant analysis) e aplicaram essa metodologia em conhecidos bancos de dados de expressão gênica de câncer.

\section{Considerações Finais}

Nesse capítulo foi apresentado uma revisão dos principais paradigmas usados para reduzir a dimensão de dados: seleção de atributos (SA) (Liu e Motoda, 2007; Saeys et al., 2007) e extração de atributos (EA) (Guyon et al., 2006). Os métodos de SA procuram subconjuntos reduzidos de atributos que mostrem associação com a variável classe. Os métodos de EA buscam novos espaços de representação dos dados que facilitem a discriminação de classes, sendo as dimensões obtidas geralmente como combinações lineares ou não lineares dos atributos originais. SA tem sido a abordagem mais usada em dados de microarranjo devido a sua propriedade de reter a acepção original dos atributos (o qual ajuda a entender o fenômeno gerador de classes) (Saeys et al., 2007). No entanto, alguns estudos apontaram que se o objetivo principal é a acurácia do classificador alvo,os método baseados em EA podem ser uma melhor escolha (Liu e Motoda, 1998; Dai et al., 2006). Uma explicação para isso é que SA está atado ao espaço original de atributos, enquanto que EA não possui tal restrição, proporcionando assim maiores chances de encontrar representações mais compactas e informativas para a classificação. De fato, visto desde uma perspectiva abrangente, SA é um caso especial de EA no qual se procura um espaço de representação cujas dimensões são combinações lineares dos atributos originais, com a restrição de que os coeficientes de combinação são valores binários (Liu e Motoda, 1998). 


\section{Capítulo 3}

\section{Projection Pursuit}

Neste capítulo é introduzida uma revisão dos conceitos teóricos da técnica de Projection Pursuit (PP). A Seção 3.1 inicia introduzindo alguns conceitos básicos associados à teoria de projeções. Em seguida, na Seção 3.2, apresenta-se a teoria referente a PP. Na Seção 3.3 são revisados alguns dos mais populares índices de projeção. Na Seção 3.4 apresenta-se uma revisão das abordagens existentes para otimização de PP. Na Seção 3.5 é descrito o algoritmo SPP, o qual constitui o marco base usado para a obtenção de projeções do presente trabalho. Finalmente, na Seção 3.5 são dadas algumas considerações finais a respeito da seleção de parâmetros em PP.

\subsection{Projeção dimensional}

Matematicamente, cada amostra $\mathbf{x}_{i} \in \mathbf{X}$ pode ser considerada como um ponto num espaço $p$-dimensional. É sempre possível encontrar uma nova representação $\mathbf{S}^{(n \times k)}$ para esses pontos num espaço $k$-dimensional $(k<p)$ fazendo uma transformação $\mathbb{R}^{p} \rightarrow \mathbb{R}^{k}$ a cada ponto $\mathbf{x}_{i}$, processo conhecido como projeção dimensional. Quando $\mathbf{S}$ é obtido mediante a transformação linear $\mathbf{S}=\mathbf{X A}$, onde $\mathbf{A} \in \mathbb{R}^{p \times k}$, diz-se que $\mathbf{S}$ é uma projeção dimensional linear de $\mathbf{X}$, onde $\mathbf{A}$ é chamada de matriz de projeção e as colunas de $\mathbf{A}$ representam as bases do espaço de projeção (Cook et al., 2008).

Um objetivo importante ao projetar os dados é encontrar projeções que facilitem encontrar aspectos relevantes dos dados. Por exemplo, na Figura 3.1 é mostrado um objeto e dois planos de projeção $H_{1}, H_{2}$. É evidente que $H_{2}$ apresenta a melhor projeção do objeto que facilita a 
sua identificação.

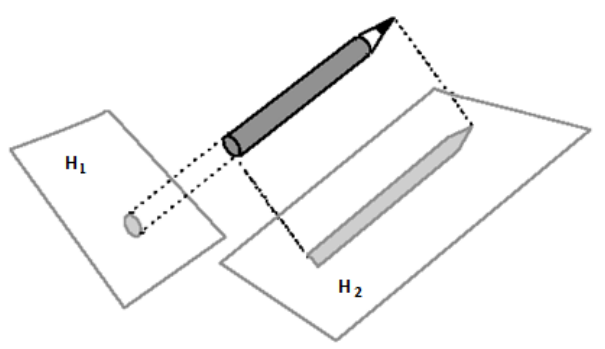

Figura 3.1: Projeção de um objeto sobre dois planos. A projeção no plano $H_{2}$ apresenta a informação mais relevante do objeto para facilitar sua identificação

Geralmente, na busca projeções lineares, é imposta a restrição de ortonormalidade nas bases de projeção, assim $\mathbf{A}^{T} \cdot \mathbf{A}=\mathbf{I}_{k}$. Esta restrição é feita para garantir que as dimensões do espaço de projeção ofereçam informações distintas e complementares do banco de dados (Anton e Busby., 2006).

\subsection{Projection Pursuit (PP)}

O conceito de PP foi formalmente introduzido no trabalho de Friedman e Tukey (1974), embora as idéias seminais foram originalmente propostas por Kruskal (1969). PP é uma técnica estatística que nasce pela necessidade de automatizar o processo de busca de projeções, inicialmente de uma ou duas dimensões, que era anteriormente realizado de forma manual (Friedman e Tukey, 1974). Dado que a idéia inicial de PP foi na análise exploratória visual temse que muitas vezes esta técnica é chamada de Exploratory Projection Pursuit (EPP) (Posse, 1995b; Crawford, 1991; Friedman, 1987). Nas aplicações iniciais, PP foi usado no processo de descoberta do conhecimento como uma ferramenta para buscar e propor projeções relevantes dos dados, onde estruturas 1 "interessantes" eram evidenciadas. A análise e interpretação das projeções era deixada para os usuários, reconhecendo as elevadas capacidades humanas em descobrir padrões em baixas dimensões (Dayal, 2011). A medição da relevância de uma projeção era realizada com uma função de pontuação, chamada de função índice.

Formalmente, PP busca uma projeção linear $\mathbf{S}=\mathbf{X A}$ num espaço de projeção $k$-dimensional $(k<p)$, sendo $\mathbf{A}^{(p \times k)}=\left[\mathbf{L}_{1}, \mathbf{L}_{2}, \ldots, \mathbf{L}_{k}\right]$ a matriz de projeção. As bases do espaço de pro-

\footnotetext{
${ }^{1}$ Uma estrutura pode ter vários significados e em geral não é definida a não ser que se conheça exatamente o que se esteja procurando. Geralmente uma estrutura só é reconhecida quando é encontrada. Podendo-se encaixar em diversos contextos, como por exemplo: tendências, agrupamentos, padrões, outliers, buracos, etc.
} 
jeção são as colunas $\mathbf{L}_{i}$ de $\mathbf{A}$ e são restringidas a ser ortonormais. Vamos considerar também uma função índice $\mathfrak{I}$ que mede o "interessante" da projeção XA. O problema de PP pode ser definido então como um problema de otimização restrito (Equação 3.1), onde se procura a matriz A que maximize $\mathfrak{I}$ sujeito à restrição de ortonormalidade (Rodriguez-Martinez et al., 2010; Nason, 1995).

$$
\begin{aligned}
\qquad \mathbf{A}^{*}= & \arg \max _{\mathbf{A}}\{\mathfrak{I}(\mathbf{X A})\} \\
\text { sujeito a } & \mathbf{A}^{T} \mathbf{A}=\mathbf{I} .
\end{aligned}
$$

A seleção do índice de projeção é um fator relevante em PP. Grande parte das pesquisas a esse respeito centraram-se na construção de índices robustos e de utilidade geral embora sua efetividade seja comumente dependente do problema e as características dos conjuntos de dados (Rodriguez-Martinez et al., 2010; Jee, 2009).

\section{3 Índices de projeção}

Grande parte da literatura de PP têm-se concentrado no desenvolvimento de índices para diversos tipos de análise e características dos dados. Por exemplo, é possível encontrar índices para análise de agrupamentos (Perisic e Posse, 2005; Pena e Prieto, 2001; Posse, 1995a,b; Cook et al., 1993; Jones e Sibson, 1987; Friedman e Tukey, 1974), classificação de dados (Grochowski e Duch, 2008; Lee e Cook, 2010; Lee et al., 2005; Jimenez e Landgrebe, 1999), análise de regressão (Friedman e Stuetzle, 1981; Hall, 1989) e estimativa de funções de densidade de probabilidade (Aladjem, 2005) .

A seguir são descritos brevemente os principais índices da literatura tanto para análise não supervisionada (Subseção 3.3.1) quanto para a análise supervisionada (Subseção 3.3.2). A maioria dos índices são descritos para espaços de projeção alvo de uma dimensão (1D), razão pela qual usa-se a notação $\mathbf{L}_{1}$ em lugar de $\mathbf{A}$ para indicar que se trata de uma única base de projeção $(p \times 1)$. A razão por descrever os índices em 1D é motivada pela proposta deste texto em que somente se otimiza índices unidimensionais de cada vez, embora o espaço de projeção resultante não esteja restrito a esta dimensionalidade, como será descrito no capitulo seguinte. 


\subsection{1 Índices para análise não supervisionada}

Índice da Entropia: Friedman et al. (1984) apresentaram o índice baseado na entropia para encontrar as melhores direções de projeção, minimizando a função de densidade normal $f($.$) . Um problema associado a este índice é seu intenso cálculo computacional,$ isto porque precisaria do cálculo de estimadores de densidade e integrais de alta ordem quando são requeridas projeções em $2 D$ ou $3 D$ (Cook et al., 1993; Friedman, 1987). Para $1 D$ este índice é definido $\mathfrak{I}_{\text {Entropy }}=-\int_{-\infty}^{\infty} f(x) \cdot \log f(x) d x$, onde $f(x)$ representa uma estimativa da densidade dos dados na direção projetada. Uma forma frequente de se aproximar a função de densidade $f(x)$ em $1 D$ é mediante a mistura de funções de kernels gaussianos (Jones e Sibson, 1987) aplicados nos pontos projetados $\mathbf{s}=\mathbf{X L}_{1}$. Assim, o ponto projetado $s_{i} \in \mathbf{s}$ é modelado com a função kernel $K\left(x, s_{i}, h\right)=\frac{1}{\sqrt{2 \cdot p i}} *$ $\exp \frac{-\left(x-s_{i}\right)^{2}}{2 . h^{2}}$ que esta centrado em $s_{i}$ e com uma amplitude controlada por $h$ (parâmetro de smooth). A Equação 3.2 mostra o índice de entropia calculado com a mistura de kernels (Jones e Sibson, 1987).

$$
\begin{aligned}
\mathfrak{I}_{\text {Entropy }} & =-\int_{-\infty}^{\infty} f(x) \cdot \log f(x) d x \\
f(x) & =\frac{1}{n \cdot h} \sum_{i=1}^{n} K\left(x, s_{i}, h\right),
\end{aligned}
$$

É possível estender a Equação 3.2 para duas ou mais dimensões aumentando uma integral por cada dimensão e definindo a função Kernel na dimensão alvo.

Índice baseado em Momentos: Este índice foi desenvolvido por Jones e Sibson (1987), tentando aliviar o cálculo das integrais do índice baseado na entropia. Computacionalmente é mais rápido porque está baseado no cálculo de momentos de terceira e quarta ordem. Para $1 D$ este índice é dado na Equação 3.3.

$$
\mathfrak{I}_{M}=\frac{1}{12}\left(\kappa_{3}^{2}+\frac{1}{4} \kappa_{4}^{2}\right)
$$

onde $\kappa_{3}=\mu_{3}$ e $\kappa_{4}=\mu_{4}-3$ são os cumulantes de terceiro e quarto momento. $\mu_{3}$ e $\mu_{4}$ são os respectivos momentos calculados nos dados projetados $\mathbf{s}=\mathbf{X L}_{1}$.

Índice de curtose: Pena e Prieto (2001) propuseram este índice para à identificação de agrupamentos, usando como direções de projeção aquelas que maximizam ou minimizam o coeficiente de curtose. Os autores mostraram que, sob certas condições, minimizar 
o coeficiente de curtose pode ajudar a encontrar grupos, maximizando a separação entre eles, enquanto que maximizar o coeficiente de curtose ajudaria a detectar outliers. Este índice é definido na Equação 3.4 para 1D (Pena e Prieto, 2001).

$$
\mathfrak{I}_{\text {Curtose }}=\frac{(n-1)^{2} \sum_{i=1}^{n}\left(s_{i}-\overline{\mathbf{s}}\right)^{4}}{n\left(\sum_{i=1}^{n}\left(s_{i}-\overline{\mathbf{s}}\right)^{2}\right)^{2}},
$$

onde $\mathbf{s}=\mathbf{X L}_{1}$ e $\overline{\mathbf{s}}$ a média de $\mathbf{s}$.

- Índice Qui-Quadrado: Este índice foi descrito para projeções em duas dimensões e tentam favorecer projeções que se afastem da distribuição normal, que sejam insensíveis a rotações dos dados e que também sejam robustas à presença de outliers. Para calcular o índice, Posse (1995a,b) propôs dividir um plano de projeção $(\alpha, \beta)$ (definido pelos vetores bases ortonormais $\alpha$ e $\beta$ ) em 48 regiões $B_{k}$ distribuídas em anéis com uma largura angular de 45 graus e um raio $R=2 \log 6^{\frac{1}{2}}$ (Figura3.2). Teoricamente, se a projeção dos dados no plano de projeção é normal então é esperado que cada uma das 48 regiões, apresente uma mesma densidade dos dados. Baseado nessa propriedade, o índice Qui-Quadrado é calculado como a integração das diferenças em cada região em relação ao esperado com uma distribuição normal. A Equação 3.5 é uma aproximação eficiente dessa integração (Posse, 1995a).

$$
\mathfrak{I}_{X^{2}}(\alpha, \beta)=\frac{1}{9} \sum_{j=0}^{8} \sum_{k=1}^{48} \frac{1}{c_{k}}\left[\frac{1}{n} \sum_{i=1}^{n} I_{B_{k}}\left(x_{i}^{T} \alpha\left(\eta_{j}\right), x_{i}^{T} \beta\left(\eta_{j}\right)\right)-c_{k}\right]^{2},
$$

onde $n$ é o número de amostras; $k$ itera sobre as regiões; $c_{k}$ é a probabilidade medida sobre a $k$-ésima região usando a probabilidade bivariada $\phi_{2}, I_{B_{k}}$ é o identificador de região $B_{k}, \eta_{j}=(\pi \dot{j}) / 36, j=0, \ldots, 8$ é o ângulo pelo qual os dados são rotacionados no plano de projeção e $\left(\alpha\left(\eta_{j}\right), \beta\left(\eta_{j}\right)\right)=\left(\alpha \cos \left(\eta_{j}\right)-\beta \sin \left(\eta_{j}\right), \alpha \sin \left(\eta_{j}\right)+\beta \cos \left(\eta_{j}\right)\right)$. 


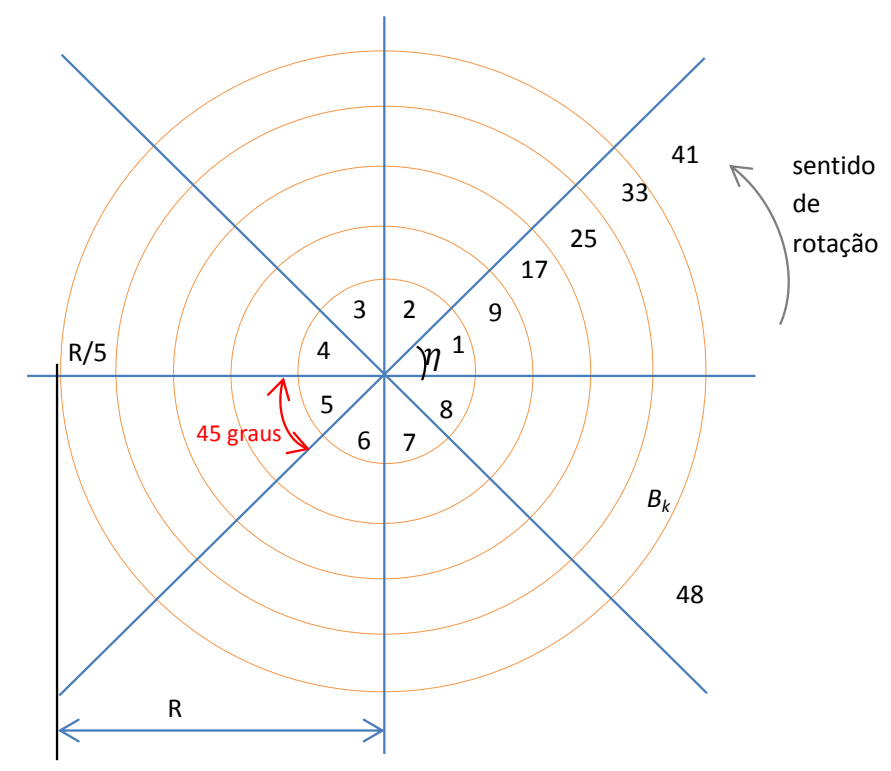

Figura 3.2: Divisão do plano de projeção para a derivação do índice de projeção Qui-quadrado. Esta divisão é realizada a fim de gerar regiões de densidade equivalentes dos dados para o caso de distribuições gaussianas. Assim o índice integra as diferenças da densidade observada dos dados em cada região em relação à esperada no caso gaussiano. Figura adaptada de Posse (1995a).

Índices Holes, Massa Central e PCA: Estes índices, formalizados por Cook et al. (1993), são caracterizados por sua simplicidade de implementação e rapidez de cálculo.Os índices Holes e Massa Central são derivados da função de densidade normal Cook et al. (1993). A diferença entre eles é que o primeiro é sensível a projeções com poucos pontos no centro e o segundo é mais sensível a projeções com bastantes pontos no centro (Cook e Swayne, 2007). O índice Holes (Equação 3.6) consegue retornar resultados semelhantes ou as vezes melhores do que o índice de entropia (Webb-Robertson et al., 2005) sem necessitar calcular ou aproximar as custosas integrais do índice de entropia. O índice de Massa Central é definido na Equação 3.7. O índice PCA pode ser considerado uma extensão do índice Massa Central, na qual o aspecto de interesse é a variância total dos dados projetados, sendo assim, este índice busca a contribuição de cada projeção sobre a variância total dos dados, favorecendo projeções com mais dispersão. Este índice é definido na Equação 3.8 para projeções em uma dimensão.

$$
\begin{gathered}
\mathfrak{I}_{\text {Holes }}=\frac{1-\frac{1}{n} \sum_{i=1}^{n} e^{-\frac{1}{2} s_{i}{ }^{2}}}{1-e^{-\frac{p}{2}}} \\
\mathfrak{I}_{M C}=1-\frac{1-\frac{1}{n} \sum_{i=1}^{n} e^{-\frac{1}{2} s_{i}{ }^{2}}}{1-e^{-\frac{p}{2}}}
\end{gathered}
$$




$$
\mathfrak{I}_{P C A}=\frac{1}{n} \sum_{i=1}^{n} s_{i}^{2}
$$

onde $s_{i}$ é um ponto pertencente ao conjunto de dados projetados $\mathbf{S}=\mathbf{X L}_{1}$.

。 Índice Lp (PI_Lp): Este índice não foi descrito como tal, senão como critério de otimização do método de redução Locality Preserving Projections (LPP) (He et al., 2005) para reconhecimento de faces. A ideia deste índice é favorecer as projeções que conservam a vizinhança dos dados. A Equação 3.9 mostra uma adaptação deste critério (o recíproco) para ser usado como índice no presente trabalho, já que o critério original foi definido para minimização.

$$
\mathfrak{I}_{L p}=1 /\left(\mathbf{L}_{1}^{T} \mathbf{X} \mathfrak{L} \mathbf{L}_{1}\right),
$$

onde $\mathfrak{L}$ é a matriz Laplaciana do grafo de vizinhança (grafo não orientado resultante de conectar os $K$ vizinhos mais próximos de cada amostra).

\subsection{2 Índices para análise supervisionada}

- Índice Bhattacharya (PI_Bhattacharyya): Este índice está baseado na distância Bhattacharya entre classes e em estatísticas de primeira e segunda ordem. O índice Bhattacharya é definido na equação 3.10 para espaços de projeção de uma dimensão e múltiplas classes (Jimenez e Landgrebe, 1999).

$$
\mathfrak{I}_{\text {Bhatt }}=\min _{i, j \in C}\left\{\frac{1}{4} \frac{\left(\mu_{i}-\mu_{j}\right)^{2}}{\sigma_{i}+\sigma_{j}}+\frac{1}{2} \log \left(\frac{\sigma_{i}+\sigma_{j}}{2 \sqrt{\sigma_{i} \sigma_{j}}}\right)\right\},
$$

onde $\mu_{i}$ e $\sigma_{i}$ denotam respectivamente a média e a variância da projeção das amostras $\mathbf{X L}_{1}$ pertencentes à classe $i$.

Índice LDA (PI_lda): O índice LDA é derivado do clássico método Linear Discriminant Analysis (Jee, 2009; Lee et al., 2005) e favorece projeções lineares com a maior separação entre classes (no sentido dos mínimos quadrados) e a menor dispersão intra-classe (classes compactas). A Equação 3.11 mostra a formulação para o cálculo do índice LDA (Jee, 2009).

$$
\mathfrak{I}_{l d a}=1-\frac{\left|\mathbf{L}_{1}^{T} \mathbf{W} \mathbf{L}_{1}\right|}{\left|\mathbf{L}_{1}^{T}(\mathbf{W}+\mathbf{B}) \mathbf{L}_{1}\right|},
$$

onde $\mathbf{B}$ é a matriz distância entre classes e $\mathbf{W}$ é a matriz de dispersão intra-classes. 
Índice QPC (PI_qpc): O índice Quality of Projected clusters (QPC), descrito recentemente por Grochowski e Duch (2011), visa favorecer projeções que representem as classes como grupos compactos e bem separados um dos outros, para assim facilitar a tarefa de classificação. O índice QPC para 1D é definido na Equação 3.12. Note-se que o valor do índice aumenta quando duas amostras da mesma classe são projetadas em localizações próximas, caso contrário o índice é penalizado. O valor da penalização depende da distância entre os pontos projetados.

$$
\Im_{Q P C}=\sum_{i=1}^{n} \sum_{j=1}^{n} \alpha_{i, j} G\left(\left(\mathbf{x}_{i}-\mathbf{x}_{j}\right) \mathbf{L}_{1}\right),
$$

onde $\alpha_{i, j}>0$ se as amostras $\mathbf{x}_{i}$ e $\mathbf{x}_{j}$ pertencem à mesma classe $\left(c_{i}=c_{j}\right)$, caso contrário $\alpha_{i, j}<0$; a função $G($.$) deveria ser tal que seu máximo valor seja na origem. Neste tra-$ balho usa-se a função Gaussiana para este propósito, tal como sugerido por seus autores.

Índice NCA (PI_nca): Este índice não foi proposto como tal, e sim como função objetivo do método Neighborhood Components Analysis (NCA) (Goldberger et al., 2005). NCA foi usado com sucesso em diversas aplicações (por exemplo, (Yang et al., 2012; Nguyen e Bai, 2010; Khandelwal et al., 2009)), razão pela qual foi considerado no presente trabalho. O critério (Equação 3.13) é derivado de um esquema KNN estocástico, onde a atribuição de vizinhos é proporcional ao número esperado de pontos corretamente classificados com esse esquema de classificação:

$$
\mathfrak{I}_{N C A}=\sum_{i}^{n} \sum_{j \in \Omega_{i}} p_{i j}
$$

onde $\Omega_{i}$ denota o conjunto de amostras na mesma classe $i$ dado por $\Omega_{i}=\left\{\mathbf{x}_{j} \mid c_{j}=c_{i}\right\}$; $p_{i i}=0$ e $p_{i j}=\frac{\exp \left(-\left\|\mathbf{x}_{i} \mathbf{L}_{1}-\mathbf{x}_{j} \mathbf{L}_{1}\right\|^{2}\right)}{\sum_{k \neq i} \exp \left(-\left\|\mathbf{x}_{i} \mathbf{L}_{1}-\mathbf{x}_{k} \mathbf{L}_{1}\right\|^{2}\right)}$ é a probabilidade da amostra $\mathbf{x}_{i}$ escolher a amostra $\mathbf{x}_{j}$ como seu vizinho e herdar seu rótulo de classe.

Índice LpS (PI_LpS): Este índice é proposto neste trabalho como uma extensão do índice não-supervisionado PI_Lp (Equação 3.9) para propósitos de classificação. A única diferença em relação ao índice de PI_Lp é que PI_LpS escolhe os k-vizinhos mais próximos para cada amostra $\mathbf{x}_{i}$ entre as amostras do conjunto $\left\{\mathbf{x}_{j} \in \mathbf{X} \mid c_{j}=c_{i}\right\}$, isto é, o conjunto de amostras que possuem a mesma etiqueta de classe que $\mathbf{x}_{i}$. Com isto, pretende-se preservar a informação de vizinhança local relativa à classe de cada amostra. 
As Tabelas 3.1 e 3.2 sumarizam brevemente os índices de projeção apresentados neste capitulo.

Tabela 3.1: Índices para análise não supervisionada

\begin{tabular}{|c|c|c|}
\hline Índice & Referência & Equação \\
\hline Entropia & Friedman et al. (1984) & $\mathfrak{I}_{\text {Entropy }}=-\int_{-\infty}^{\infty} f(x) \cdot \log f(x) d x$ \\
\hline Momentos & Jones e Sibson (1987) & $\mathfrak{I}_{M}=\frac{1}{12}\left(\kappa_{3}^{2}+\frac{1}{4} \kappa_{4}^{2}\right)$ \\
\hline Curtose & Pena e Prieto (2001) & $\mathfrak{I}_{\text {Curtose }}=\frac{(n-1)^{2} \sum_{i=1}^{n}\left(s_{i}-\overline{\mathbf{s}}\right)^{4}}{n\left(\sum_{i=1}^{n}\left(s_{i}-\overline{\mathbf{s}}\right)^{2}\right)^{2}}$ \\
\hline Qui-Quadrado & Posse (1995a,b) & $\mathfrak{I}_{X^{2}}=\frac{1}{9} \sum_{j=0}^{8} \sum_{k=1}^{48} \frac{1}{c_{k}}\left[\frac{1}{n} \sum_{i=1}^{n} I_{B_{k}}\left(x_{i}^{T}(\alpha, \beta)\right)-c_{k}\right]^{2}$ \\
\hline Holes & Cook et al. (1993) & $\mathfrak{I}_{\text {Holes }}=\frac{1-\frac{1}{n} \sum_{i=1}^{n} e^{-\frac{1}{2} s_{i}{ }^{2}}}{1-e^{-\frac{p}{2}}}$ \\
\hline Massa Central & Cook et al. (1993) & $\mathfrak{I}_{M C}=1-\frac{1-\frac{1}{n} \sum_{i=1}^{n} e^{-\frac{1}{2} s_{i}{ }^{2}}}{1-e^{-\frac{p}{2}}}$ \\
\hline PCA & Cook et al. (1993) & $\mathfrak{I}_{P C A}=\frac{1}{n} \sum_{i=1}^{n} s_{i}{ }^{2}$ \\
\hline Lp & (He et al., 2005) & $\mathfrak{I}_{L p}=1 /\left(\mathbf{L}_{1}^{T} \mathbf{X} \mathfrak{X} \mathbf{L}_{1}\right)$ \\
\hline
\end{tabular}

Tabela 3.2: Índices para análise supervisionada

\begin{tabular}{|c|c|c|}
\hline Índice & Referência & Equação \\
\hline Bhattacharya & $($ Jimenez e Landgrebe, 1999) & $\mathfrak{I}_{B h a t t}=\min _{i, j \in C}\left\{\frac{1}{4} \frac{\left(\mu_{i}-\mu_{j}\right)^{2}}{\sigma_{i}+\sigma_{j}}+\frac{1}{2} \log \left(\frac{\sigma_{i}+\sigma_{j}}{2 \sqrt{\sigma_{i} \sigma_{j}}}\right)\right\}$ \\
\hline$L D A$ & (Jee, 2009; Lee et al., 2005) & $\mathfrak{I}_{l d a}=1-\frac{\left|\mathbf{L}_{1}^{T} \mathbf{W L}_{1}\right|}{\left|\mathbf{L}_{1}^{T}(\mathbf{W}+\mathbf{B}) \mathbf{L}_{1}\right|}$ \\
\hline$Q P C$ & Grochowski e Duch (2011) & $\mathfrak{I}_{Q P C}=\sum_{i=1}^{n} \sum_{j=1}^{n} \alpha_{i, j} G\left(\left(\mathbf{x}_{i}-\mathbf{x}_{j}\right) \mathbf{L}_{1}\right)$ \\
\hline$N C A$ & (Goldberger et al., 2005) & $\mathfrak{I}_{N C A}=\sum_{i}^{n} \sum_{j \in \Omega_{i}} p_{i j}$ \\
\hline$L p S$ & (He et al., 2005) & $\mathfrak{I}_{L p}=1 /\left(\mathbf{L}_{1}^{T} \mathbf{X} \mathfrak{L}_{1}\right)$ \\
\hline
\end{tabular}

\subsection{Otimização em Projection Pursuit}

A otimização em PP é o processo pelo qual tenta-se encontrar uma solução $\mathbf{A}^{*}$ ao problema colocado na Equação 3.1, isto é, o conjunto de bases que definem o espaço onde a projeção linear dos dados maximiza a função índice. As primeiras abordagens propostas para tratar esse problema foram inspiradas nas técnicas de otimização baseadas em gradiente e NewtonRaphson (Nason, 1995, 1992; Jones e Sibson, 1987; Friedman, 1987; Friedman e Tukey, 1974). No entanto, esses métodos mostraram uma alta propensão a cair em ótimos locais de pouca relevância, dada a natureza acidentada (muitos ótimos locais) do espaço de otimização induzida pelas não linearidades da maioria de índices de projeção (Posse, 1995a). Outra limitação encontrada nas primeiras abordagens de otimização de PP era a dificuldade computacional em 
buscar projeções em espaços maiores a três dimensões. A quantidade de cálculos dos índices de projeção nesses espaços tornavam o processo de otimização impraticável nesses casos (Guo et al., 2001), sendo que a maioria de aplicações iniciais de PP eram no contexto de análise exploratória visual.

Devido à frequente ineficácia dos métodos baseados em gradiente em encontrar projeções ótimas, alguns pesquisadores concentraram-se em desenvolver métodos de otimização mais globais para PP. Por exemplo, Posse (1995b) descreveu um método de otimização para encontrar planos de projeção sem precisar de derivadas, colocando uma forte ênfase na busca de um 'bom' ponto inicial (com random search), o qual é refinado sucessivamente, reduzindo cada vez mais a área de busca. Guo et al. (2000) propuseram a aplicação de um AG canônico para otimizar índices unidimensionais de forma sequencial. Webb-Robertson et al. (2005) propuseram o algoritmo Random Scan Sampling Algorithm (RSSA), o qual evolui uma solução baseado em simulação de Monte-Carlo, iterando entre um passo preditivo (onde a solução é perturbada com valores aleatórios pequenos) e um passo de amostragem (a modificação é aceita baseada na distribuição de Boltzmann-Gibbs). Os autores mostraram as vantagens de RSSA numa aplicação com dados hiperespectrais. Lee et al. (2005) apresentaram uma abordagem de otimização baseada na técnica de Simulated Annealing (SA) que, ao igual que RSSA, trabalha iterativamente sobre uma única solução inicializada aleatoriamente. A cada iteração, SA escolhe uma solução candidata da vizinhança atual, a qual será aceita com base no potencial aumento do valor do índice. Recentemente, Berro et al. (2010) aplicaram PSO na maximização de índices unidimensionais. De forma similar aos AGs, PSO evolui paralelamente uma população de soluções. No entanto, a evolução em PSO é baseada no comportamento dinâmico das soluções ao invés de operadores genéticos como nos AGs.

Em relação à dificuldade em buscar projeções em espaços maiores a três dimensões, um dos trabalhos mais relevantes que aborda este problema veio de Guo et al. (2000). Nesse trabalho foi descrito o Sequential Projection Pursuit (SPP), uma metodologia que torna um problema de otimização de $k$ bases de projeção em $k$ problemas de otimização de uma base. Com a proposta de SPP foram abertas novas possibilidades de aplicação de PP, além de tarefas exploratórias visuais. Por exemplo, SPP tem sido aplicado em seleção de atributos (Guo et al., 2001), análise de agrupamentos (Webb-Robertson et al., 2005) e aprendizado de máquina supervisionado Rodriguez-Martinez et al. (2010). Dada a capacidade de SPP em facilitar a busca de projeções em espaços de dimensão arbitrária, este foi adotado como a metodologia base do presente 
trabalho, sobre a qual se elaboraram novas estratégias de busca de projeções para dados de elevada dimensionalidade. A Seção 3.5 descreve em detalhe a metodologia de SPP.

\subsection{Sequential Projection Pursuit (SPP)}

Em SPP as bases do espaço de projeção (também chamadas de fatores de projeção) são obtidas uma após a outra e em ordem decrescente de importância (definida pelo índice). A cada iteração obtém-se uma base de projeção mediante a otimização de uma função índice (definida em 1D). Guo et al. (2000) descreveram um AG para tal propósito, o qual representa as bases de projeção (soluções no AG) como sendo vetores de cadeias binárias nos quais se aplica operadores canônicos de cruzamento e mutação binária. A primeira base de projeção, $\mathbf{L}_{1} \in \mathbb{R}^{p}$ é obtida otimizando o índice unidimensional da projeção dos dados originais, isto é, $\Im\left(\mathbf{X L}_{1}\right)$. A segunda base $\mathbf{L}_{2}$ é sujeita à restrição de ortonormalidade em relação à primeira base encontrada (restrição da Equação 3.1). Para garantir isso, SPP retira de $\mathbf{X}$ toda a informação relativa à primeira projeção (obtém uma matriz residual) da seguinte maneira: $\mathbf{X}=\mathbf{X}-\left(\mathbf{X} \cdot \mathbf{L}_{1}\right) \mathbf{L}_{1}^{T}$ (processo conhecido como remoção da estrutura). A base $\mathbf{L}_{2}$ é então encontrada otimizando a projeção dos dados residuais $\mathfrak{I}\left(\mathbf{X} \cdot \mathbf{L}_{2}\right)$. Da mesma forma, são obtidas as subsequentes bases, $\mathbf{L}_{3}, \mathbf{L}_{4}, \ldots$, até atingir o número estipulado de bases $k$. Resumindo, cada base resulta da otimização do índice com dados residuais (nos quais se retirou as estruturas previamente encontradas), garantindo assim que cada base capture um aspecto distinto e complementar dos dados (em relação ao índice usado) e em forma decrescente de importância (já que as primeiras bases têm mais informação disponível a capturar do que as últimas). O Algoritmo 1 apresenta o pseudocódigo da metodologia SPP, a qual requer como entrada a matriz de dados originais $\mathbf{X}$, o número de bases a encontrar $k$, o tamanho da população $r$ para o AG e a função índice.

\section{Considerações Finais}

Nesse capítulo foi apresentado uma revisão da técnica de PP, alguns índices de projeção importantes, métodos de otimização, e uma descrição do algoritmo SPP para encontrar projeções maiores a três dimensões. Foi visto que PP é uma metodologia de grande flexibilidade, conseguindo-se adaptar a diversos requerimentos de análise, mediante a escolha adequada do índice de projeção, desse modo técnicas como: PCA, LDA ou ICA podem ser instanciadas no marco de PP com a simples mudança da função índice. No entanto, diversas considerações 


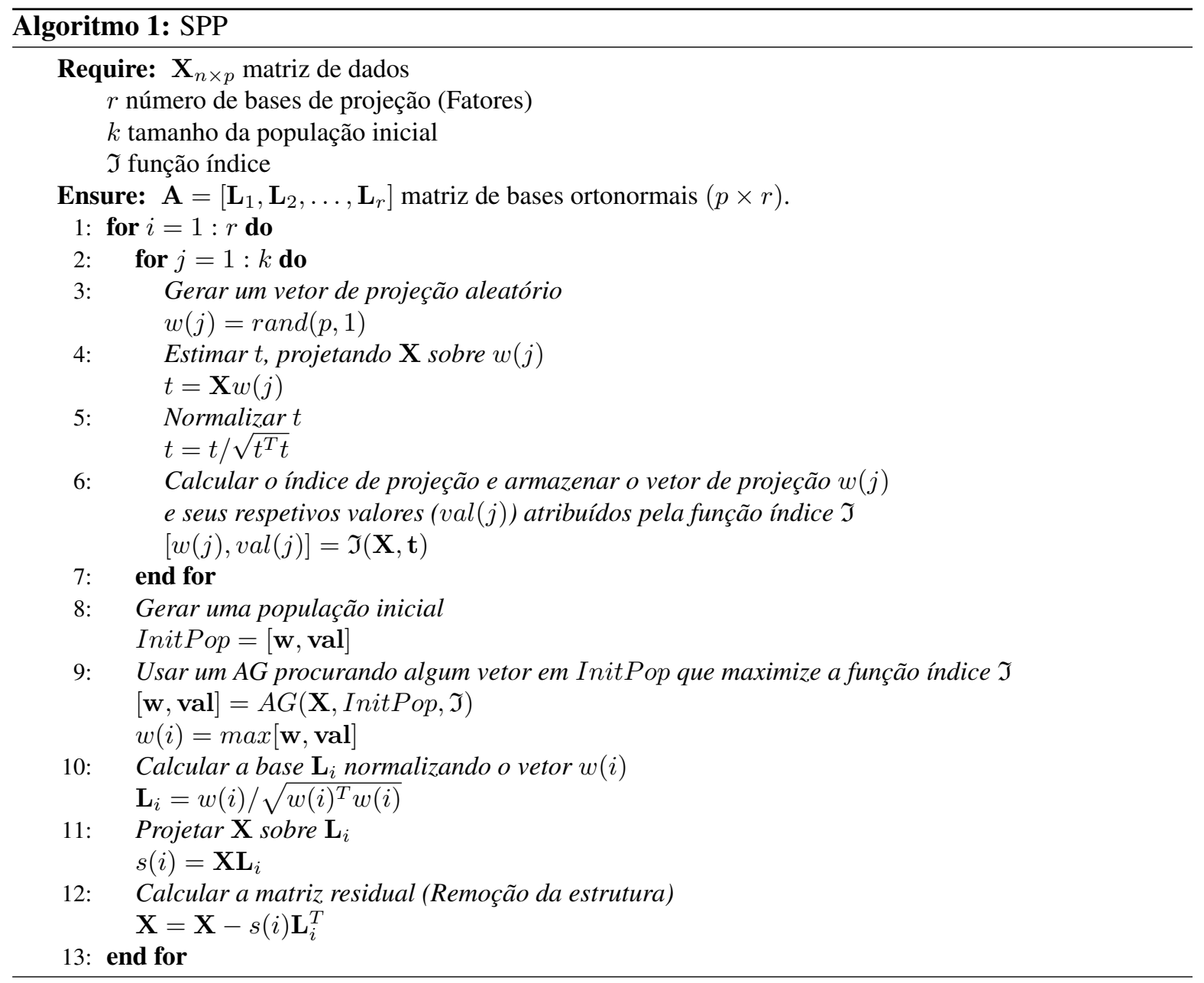

devem ser tomadas em consideração ao se trabalhar com PP, as quais são sumarizadas a seguir:

Escolha do índice de projeção. Uma grande parte das pesquisas sobre PP centram-se na construção de um índice que seja robusto e globalmente útil. No entanto, algumas evidências indicam que a efetividade dos índices depende frequentemente da aplicação e das caraterísticas do banco de dados (Jee, 2009), razão pela qual a escolha dos mesmos deve ser guiada por experimentação em cada caso.

- Otimização. A otimização em PP é um processo difícil de ser realizada, especialmente quando a dimensão original é elevada. Técnicas tradicionais baseadas em gradiente são na grande maioria não aplicáveis dada sua alta propensão a cair em ótimos locais irrelevantes. Otimizadores mais avançadas baseadas em AGs (Tu et al., 2003; Liu e Wechsler, 2000; Guo et al., 2000), PSO (Berro et al., 2010) e SA (Webb-Robertson et al., 2005; Lee et al., 2005) têm reportado melhorar a profundidade de busca e a eficiência computacional, embora a busca por melhores otimizadores é um tema de constante pesquisa. 


\section{Capítulo 4}

\section{Redução de dimensão com Projection Pursuit}

Neste capítulo, descrevem-se as abordagens propostas para reduzir a dimensão de dados alto-dimensionais usando PP. Na Seção 4.1, descreve-se o método SPPM, uma nova versão SPP que melhora vários aspectos da versão original tentando aprimorar a sua eficiência. Em seguida, na Seção 4.2, é descrita a primeira estratégia de redução dimensional proposta para dados de muito alta dimensão, o Block-SPPM. Finalmente, na Seção 4.3, é descrita a segunda estratégia proposta para redução dimensional, a qual foi denominada de W-SPPM.

\subsection{SPPM}

Como indicado no Capítulo 3, o surgimento da metodologia SPP (Guo et al., 2000) tem facilitado a expansão da prática corrente de PP para outras aplicações, além da análise exploratória visual. No entanto, na proposta original de SPP é possível encontrar algumas limitações. A primeira limitação, apontada por Webb-Robertson et al. (2005), tem a ver com a ineficiência computacional do AG usado para otimizar os índices de projeção. Webb-Robertson et al. (2005) propuseram um novo otimizador para esse propósito, o RSSA, o qual mostrou melhorar os tempos computacionais do AG original de SPP, embora gerando projeções de qualidades similares.

A segunda limitação reside na forma como se evita encontrar bases de projeção similares no processo de construção do espaço de projeção. SPP usa para este fim um procedimento cha- 
mado de remoção de estrutura, proposto originalmente por Friedman (1987), o qual calcula a matriz de dados residuais para a seguinte otimização realizando uma 'gaussianização' dos dados na direção encontrada, com o objetivo de que tal direção não seja favorecida novamente pela função de índice nas seguintes buscas de bases. Apesar de Friedman (1987) afirmar que tal procedimento afeta marginalmente a informação dos dados em outras direções, Posse (1995a) encontrou que usar tal procedimento de forma repetitiva (como é o caso de SPP) pode implicar em grandes distorções dos dados. Assim, após sucessivas aplicações do procedimento de remoção de estrutura é possível observar que os ótimos encontrados nos dados residuais resultantes não estejam mais relacionados com ótimos nos dados originais (e, portanto não representem mais projeções de interesse).

Nesta seção é descrita uma versão melhorada de SPP, chamada de SPPM (Figura 4.1), para abordar os problemas mencionados. Apesar de Webb-Robertson et al. (2005) ter apontado que o AG original de SPP não era eficiente, o autor considera que a otimização com AGs pode ainda ser bem sucedida se os operadores genéticos fossem adequadamente selecionados. Esta foi uma das considerações assumidas neste trabalho para gerar um melhor otimizador para SPPM baseado em AGs. Certamente, os AGs têm mostrado em numerosas ocasiões seu potencial para lidar com situações em que o espaço de busca é amplo e complexo (Pham e Karaboga, 2012). No entanto, tal potencial não tem sido bem explorado na otimização de SPP, sendo que para seu otimizador original foi realizada uma escolha arbitrária dos seus operadores genéticos. A otimização com AGs pode trazer várias vantagens, tais como: i) capacidade de explorar em espaços de alta dimensão em forma paralela e multidireccional, dando oportunidade de encontrar soluções mais globais (Goldberg, 1989); ii) não há necessidade da função objetivo ser contínua ou diferenciável (propriedade necessária para os algoritmos de otimização baseados em gradiente) (Tu et al., 2003); iii) em qualquer momento uma solução pode ser captada, a qual melhora (idealmente) com o tempo (Duda et al., 2001); e iv) é possível controlar a diversidade da população, o qual pode ser de utilidade em aplicações de análise exploratória em que muitas soluções alternativas são necessárias para inspeção. Dadas essas vantagens, o otimizador apresentado aqui para SPPM (chamado de PPGA, Seção 4.1.1), resulta de avaliar o potencial de diversos operadores de cruzamento com o intuito de melhorar a sua capacidade de tornar a busca de bases de projeção mais profunda e menos demorada.

Em relação ao problema de como evitar as direções de projeção previamente encontradas, SPPM aproveita os desenvolvimentos realizados em (Zhang e Chan, 2006; Rodriguez-Martinez 
et al., 2010). Em (Zhang e Chan, 2006) foi descrito (no contexto de ICA) um procedimento chamado de deflation que, ao invés de realizar alterações nos dados para desfavorecer as projeções prévias, propõe realizar a busca da seguinte projeção no espaço complemento ortogonal ${ }^{1}$ das bases de projeção encontradas até o momento. Em (Rodriguez-Martinez et al., 2010) foi melhorado o processo deflation anterior (baseado originalmente no processo Gram-Schmidt) a fim de balancear o compromisso rapidez computacional/memória em favor do primeiro.

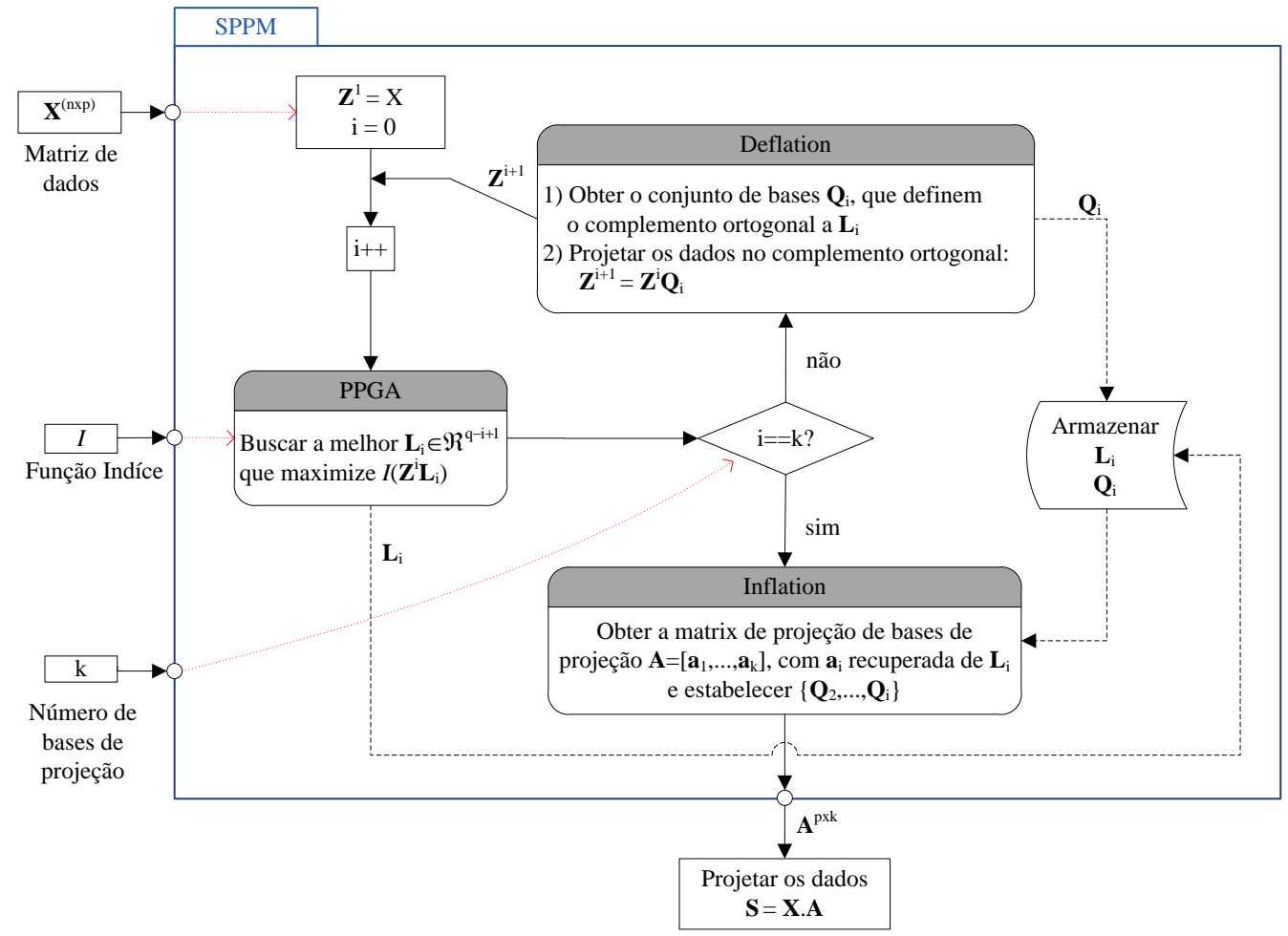

Figura 4.1: Esquema do algoritmo Sequential Projection Pursuit Modified (SPPM). Nesse esquema pode ser observado que SPPM incorpora os seguintes processos: i) busca de bases de projeção baseado no algoritmo PPGA; ii) processo deflation; iii) processo inflation. O resultado de SPPM é a matriz de projeção $\mathbf{A}$.

A Figura 4.1 mostra a arquitetura adotada para SPPM. Esta recebe como entrada um banco de dados $\mathbf{X}^{(n \times p)}$ e, no caso supervisionado, os correspondentes rótulos de classe. É necessário também especificar a função de índice (I) a otimizar e o número de bases $(k)$ que se pretende obter (dimensão do espaço de projeção). Similar ao SPP, SPPM obtém sequencialmente as bases do espaço de projeção. Na iteração $i$, a base $\mathbf{L}_{i}$ de $\mathbf{A}$ é procurada. Tal busca é executada pelo otimizador PPGA (descrito abaixo), o qual usa como dados de entrada os dados residuais

\footnotetext{
${ }^{1}$ O complemento ortogonal de um vector $x \in \mathbb{R}^{n}$ é o espaço de vetores $y$, os quais são todos ortogonais a $x$. Portanto, tal espaço pode ser expandido por $n-1$ vectores base. Ou seja, o espaço ortogonal de um vector $x$ $n$-dimensional é sempre de dimensão $n-1$.
} 
atuais $\mathbf{Z}^{i}$ (de dimensão $n \times p-i+1$ ). Para a busca da primeira base $\mathbf{L}_{i}$, usa-se os dados originais $\mathbf{X}$ como dados residuais. Uma vez a base $\mathbf{L}_{i}$ é devolvida por PPGA, inicia-se o processo de Deflation (Algoritmo 2), o qual calcula um conjunto de bases $\mathbf{Q}_{i}^{(p-i+1) \times(p-i)}$ que definem o complemento ortogonal da base encontrada $\mathbf{L}_{i}$. Os dados atuais são então projetados sobre o complemento ortogonal definido pelas bases $\mathbf{Q}_{i}$, obtendo-se a nova matriz de dados residuais $\mathbf{Z}^{i+1}=\mathbf{Z}^{i} \mathbf{Q}_{i}$ que será usada na seguinte iteração. Note que a dimensão dos dados residuais diminui em uma unidade à cada iteração. A matriz de bases $\mathbf{Q}_{i}$ é também armazenada para realizar o procedimento de inflation ao final do processo de busca. O ciclo é repetido até encontrar todas as $k$ bases. Quando isso acontece, o procedimento de inflation (Algoritmo 3) é executado, o qual coloca todas as bases encontradas $\mathbf{L}_{i}(i>=2)$ no sistema de coordenadas do espaço original dos dados, para assim formar a matriz de projeção final A. Basicamente, colocar uma base $\mathbf{L}_{i}$ no espaço original (processo conhecido como "inflar a base") consiste em uma cadeia de multiplicações desse vector e todos os $\mathbf{Q}_{j}$ prévios (todo $j<i$ ). SPPM retorna a matriz $\mathbf{A}$ formada por todas as bases infladas, a qual pode ser usada para mapear qualquer dado $\mathbf{x} \in \mathbb{R}^{p}$ em uma representação de dimensão reduzida $\mathbf{s} \in \mathbb{R}^{k}$, assim $\mathbf{s}=\mathbf{x A}$.

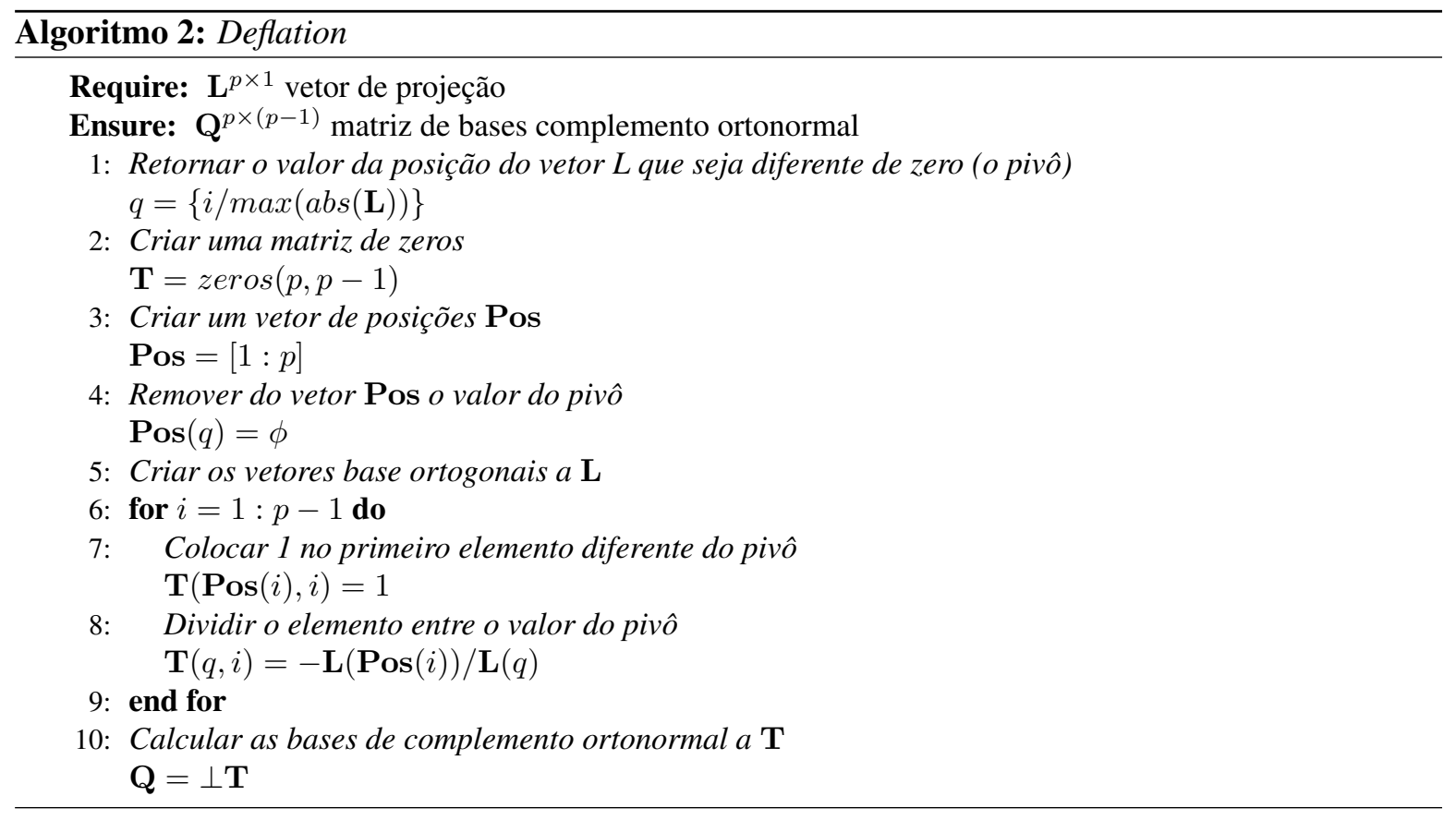

$\mathrm{O}$ uso do esquema de deflation-inflation tem a vantagem de ser mais rápido que o procedimento de Gram-Schmidt descrito por Zhang e Chan (2006), conseguindo reduzir o cálculo computacional e garantindo a ortogonalidade das bases. A desvantagem é a necessidade de armazenar todos os $\mathbf{Q}_{i}$, para que a matriz de projeção $\mathbf{A}^{*}$ possa ser construída (RodriguezMartinez et al., 2010). No entanto, tal desvantagem não é de importância com os recursos 
computacionais atuais.

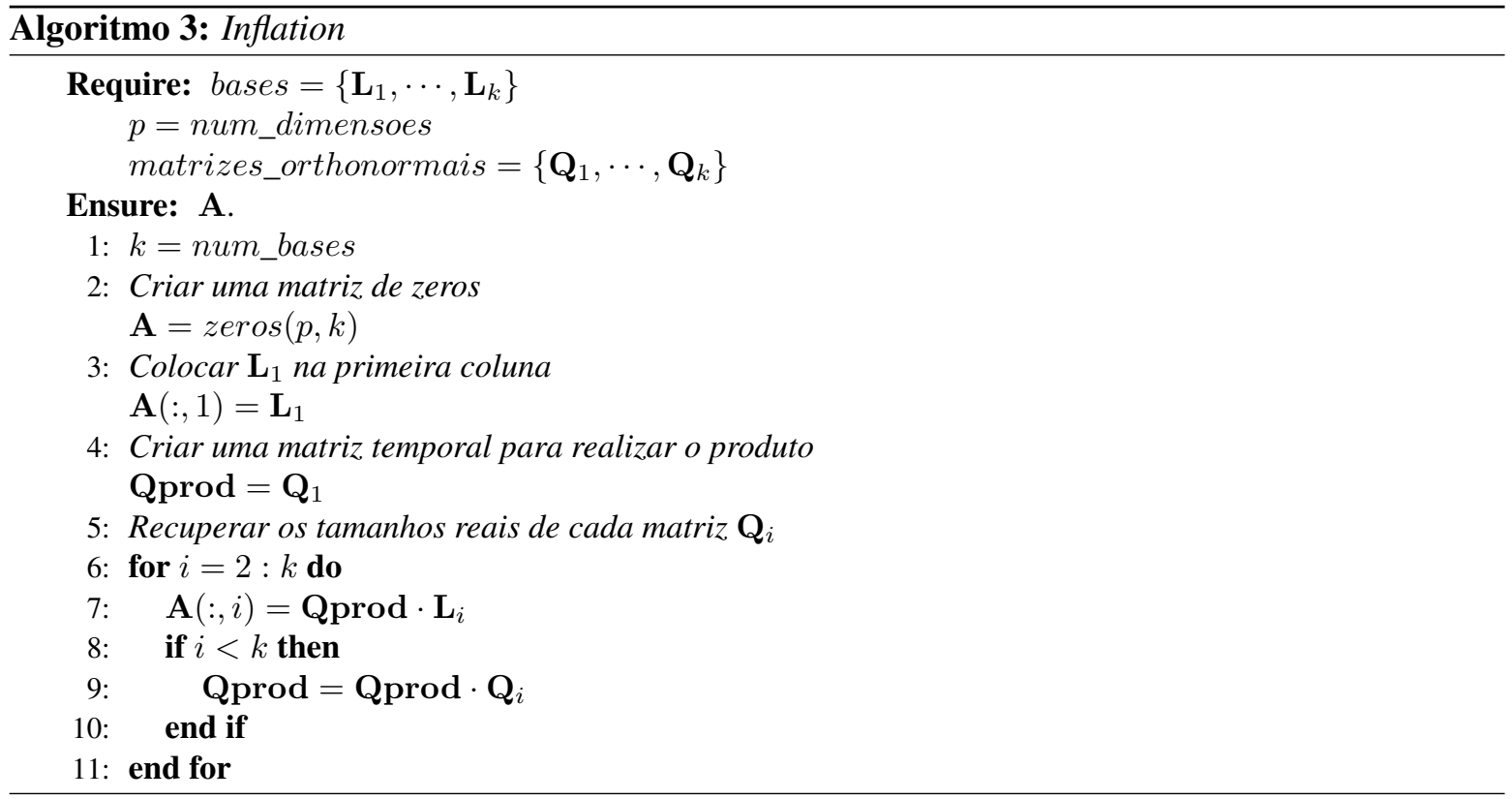

\subsubsection{Projection Pusuit Genetic Algorithm (PPGA)}

PPGA é o otimizador implementado para buscar as bases em SPPM. A estrutura de PPGA corresponde a uma estrutura clássica de um AG (Wright, 1991), o qual começa gerando de forma aleatória uma população de indivíduos (bases de projeção) para depois, mediante uma função de aptidão (índice de projeção), atribuir um valor de aptidão a cada indivíduo gerado nessa população. Um processo iterativo é realizado em seguida, onde a cada iteração (geração) é criada uma nova população de indivíduos para a próxima geração. PPGA finaliza quando um critério de convergência é satisfeito, devolvendo o melhor individuo $\mathbf{L}^{*}$ encontrado e seu valor de aptidão $\left(I v a l^{*}\right)$ resultante da avaliação do índice com a projeção dos dados nessa direção. A diferença de PPGA em relação ao AG original de SPP é que a escolha do seu operador de cruzamento foi realizada com base em um estudo de desempenho de vários operadores (alguns existentes na literatura e outros propostos para este trabalho), estudo que é apresentado no Capítulo 5 do presente texto.

Sabe-se que a seleção do operador de cruzamento é de importância fundamental para o bom desempenho de um AG, já que ele é o principal mecanismo de busca, responsável pelo rápido intercâmbio de informação entre soluções para criar melhores soluções (Srinivas e Patnaik, 1994). Na maioria dos trabalhos relativos a PP que descreveram otimizadores baseados em AGs escolheram operadores canônicos para realizar o cruzamento, tais como cruzamento aritmético 
(Chiang et al., 2001) ou cruzamento binário (Tu et al., 2003; Qiang et al., 2002; Guo et al., 2001, 2000). No entanto, é difícil encontrar na literatura operadores específicos para PP ou estudos comparativos relatando a adequação de operadores na busca de bases de projeção, o qual pode ter desencorajado o uso de AGs para esse problema (Webb-Robertson et al., 2005).

A seguir são descritos oito operadores de cruzamento que podem ser usados em PPGA, três comumente utilizados na literatura: cruzamento aritmético e cruzamento de um-ponto e multiponto; e cinco novos operadores propostos para este trabalho: uma extensão do cruzamento aritmético simples, dois cruzamentos hiper-cônicos e dois cruzamentos guiados pela aptidão. Uma avaliação experimental destes operadores é apresentada no Capitulo 5 e também foi publicada em (Espezua et al., 2013, 2012).

Os operadores binários (de um-ponto e multiponto) foram adaptados para valores reais, considerando cada coordenada como uma unidade de informação a ser transferida (gene). Todos os operadores requerem dois indivíduos pais como entrada e retornam dois indivíduos filhos como saída. Os pais são denotados como a1 $=\left[a 1_{1}, \ldots, a 1_{p}\right]^{T}$ e a2 $=\left[a 2_{1}, \ldots, a 2_{p}\right]^{T}$ e os filhos como b1 $=\left[b 1_{1}, \ldots, b 1_{p}\right]^{T}$ e b2 $=\left[b 2_{1}, \ldots, b 2_{p}\right]^{T}$. A função Normalize $(\mathbf{x})=$ $\mathbf{x} / \sqrt{\mathbf{x}^{T} \cdot \mathbf{x}}$ é usada para produzir um vetor de comprimento unitário na direção de $\mathbf{x}$. Esta operação é realizada em todos os operadores de cruzamento, a fim de garantir a normalidade das bases de projeção. Dessa forma, as projeções dos dados não são escaladas pelos vetores de projeção e a única informação que determina o valor do índice é a direção das bases de projeção codificadas pelos indivíduos.

1. Operador de cruzamento aritmético interno (CX1). Este operador foi usado no Projection Pursuit Exploratory Analysis (PPEA) (Chiang et al., 2001). Os filhos produzidos são os seguintes:

$$
\begin{array}{r}
\mathbf{b} \mathbf{1}=\text { Normalize }(r \mathbf{a} \mathbf{1}+(1-r) \mathbf{a} \mathbf{2}) \\
\mathbf{b} \mathbf{2}=N \text { ormalize }((1-r) \mathbf{a} \mathbf{1}+r \mathbf{a} \mathbf{2}),
\end{array}
$$

onde $r$ é um número aleatório entre $-0,5$ e 0,5 , gerado seguindo uma distribuição uniforme. Os vetores filhos são gerados no plano dos pais e são localizados simetricamente em ambos os lados da bissetriz dos pais, os quais limitam a região onde os filhos podem ser gerados. Na Figura 4.2(a) exemplifica-se a geração dos filhos para este operador. 


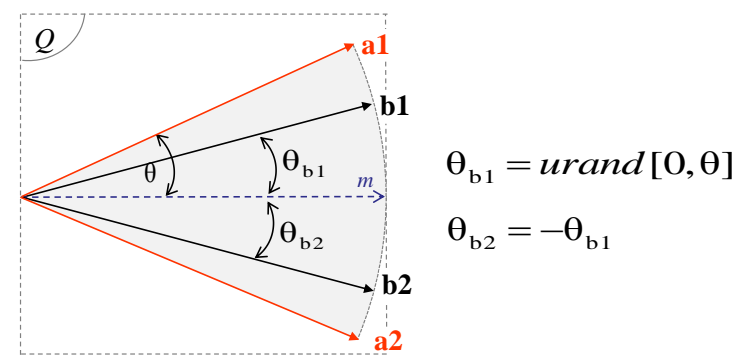

(a) CX1

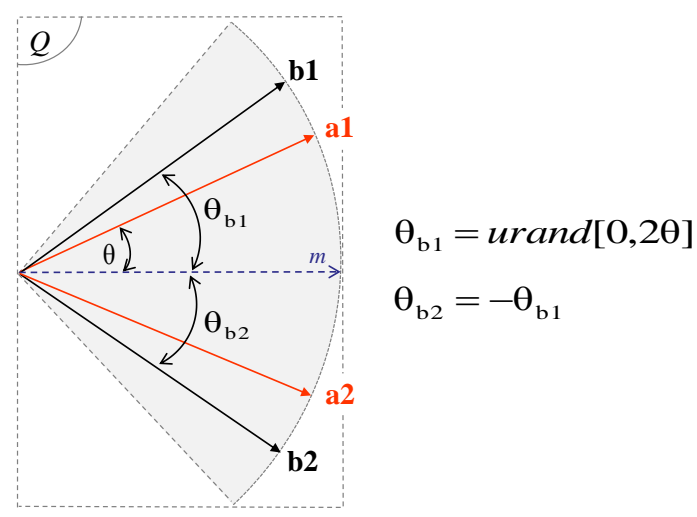

(b) $\mathrm{CX} 2$

Figura 4.2: Exemplo de geração dos indivíduos filhos nos operadores CX1 e CX2. $\theta$ é o angulo formado por qualquer pai ( $a 1$ ou $a 2$ ) e m, a bissetriz dos pais. $\theta_{b 1}$ e $\theta_{b 2}$ são os ângulos formados pelos filhos $b 1$ e $b 2$ em torno da bissetriz. urand $[a, b]$ é um número aleatório no intervalo $[a, b]$, gerado seguindo uma distribuição uniforme.

2. Operador de cruzamento aritmético interno-externo (CX2). Este operador é proposto neste trabalho como uma extensão do operador CX1. Os filhos são produzidos da mesma forma como na Equação 4.1. A única diferença entre estes operadores está no intervalo em que o número aleatório $r$ é gerado, o qual é $[-0.5,0.5]$. Assim, os vetores filhos são produzidos no plano dos pais em ambos os lados da sua bissetriz, mas podem cair fora da região delimitada pelos pais, formando um ângulo máximo com relação à bissetriz de até $2 \theta$, sendo $\theta$ o ângulo entre qualquer dos pais e a bissetriz. Na Figura 4.2(b) exemplifica-se como podem ser gerados os filhos dentro e fora dos espaço dos pais.

3. Operador de cruzamento de um-ponto (CX3). Este é um operador comumente usado nos AGs (Goldberg, 1989) e foi formulado para recombinar sequências de tipo binário a partir da seleção de um único ponto de corte nas strings dos pais. Neste trabalho é implementada uma versão do tipo real para este operador (uma ilustração deste procedimento é apresentado na Figura 4.3). Primeiro, um valor $r$ é escolhido aleatoriamente do 
conjunto $\{1,2, \ldots, p-1\}$. Seguidamente, os filhos são criados como segue:

$$
\begin{aligned}
& \mathbf{b} \mathbf{1}=\operatorname{Normalize}\left(\left[a 1_{1}, \ldots, a 1_{r}, a 2_{r+1}, \ldots, a 2_{p}\right]^{T}\right) \\
& \mathbf{b 2}=\operatorname{Normalize}\left(\left[a 2_{1}, \ldots, a 2_{r}, a 1_{r+1}, \ldots, a 1_{p}\right]^{T}\right)
\end{aligned}
$$

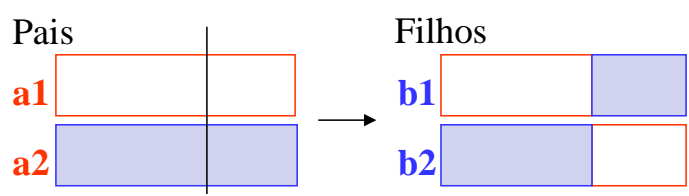

Figura 4.3: Exemplo da geração dos filhos no operador CX3. Os filhos são gerados intercambiando trechos dos pais definidos pelo ponto de cruzamento (escolhido aleatoriamente).

4. Operador de cruzamento multiponto (CX4). Este operador (Goldberg, 1989) pode ser visto como uma extensão do operador CX3. Na Figura 4.4 é ilustrado como este operador cria os filhos. Primeiro, é criada uma máscara binária aleatória do mesmo comprimento $p$ dos indivíduos, tentando manter a mesma quantidade de 0 s e $1 \mathrm{~s}$. Seguidamente são gerados os filhos b1, b2, o filho b1 é gerado copiando a1 e logo substituindo os valores por aqueles em a2 cujas posições na máscara é 0 . O filho b2 é gerado de forma similar e complementar, isto e, b2 toma os valores de a2 nas posições onde a máscara é 1 e os valores de a1 nas outras posições.

Máscara
\begin{tabular}{|l|ll|ll|l|}
\hline 1 & 0 & 0 & 1 & 1 & 0 \\
\hline
\end{tabular}

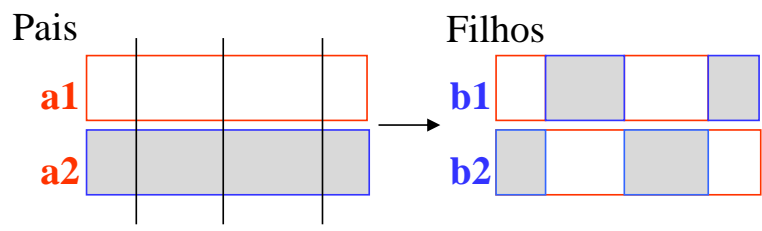

Figura 4.4: Exemplo da geração dos filhos no CX4. Os filhos são gerados intercambiando vários segmentos dos pais. Uma máscara aleatória é usada para gerar o intercâmbio.

5. Operador de cruzamento hiper-cônico interno (CX5). Este operador é proposto neste trabalho para permitir que os filhos possam ser gerados fora do plano dos pais. Os filhos são gerados na região interior do hiper-cone resultante da rotação dos pais em torno da sua bissetriz. Na figura 4.5(a), é apresentado este esquema de geração dos filhos. Primeiro, é calculada a bissetriz como $\mathbf{m}=\operatorname{Normalize}(\mathbf{a} 1+\mathbf{a} 2)$. Em seguida, um plano contendo essa bissetriz é escolhido de forma aleatória (plano de cruzamento). 
Para realizar tal escolha, considera-se à bissetriz $\mathbf{m}$ como uma das bases geradoras do plano. A outra base $\mathbf{v}$ é um vetor ortogonal a ela. $\mathbf{v}$ pode ser construída escolhendo aleatoriamente um componente não-zero de $\mathbf{m}, m_{j}$, e uma posição $l \neq j$; com isso, o vetor ortogonal é composto por: $v_{i}=0(i \neq j, l), v_{l}=1$, e $v_{j}=-m_{l} / m_{j}$. Dessa forma, as bases do plano de cruzamento são $Q=[\mathbf{m}, \mathbf{v}]$. Neste plano, a bissetriz está sobre a abscissa e os pais estão localizados em ângulos $\theta \mathrm{e}-\theta$. O vetor filho $\mathbf{b} \mathbf{1}^{Q}$ é gerado sobre este plano formando um ângulo $\theta_{r}$ em relação à abcissa, onde $\theta_{r}$ é escolhida aleatoriamente no intervalo $[0, \theta]$. O filho $\mathbf{b 2}{ }^{Q}$ é gerado de forma simétrica ao filho b1 ${ }^{Q}$. Para recuperar os filhos no espaço original utilizam-se as bases do plano, assim: $\mathbf{b} i=Q \cdot \mathbf{b} i^{Q}, i=1,2$. Com este esquema de cruzamento existem até $p(p-1)$ possíveis planos de cruzamento, todos intersectando-se na bissetriz dos pais.

6. Operador de cruzamento hiper-cônico interno-externo (CX6). Este operador é proposto neste trabalho como uma extensão do operador CX5. De forma semelhante, os filhos podem ser gerados em um dos $p(p-1)$ possíveis planos de cruzamento de forma simétrica à bissetriz dos pais. A diferença em relação a CX5 é que os filhos podem ser gerados fora do hiper-cone gerado pela rotação dos pais em torno da sua bissetriz. O procedimento para produzir os filhos é semelhante ao operador CX5, diferindo no intervalo onde $\theta_{r}$ é gerado (entre $[0,2 \theta]$ ). Consequentemente, os filhos podem nascer num espaço maior do que o hiper-cone do operador de CX5. Na Figura 4.5(b), apresenta-se o esquema deste operador de cruzamento como uma extensão do operador CX5.

7. Operador de cruzamento interno guiado pela aptidão (CX7). Este operador foi proposto neste trabalho para guiar a geração dos filhos em torno do pai de maior aptidão (sob a premissa que nessa região podem ser encontradas soluções melhores). A Figura 4.6(a) ilustra o procedimento de criação. O cruzamento tem lugar no plano dos pais, de forma similar a CX1 e CX2. No entanto, os filhos não são mais simétricos à bissetriz $\mathbf{m}$ dos pais. A segunda base (v) do plano de cruzamento é escolhida de tal forma que o pai com maior aptidão forme um ângulo negativo com relação à primeira base (bissetriz $\mathbf{m}$ ). Considere $\mathbf{a}_{b e s t}$ o pai com o melhor aptidão e $\mathbf{a}_{\text {worst }} \mathrm{o}$ outro pai. Os vectores base no plano são $Q=[\mathbf{m}, \mathbf{v}]$, onde $\mathbf{m}$ é a bissetriz e $\mathbf{v}$ é calculada usando Normalize $\left(\mathbf{a}_{\text {best }}-\left(\mathbf{a}_{\text {worst }}^{T} \cdot \mathbf{m}\right) \mathbf{m}\right)$. Neste plano, os pais estão localizados entre os ângulos $-\theta$ (o melhor pai) e $\theta$ (o pior pai). Para gerar um filho $\mathbf{b}_{i}(i=1,2)$, um ângulo aleatório $\theta_{b i}$ (gerado seguindo uma distribuição uniforme) é escolhido no intervalo 


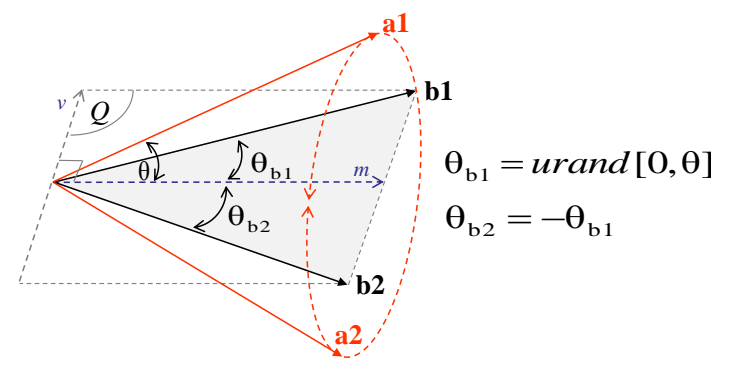

(a) CX5

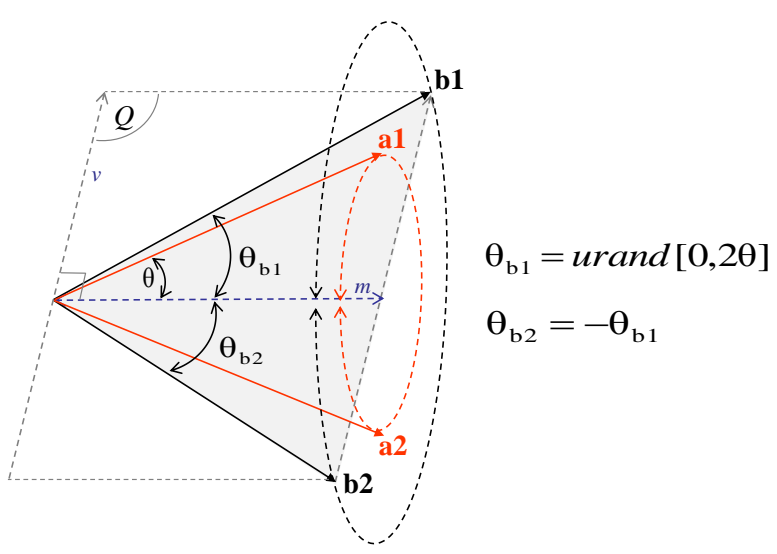

(b) CX6

Figura 4.5: Exemplo de geração dos filhos nos operadores CX5 e CX6. $\theta$ é o angulo formado por qualquer dos pais ( $a 1$ ou $a 2$ ) e $\mathbf{m}$, a bissetriz dos pais. $\theta_{b 1}$ e $\theta_{b 2}$ são os ângulos formados pelos filhos $b 1$ e $b 2$ entorno da bissetriz. urand $[a, b]$ é um número no intervalo $[a, b]$, gerado aleatoriamente seguindo uma distribuição uniforme.

$[-\theta, \theta]$. Em seguida, esse ângulo é distorcido (a favor de $-\theta$ ) usando a seguinte função:

$$
\theta_{b i}^{(\text {biased })}=2 \theta\left(\left(\theta_{i}+\theta\right) / 2 \theta\right)^{\beta}-\theta
$$

onde $\beta>1$ controla a intensidade da distorção. Em nossos experimentos, são usados $\beta=\left(\text { Fitness }\left(\mathbf{a}_{\text {best }}\right) / \text { Fitness }\left(\mathbf{a}_{\text {worst }}\right)\right)^{4}$. Com a Equação 4.3 os ângulos dos filhos sempre são gerados no intervalo $[-\theta, \theta]$. Os filhos bi são gerados calculando o $\theta_{b i}^{(b i a s e d)}$ como foi explicado no CX1.

8. Operador de cruzamento interno-externo guiado pela aptidão (CX8). Este operador foi proposto neste trabalho como uma extensão de CX7. A única diferença em relação a este último operador é que CX8 gera o valor de $\theta_{b i}$ (e por conseguinte $\theta_{b i}^{(b i a s e d)}$ ), no intervalo $[-2 \theta, 2 \theta]$. Assim, os vetores filhos são produzidos no plano dos pais e com uma tendência a cair mais próximo do melhor pai. Na Figura 4.6(b), é apresentado o esquema de geração deste operador. 


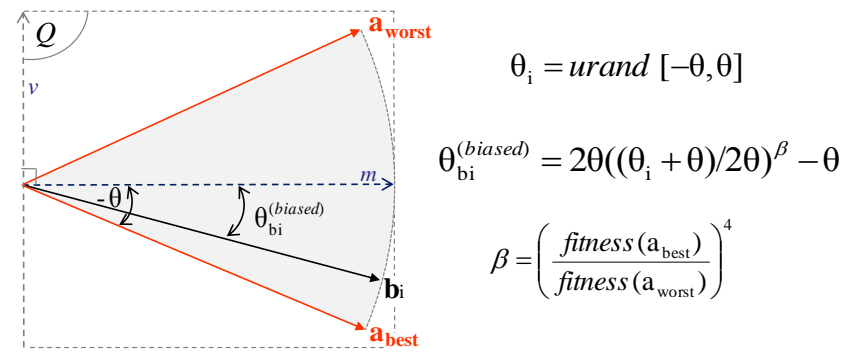

(a) $\mathrm{CX} 7$

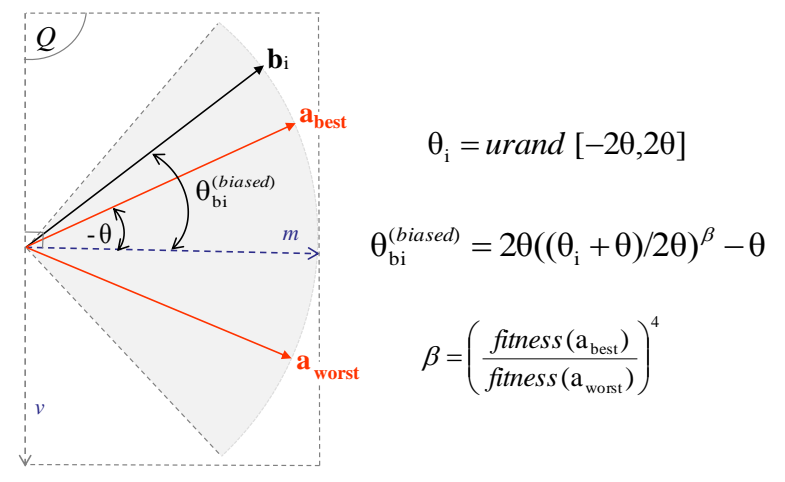

(b) CX8

Figura 4.6: Exemplo de geração dos filhos nos operadores CX7 e CX8 (guiados pela aptidão). $\theta$ é o angulo formado por qualquer dos pais ( $a 1$ ou $a 2$ ) e $\mathbf{m}$ é a bissetriz formada pelos pais. $\theta_{b 1}$ e $\theta_{b 2}$ são os ângulos formados pelos filhos $b 1$ e $b 2 \mathrm{em}$ torno da bissetriz. urand $[a, b]$ é um número gerado no intervalo $[a, b]$ seguindo uma distribuição uniforme. $\theta_{b i}^{(b i a s e d)}$ é o ângulo formado com o filho $b i$ inclinado a favor do pai com melhor aptidão.

A seleção de indivíduos pais para cruzamento em PPGA é baseado no método de torneio (Pham e Karaboga, 2012). Com este método, cada pai é selecionado a partir da competição dos valores de aptidão de $t s$ indivíduos (tamanho do torneio) escolhidos aleatoriamente da população atual (de tamanho $w$ ). Usando este método de seleção, são selecionados $w / 2$ casais para formar o "Mating Pool" 2 e gerar assim a população filha de $w$ novos indivíduos. Esta população filha é então juntada com a população atual para assim selecionar os melhores $w$ indivíduos que formarão a população da seguinte geração. PPGA finaliza quando um número máximo de gerações é atingido ou a diferença da aptidão média de duas gerações sucessivas cai dentro de um limiar de precisão.

\footnotetext{
2 “Mating Pool” é entendido no texto como um conjunto de casais de indivíduos selecionados para reprodução.
} 


\subsection{Block-SPPM}

Nesta seção é descrita uma metodologia para tornar viável a aplicação de SPPM quando a dimensão dos dados é muito grande (milhares de atributos), tal como no caso de dados de microarranjo. Apesar das melhoras implementadas em SPPM, a aplicação direta do mesmo nesses cenários resultaria em um processo extremamente demorado, dada a magnitude do espaço de otimização e à grande quantidade de parâmetros a otimizar. Por exemplo, se a dimensão dos dados originais fosse 10000 (ordem de magnitude frequente em dados de microarranjo) e o espaço de projeção requerido fosse de 10 dimensões, a quantidade de parâmetros a ajus$\operatorname{tar}$ (elementos da matriz $A$ ) estaria próxima a 100 mil. O esquema aqui proposto, chamado de Block-SPPM, busca aliviar esse problema particionando os atributos em blocos de tamanho moderado, sob a consideração de que aplicar SPPM em cada bloco e logo arranjar os resultados para formar o espaço de projeção final é mais computacionalmente acessível do que realizar uma única otimização no conjunto total de atributos. Adicionalmente, com o esquema proposto seria sensivelmente facilitada a paralelização do processamento, tirando assim proveito dos recursos computacionais atuais.

A Figura 4.7 mostra o esquema de Block-SPPM. A matriz de dados de entrada X é partida em $m$ blocos de atributos $\left\{\right.$ Bloco $_{1}$, Bloco $_{2}, \ldots$, Bloco $\left._{m}\right\}$, aproximadamente do mesmo tamanho. Em cada bloco $\mathrm{Bloco}_{i}$ são realizadas duas aplicações de SPPM. A primeira aplicação realiza uma otimização das bases, procurando as melhores projeções $\mathbf{A}_{i}$ de acordo ao índice escolhido. Na segunda aplicação, as amostras do bloco são primeiramente permutadas (cada coluna é permutada de forma independente) a fim de quebrar qualquer estrutura que possa estar contida no bloco. O resultado desta operação é um bloco randomizado $\left(B l o c o_{i}^{R}\right)$, que, apesar de manter as propriedades estatísticas do bloco original (média e variância), não é esperado encontrar nenhuma estrutura de interesse. Com isto se pretende obter informação acerca do nível de ruído do bloco que tem que ser superada para determinar se o bloco original possui estruturas relevantes e também para determinar a relevância das bases encontradas no bloco, $\mathbf{A}_{i}$, na matriz de projeção final $\mathbf{A}^{*}$. Após fazer as duas aplicações de SPPM no bloco $i$, é determinado o peso do mesmo $\left(w_{i}\right)$ calculando para isso a razão entre o somatório dos valores de índice de todas as bases obtidas para o $\mathrm{Bloco}_{i}$ e o somatório dos valores de índice de todas as bases obtidas para o Bloco $_{i}^{R}$, assim $w_{i}=\frac{\sum I v a l_{i}}{\sum I v a l_{i}^{R}}$. O procedimento anterior é repetido para todos os blocos, registrando-se em cada um as bases obtidas junto com seus respectivos pesos. Finalmente, a matriz $\mathbf{A}^{*}$ é construída empilhando verticalmente todas as matrizes de 
bases obtidas (começando com $\mathbf{A}_{1}$ e finalizando com $\mathbf{A}_{m}$ ), previamente ponderadas por seus pesos, tal como ilustrado na Figura 4.7. Com este processo, mantém-se a coerência entre as linhas de $\mathbf{A}^{*}$ e os respectivos atributos em $\mathbf{X}$ que a matriz $\mathbf{A}^{*}$ multiplica ao projetar. Também, a ortogonalidade das colunas de $\mathbf{A}^{*}$ é garantida, desde que SPPM garante que cada $\mathbf{A}_{i}$ é ortogonal (implícito no processo de deflation - inflation). A ponderação das bases dos blocos com seus respectivos pesos realiza então um ranqueamento implícito da relevância dos blocos, premiando assim aos blocos que apresentam estruturas de interesse e penalizando aos que não conseguem evidenciar diferenças em relação ao ruído de fundo. Note-se na Figura 4.7 que o parâmetro $r$ é usado para intensificar a diferença entre premiação e penalização. No entanto, na prática foi observado que Block-SPPM é robusto a este parâmetro, pelo que seu valor foi fixado a 1 na avaliação apresentada no Capitulo 5.

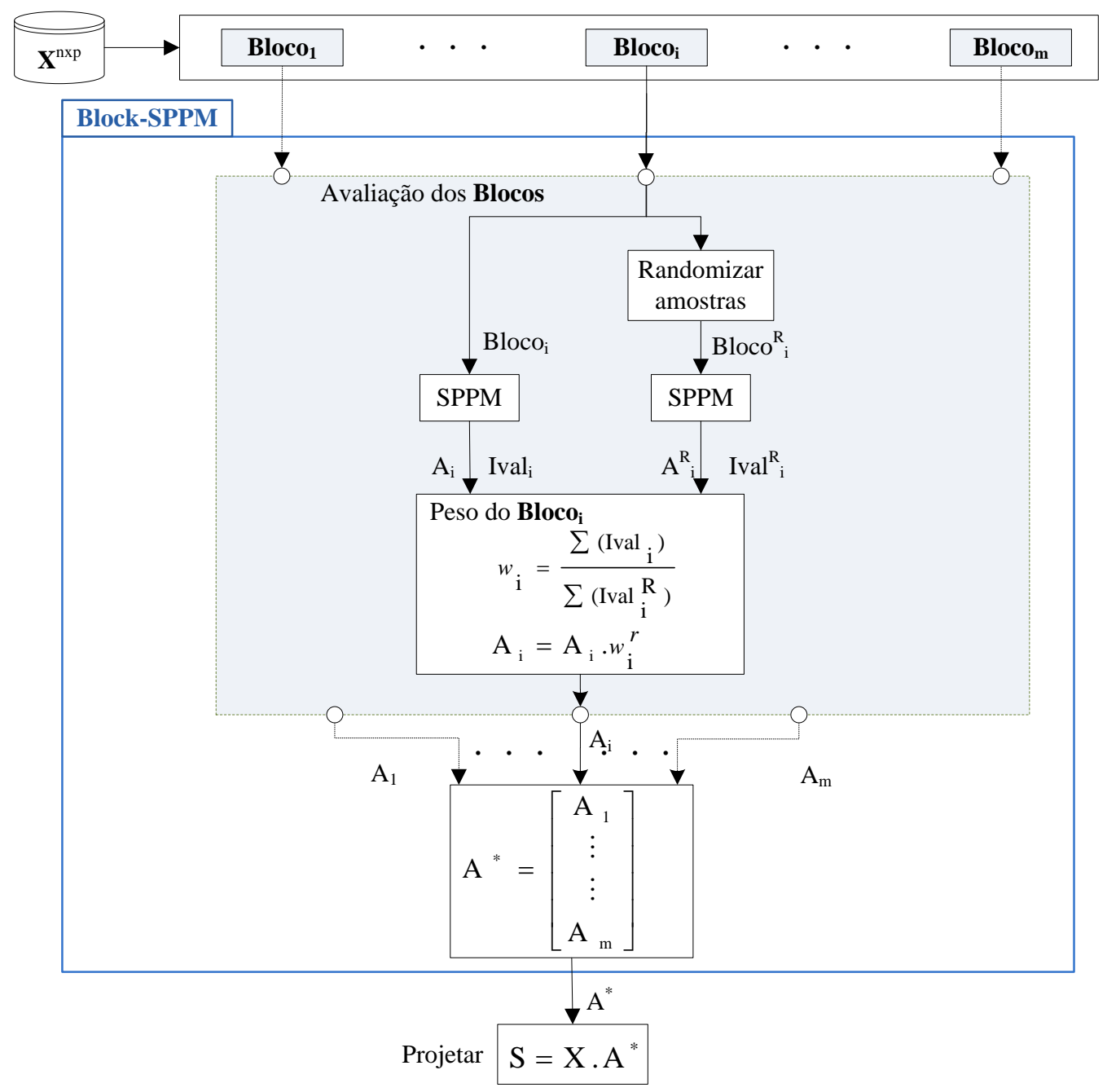

Figura 4.7: Esquema de Block-SPPM. Os blocos $\left\{\right.$ Bloco $_{1}, \ldots$, Bloco $\left._{m}\right\}$ representam subconjuntos mutuamente exclusivos e exaustivos dos atributos de $\mathrm{X}$, aproximadamente do mesmo tamanho. 


\subsection{W-SPPM}

Descrevemos aqui outra estratégia, chamada de W-SPPM, que também tenta tornar viável a aplicação de SPPM para reduzir bancos de dados de alta dimensão e poucas amostras. A consideração por trás desta estratégia é que a busca do espaço de projeção poderia ser facilitada se o banco de dados fosse primeiro transformado em uma representação mais compacta, na qual SPPM possa encontrar ótimas bases de projeção em tempos computacionais razoáveis. W-SPPM implementa tal compactação dos dados através de uma transformação por branqueamento (também chamada de transformação Whitening) (Asuncion Vicente et al., 2007), a qual pode reduzir rapidamente a dimensão dos dados na ordem de $n$ (que já é pequeno, por definição). A escolha desta transformação é baseada em algumas evidências que apontam que branqueamento pode gerar representações adequadas para análise e construção de modelos em dados de microarranjo (Alter et al., 2000; Wall et al., 2003) e em problemas de reconhecimento de objetos (Asuncion Vicente et al., 2007).

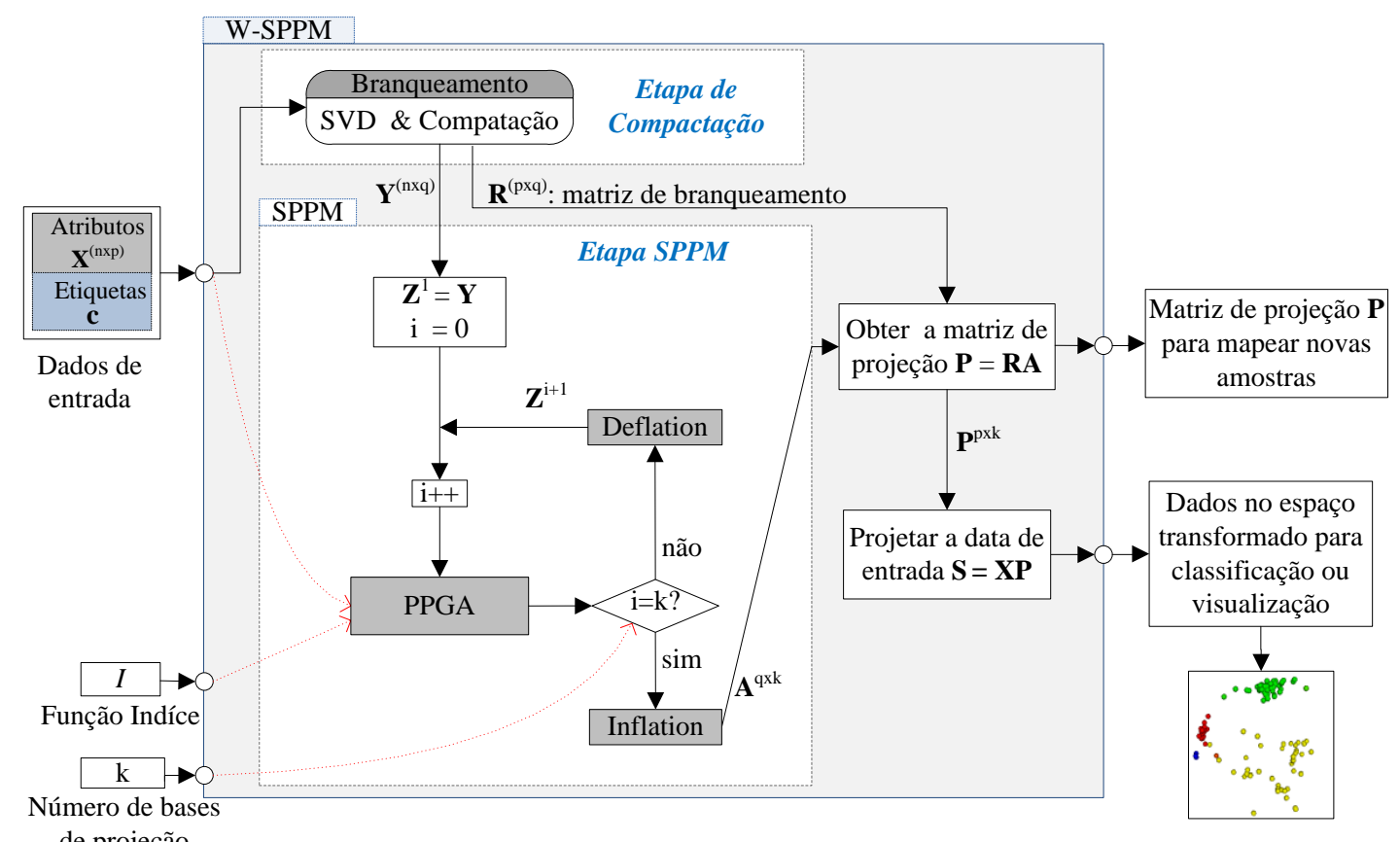

Figura 4.8: Fluxograma de W-SPPM o qual incorpora as etapas de compactação dos dados e SPPM. Os resultados de W-SPPM são uma matriz de projeção $\mathbf{P}$, a qual pode servir para mapear novas amostras e uma matriz de projeção $\mathbf{S}$ que pode ser usada em processos de classificação ou visualização.

A Figura 4.8 mostra a estrutura de W-SPPM, a qual segue duas etapas:

Etapa de compactação. Esta etapa é realizada através da transformação por branqueamento. 
O branqueamento é uma transformação que produz atributos não correlacionados e normalizados. Os efeitos do branqueamento sobre dados com grande desequilíbrio entre o número de amostras e a quantidade de atributos foram recentemente estudados por Deng et al. (2012). Nesse estudo foi encontrado que os pontos de dados transformados por branqueamento formam um simplex regular $(n-1)$ - dimensional. Isto significa que qualquer método baseado em distância falha ao tentar trabalhar sobre os dados branqueados, já que eles são equidistantes entre sim. Contudo, os autores também apontaram que retirando algumas dimensões irrelevantes (aqueles associados aos menores valores singulares) dos dados transformados, é possível produzir representações altamente informativas para uma análise posterior. Num estudo relacionado, Asuncion Vicente et al. (2007) encontrou que a parte mais influente no desempenho do método ICA é a transformação por branqueamento. Vários outros autores apontaram a viabilidade de branqueamento como uma etapa de pré-processamento em análise de dados de microarranjo (Biswas et al., 2008; Cunningham, 2007; DiPietroPaolo et al., 2006; Shen et al., 2006; Alter et al., 2003; Wall et al., 2003; Alter et al., 2000).

A transformação por branqueamento implementada em W-SPPM é realizada por meio da decomposição de valores singulares (do inglês singular value decomposition (SVD)) da matriz de dados $\mathbf{X}$ centrada ( $\mathbf{X}$ com a média subtraída), assim:

$$
\mathbf{X}=\mathbf{U D V}^{T}
$$

onde $\mathbf{U}^{n \times n}$ é a matriz de auto vetores de $\mathbf{X}^{\mathbf{T}} \mathbf{X}, \mathbf{D}^{n \times n}$ é a matriz diagonal dos valores singulares de $\mathbf{X}^{\mathbf{T}} \mathbf{X}$ (ordenados em ordem decrescente); $\mathbf{V}^{p \times n}$ é a matriz de auto vetores de $\mathbf{X} \mathbf{X}^{\mathbf{T}}$. Assume-se que os menores valores singulares (e auto vetores correspondentes) são resultado de informações irrelevantes ou ruído e, portanto eles são excluídos, ficando somente para consideração os $q$ primeiros valores singulares e auto vetores associados. No decorrer do texto, nos referimos a $\mathbf{D}$ como o sub-matriz $(q \times q)$ esquerda superior da original $\mathbf{D}, \mathbf{U}$ e $\mathbf{V}$ indicarão as primeiras $q$ colunas e as primeiras $q$ linhas das respectivas matrizes originais.

Os dados branqueados $\mathbf{Y}$ correspondem às linhas da matriz reduzida $\mathbf{U}^{(n \times q)}$, a qual pode ser expressa em termos dos dados de entrada como: $\mathbf{Y}=\mathbf{U}=\mathbf{X R}$, onde $\mathbf{R}^{(p \times q)}=\mathbf{V D}^{-1}$ é a matriz de transformação de branqueamento (também usada para obter a matriz de projeção final). Nos experimentos do presente trabalho, o valor de $q$ é selecionado tomando o mínimo de dimensões do espaço branqueado cuja soma cumulada dos respectivos valores singulares (elevados ao quadrado) seja superior ao $75 \%$ da soma total dos quadrados de todos os $n-1$ va- 
lores singulares. Na experimentação foi observado que a qualidade dos resultados de W-SPPM é pouco sensível à variação de $q$ quando este corresponde a valores entre $75 \%$ a 90\% da soma total dos quadrados dos valores singulares. No entanto, foi preferido um valor baixo, já que o tempo de otimização da etapa SPPM aumenta consideravelmente com o aumento de $q$.

Etapa SPPM. Esta etapa é responsável pela busca de projeções sobre os dados branqueados da etapa anterior. O procedimento SPPM (Seção 4.1) é usado para tal propósito, o qual devolve uma matriz de projeção $\mathbf{A}$.

Sumarizando, W-SPPM primeiro compacta os dados X com a transformação de branqueamento $\mathbf{R}$ num espaço de dimensão $q$ (obtendo-se a representação $\mathbf{X R}$ ) para logo projetar esses dados compactados com a matriz de projeção $\mathbf{A}$ ao espaço alvo final de dimensão $k$ (obtendose a representação XRA). A matriz de projeção total $\mathbf{P}$ que mapeia os dados de entrada ao espaço alvo é então calculada como: $\mathbf{P}^{p \times k}=\mathbf{R A}$. Esta matriz serve também para fazer mapeamento "out-of-sampling", isto é, projetar amostras que não intervieram na construção do espaço de projeção (não presentes em $\mathbf{X}$ ), o qual é importante quando se pretende usar W-SPPM em conjunto com um classificador, como será visto no Capitulo 5. 


\section{Capítulo 5}

\section{Avaliação Experimental}

Neste capítulo é apresentada uma avaliação experimental das abordagens descritas no Capitulo 4. Primeiro, na Seção 5.1, é relatado um estudo comparativo dos operadores de cruzamento descritos na Seção 4.1 para PPGA. Na Seção 5.2 apresenta-se uma avaliação comparativa do desempenho do otimizador PPGA contra outros algoritmos de otimização. As Seções 5.3 e 5.4, avaliam respectivamente os desempenhos de Block-SPPM e W-SPPM em sua capacidade de reduzir a dimensão de dados de microarranjo e facilitar a sua classificação.

\subsection{Avaliação de operadores de cruzamento para PPGA}

Nesta seção apresenta-se um estudo experimental dos oito operadores de cruzamento descritos no Capitulo 4 a fim de determinar sua adequação para PPGA. Para tal fim foram escolhidos quatro bancos de dados públicos do repositório UCI (Frank e Asuncion, 2010) e um quinto banco de dados público de microarranjo (o banco Yeast ${ }^{1}$ ). Uma descrição de como são gerados os dados de microarranjo pode ser encontrada no Anexo A. Esses bancos de dados são descritos a seguir:

Wine: Os dados neste banco são o resultado da análise química das amostras de três tipos de vinhos na Itália, e estão dispostos em 178 amostras e 13 atributos contínuos (constituintes encontrados para cada vinho).

WDBC: Também conhecido como Diagnóstico de Câncer de Mama Wisconsin, é um banco

\footnotetext{
${ }^{1}$ http://genome-www.standford.edu/cellcycle
} 
composto por 569 amostras e 30 atributos de valores reais. Cada amostra descreve as características presentes do núcleo de células em imagens digitalizadas tomadas do tecido da mama.

Sonar: Este banco de dados contém informações de sinais de sonar recolhidos a partir de artefatos metálicos e rochas da mesma forma no oceano a fim de facilitar a construção de classificadores. 208 amostras e 60 atributos de valores reais conformam este banco. Cada atributo representa a energia dentro de uma determinada faixa de frequências integrada ao longo de um período de tempo.

Musk: Os dados neste banco de dados representam medidas de avaliação que especialistas humanos deram sobre o odor da substância 'musk', empregada na elaboração de fragrâncias, 476 amostras e 166 atributos conformam este banco.

Yeast: Este banco de dados foi colectado por Spellman et al. (1998) para determinar a variação dos genes na fase celular da levedura ('budding Yeast'). A conformação original deste banco de dados foi de 76 amostras e 800 atributos (genes), mas para este trabalho foram descartados 57 genes que apresentavam mais de $20 \%$ amostras com valores faltantes e em 52 genes foram imputados os valores com o estimador BPCA (Oba et al., 2003).

A avaliação dos operadores de cruzamento é esquematizada na Figura 5.1. Em cada banco de dados são realizadas trezentas réplicas de experimentos a fim de obter estatísticas consistentes. Uma réplica consiste de três passos: 1) gerar uma população inicial $W$, gerando aleatoriamente $w=10 p$ vetores em $\mathbb{R}^{p}$ e normalizando para ter comprimento unitário; 2) a partir dessa população inicial, evoluir duas instâncias de PPGA por cada operador de cruzamento: uma para um tamanho de torneio $(t s)$ igual a $1 \%$ do tamanho da população e outro para um $t s=5 \%$ do tamanho da população (no total 16 instâncias de PPGA são evoluídas por cada réplica); 3) armazenar as seguintes estatísticas por cada instância de PPGA: i) aptidão média ${ }^{2}$ da população a 20 gerações, ii) aptidão média da população a 200 gerações, e iii) aptidão média e número de gerações quando a população atinge convergência. Considera-se convergência quando a diferença entre a aptidão máxima e a aptidão média da população é menor a $1 e^{-7}$ (para o banco Yeast, este valor é colocado em $1 e^{-6}$ dado o elevado tempo que se necessita para convergir neste caso; pela mesma razão, somente 50 réplicas são executadas para esse banco de dados). Se a convergência é atingida antes das 200 gerações então PPGA é mantido

\footnotetext{
${ }^{2}$ Em PPGA, a aptidão de um indivíduo é o valor da função índice da projeção que ela representa.
} 
evoluindo até chegar às 200 gerações. Se a convergência não é alcançada nas primeiras 200 gerações então a instância de PPGA é permitida executar até um máximo de 5000 gerações, sendo interrompida assim que alcançar convergência. A taxa de cruzamento para todos os experimentos é $1(c r=1)$ e a taxa de mutação é 0 (desabilitada). Com isso se obriga a que todos os casais no mating pool produzam seus filhos por cruzamento. Todas as instâncias de PPGA numa mesma réplica iniciam com a mesma população inicial $W$. Dessa maneira, o único fator influente no desempenho de PPGA é o operador de cruzamento. A função de índice usada para esta avaliação é o índice de Holes (Capítulo 3), escolhida por sua simplicidade de cálculo.

A intenção por registrar a aptidão média da população em diferentes etapas da evolução (20 e 200 gerações) foi determinar quais dos operadores seria o mais apropriado se tivermos um tempo limitado para obter a resposta. A idéia de testar dois tamanhos de torneio foi determinar como a pressão seletiva pode afetar o desempenho dos operadores de cruzamento.

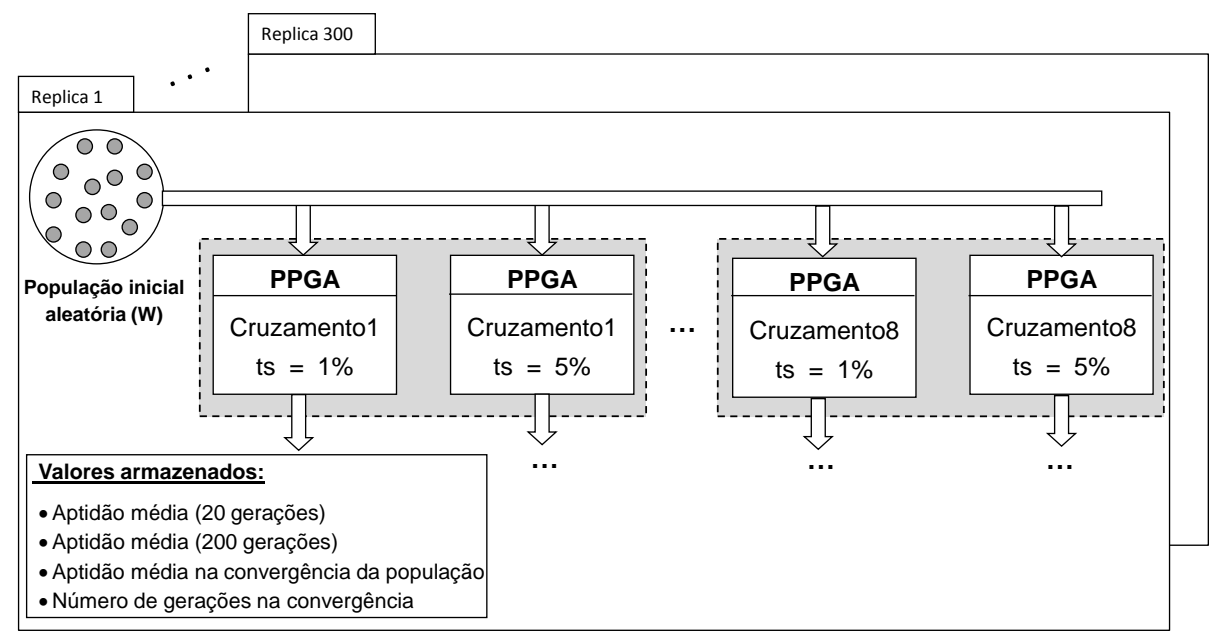

Figura 5.1: Esquema de avaliação do desempenho dos operadores de cruzamento para PPGA. Em cada réplica é gerada uma população inicial aleatória é diferente de tamanho $w$ a qual é fornecida a 16 instâncias de PPGA: 8 executando os operadores de cruzamento com tamanho de torneio $t s=0.01 w$, e as outras 8 instâncias executando um tamanho de torneio $t s=0.05 w$.

\subsubsection{Resultados em convergência}

A Figura 5.2 apresenta os resultados médios (sobre as 300 réplicas) da aptidão e o número de gerações usados pelos diferentes operadores para alcançar convergência. Cada subfigura mostra resultados para um determinado banco de dados. As curvas representam a aptidão média (cada curva para um tamanho de torneio) e as séries de barras representam o número gerações na convergência (igualmente, cada série para um determinado tamanho de torneio). 
Em relação ao número de gerações para convergir, observa-se um padrão similar para todos os bancos de dados e tamanhos de torneio: o operador CX6 apresenta os maiores valores e claramente diferenciados dos outros operadores; o operador CX4 apresenta os seguintes maiores valores; os operadores CX1 e CX7 mostram valores muito próximos, os quais são os valores mais baixos entre todos os operadores; os operadores CX2 e o CX8 também mostram valores muito próximos, os quais são os segundos valores mais baixos; os operadores CX3 e CX5 apresentam os terceiros melhores valores, com CX5 tendendo a superar o CX3 em bancos de alta dimensão (Musk e Yeast).

A Figura 5.3 apresenta uma outra perspectiva dos resultados anteriores. Nessa figura é mostrado o número médio de gerações usadas para convergir como função da dimensão dos bancos de dados para os dois tamanhos de torneio testados (não é incluído o banco Yeast devido à diferente precisão de convergência usada). Pode ser observado dois grupos de operadores com diferentes tendências em relação à dimensionalidade dos dados, independentemente do tamanho do torneio. O primeiro grupo, formado pelos operadores CX1, CX2, CX3, CX7 e CX8, apresenta uma diminuição no número de gerações usadas para alcançar convergência quando a dimensão dos dados é aumentada. O segundo grupo, formado pelos operadores CX4, CX5 e CX6, apresenta um aumento no número de gerações quando a dimensão dos dados é aumentada. Por outro lado, quando o tamanho do torneio é variado de $t s=1 \%$ a $t s=5 \%$, o número de gerações usadas para alcançar a convergência diminui em todos os operadores e em todos os bancos de dados (comportamento também observado na Figura 5.2).

Em relação à aptidão média em convergência (curvas da Figura 5.2), pode-se observar que o operador CX6 consegue convergir a soluções com valores de aptidão notoriamente maiores do que os outros operadores, especialmente nos bancos de dados de dimensões maiores (Sonar, Musk e Yeast). O operador CX4 apresenta os segundos maiores valores de aptidão para $t s=$ $1 \%$, mas quando o tamanho de torneio é aumentado para $t s=5 \%$ o operador CX5 consegue gerar soluções de qualidade similar a CX4. O operador CX3 apresenta os seguintes melhores valores de aptidão, seguido de perto pelo operador CX8. Os operadores CX1, CX2 e CX7 produzem soluções com valores de aptidão semelhantes, sendo estes os menores valores entre todos os operadores. Em relação à influência do tamanho de torneio, a tendência na maioria de operadores e bancos de dados é diminuir os valores de aptidão com o aumento do tamanho do torneio, sendo os operadores CX5 e CX6 os menos sensíveis a essa mudança (de fato, o operador CX6 é praticamente insensível). 


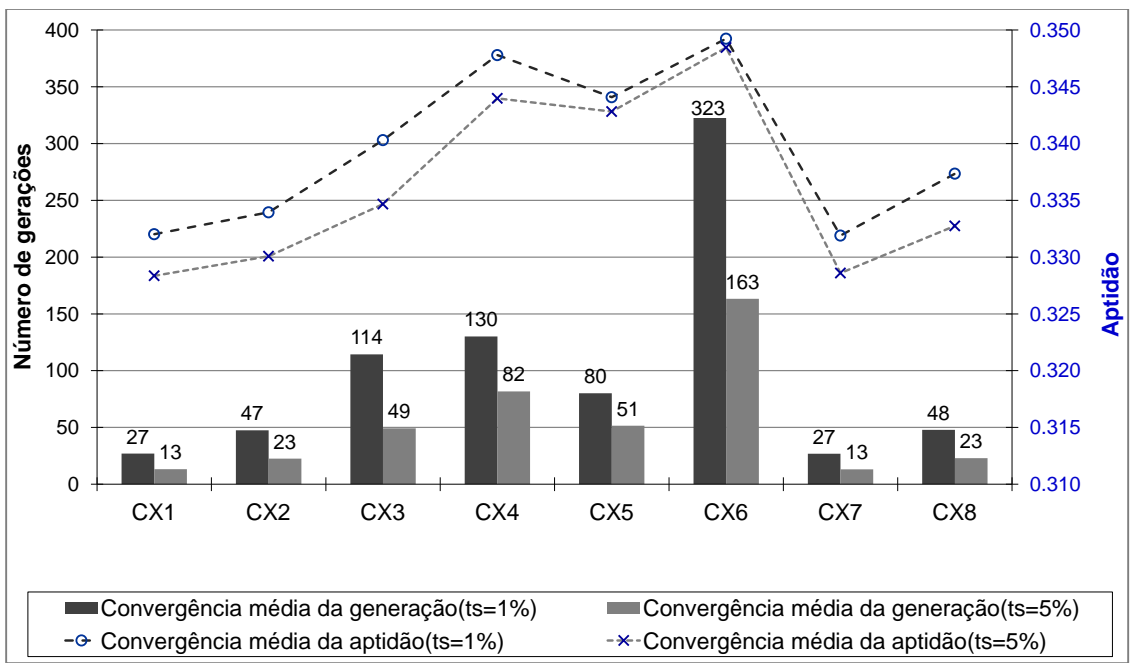

(a) Wine

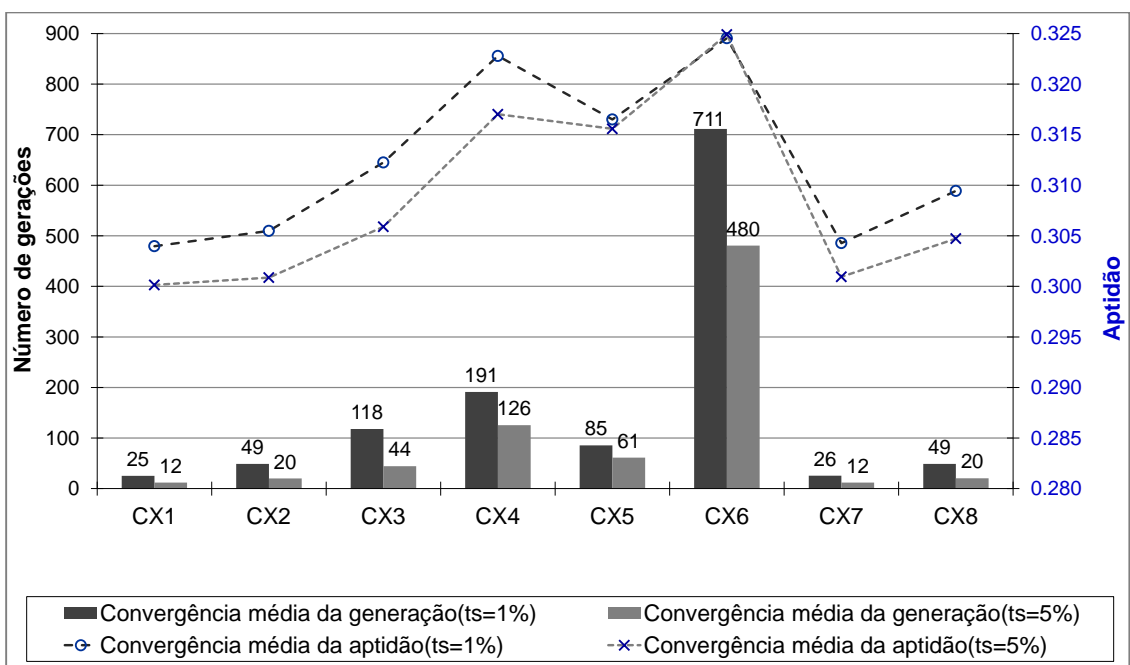

(b) WDBC

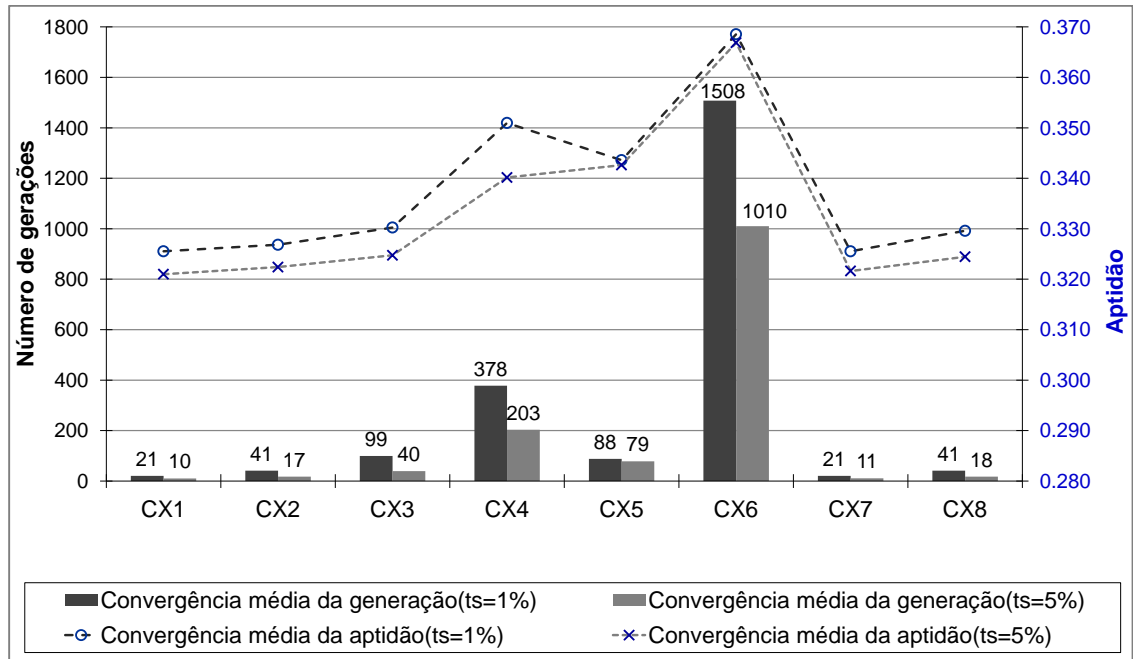

(c) Sonar 


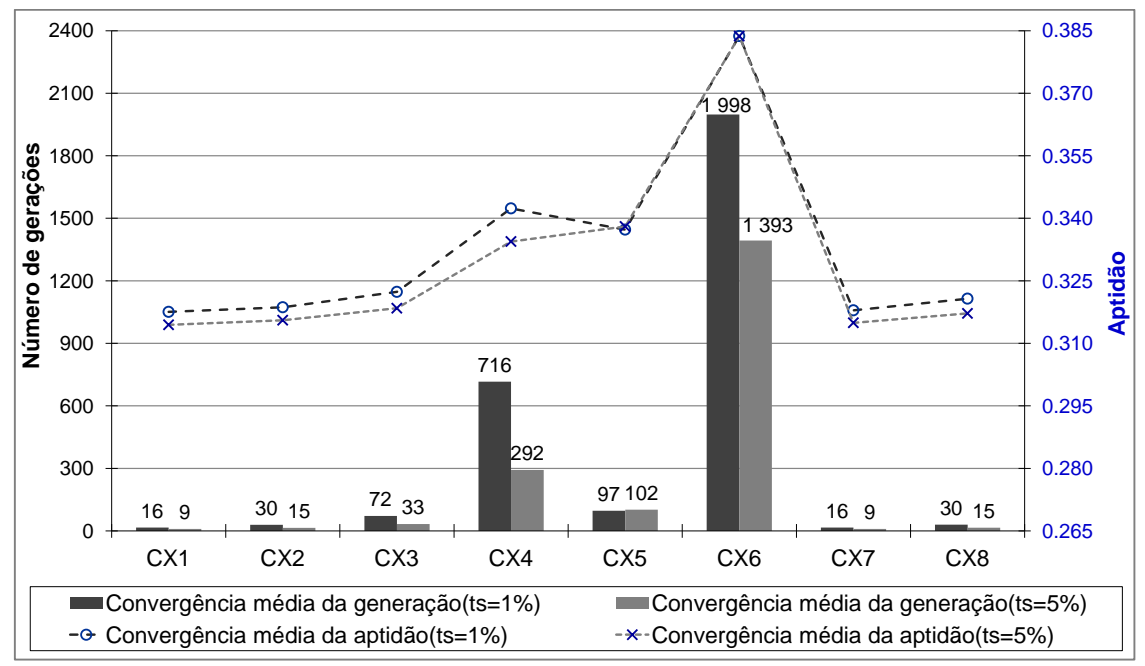

(d) Musk

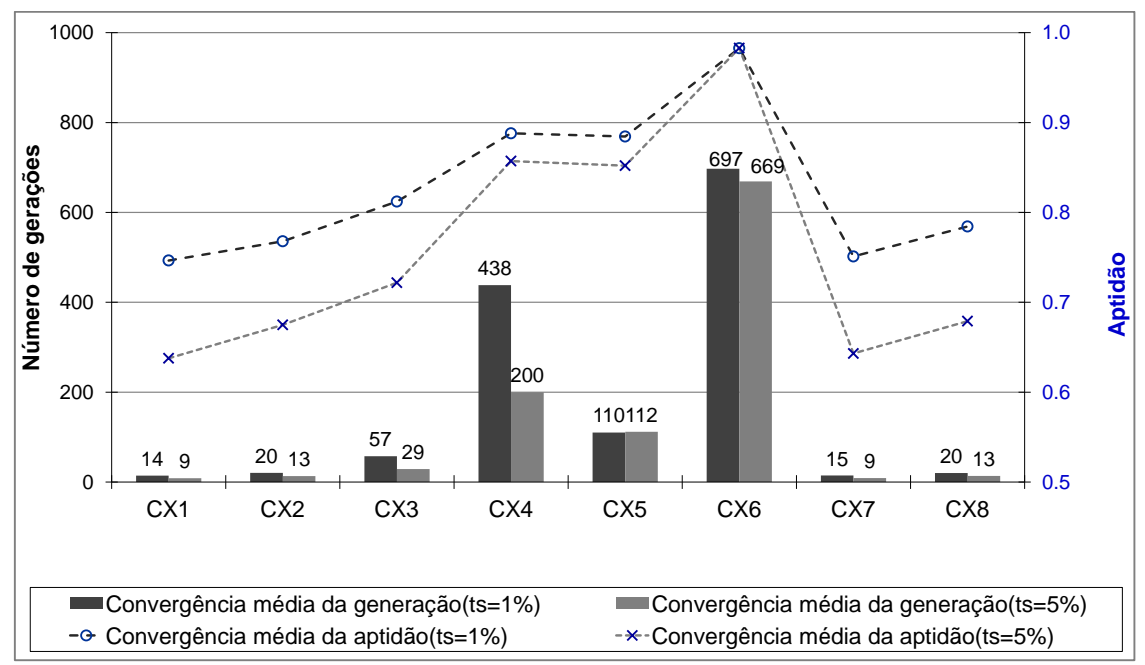

(e) Yeast

Figura 5.2: Resultados sobre o desempenho da aptidão média (curvas) e o número de gerações (barras) necessários para alcançar a convergência. A escala da esquerda representa o número de gerações e a escala da direita representa os valores de aptidão (índice de Holes) 


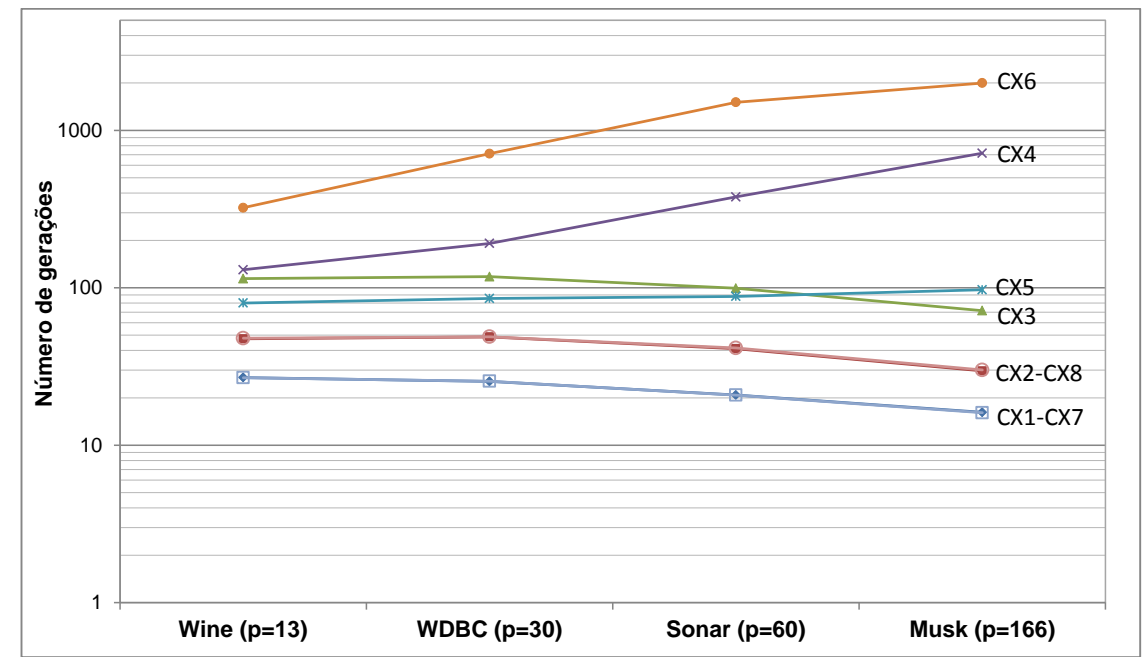

(a) ts $=1 \%$

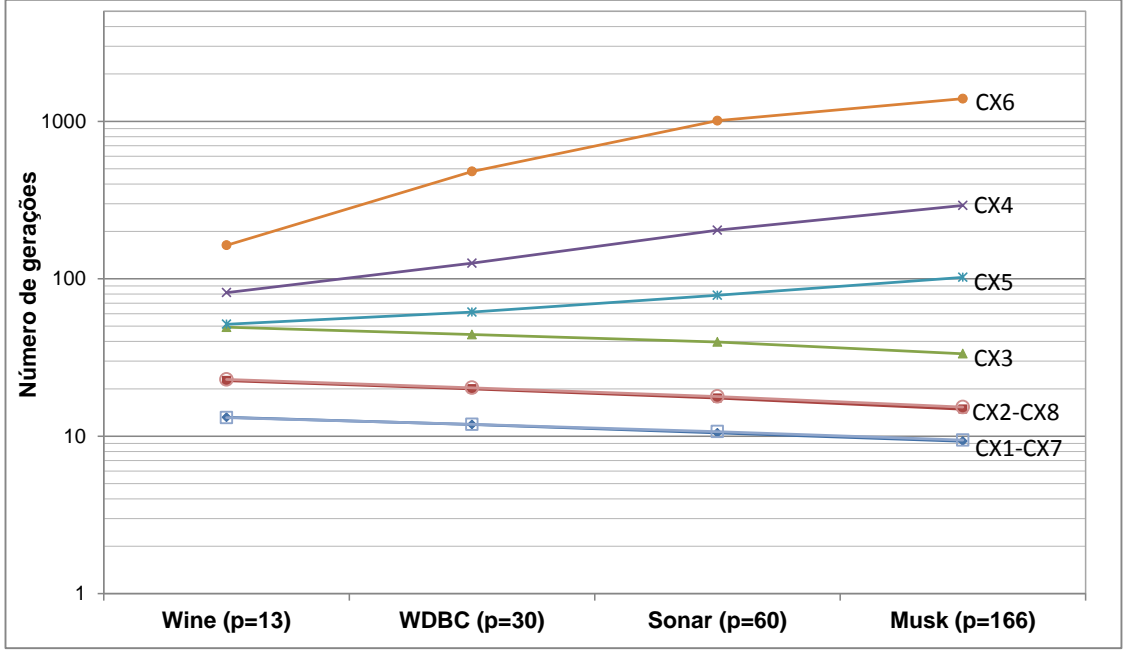

(b) ts $=5 \%$

Figura 5.3: Resultados do número médio de gerações necessário para alcançar a convergência (média das 300 réplicas) em relação aos bancos de dados (ordenados segundo a sua dimensão) para os dois tamanhos de torneio testados. É usada escala logarítmica, dadas as grandes diferenças entre operadores. 


\subsubsection{Resultados em número fixo de gerações}

A Figura 5.4 mostra, para cada banco de dados, os valores médios da aptidão populacional a 20 e 200 gerações para $t s=1 \%$ (um comportamento similar foi encontrado para $t s=5 \%$ ). As seguintes observações podem ser retiradas desses resultados: i) nos bancos de baixa dimensão (Wine eWDBC) os operadores CX4 e CX6 apresentam valores próximos e notoriamente maiores que os outros operadores nos dois números de gerações. O operador CX5 mostra também valores competitivos em 20 gerações, mas, diferente de CX4 e o Cx6, este operador não mostra uma significativa melhoria ao passar de 20 a 200 gerações; ii) nos banco de dados de maior dimensão, o operador CX6 torna-se o único operador em mostrar uma clara superioridade de aptidão em ambos os números de gerações, especialmente em 200 gerações. Nesses mesmos bancos de dados, o operador CX4 produz os segundos maiores valores de aptidão em 200 gerações, mas quando se considera somente 20 gerações, este operador é superado pelo CX5. Os operadores CX3 e CX8 geram as seguintes melhores soluções em todos os bancos de dados, com CX3 tendo um melhor aumento de aptidão ao passar de 20 a 200 gerações. Os operadores CX1, CX2 e CX7 produziram as soluções de menor aptidão em todos os bancos de dados, independentemente do número de gerações, além de apresentarem um aumento marginal da aptidão média ao passar de 20 a 200 gerações.

\subsubsection{Discussão}

Os resultados acima evidenciam que o desempenho dos operadores de cruzamento é afetado pela dimensionalidade dos dados e pela pressão seletiva usada para evoluir o PPGA. Dos resultados da aptidão em convergência, pode-se inferir que a criação de indivíduos em torno do hiper-cone gerado pela rotação dos pais ao redor da sua bissetriz (operadores CX5, CX6) é uma melhor idéia que simplesmente gerar os filhos no plano dos pais (como no caso dos operadores CX1, CX2, CX7 e CX8). Isto pode ser explicado pelo maior espaço de busca que representa o hiper-cone para PPGA. Essa observação é ainda mais evidente com o operador CX6, no qual é permitido que os filhos sejam gerados em um hiper-cone maior que o definido pela rotação dos pais, dando assim uma maior capacidade exploratória. Por outro lado, a baixa sensibilidade (em aptidão) dos operadores CX5 e CX6 à variação da pressão seletiva pode também ser explicada por sua melhor profundidade de busca, já que ao gerar os filhos em um espaço mais amplo se diminui a possibilidade de levar à população aos primeiros ótimos locais encontrados (tendência que é agravada com o aumento da pressão seletiva, dado que se desfavorece 


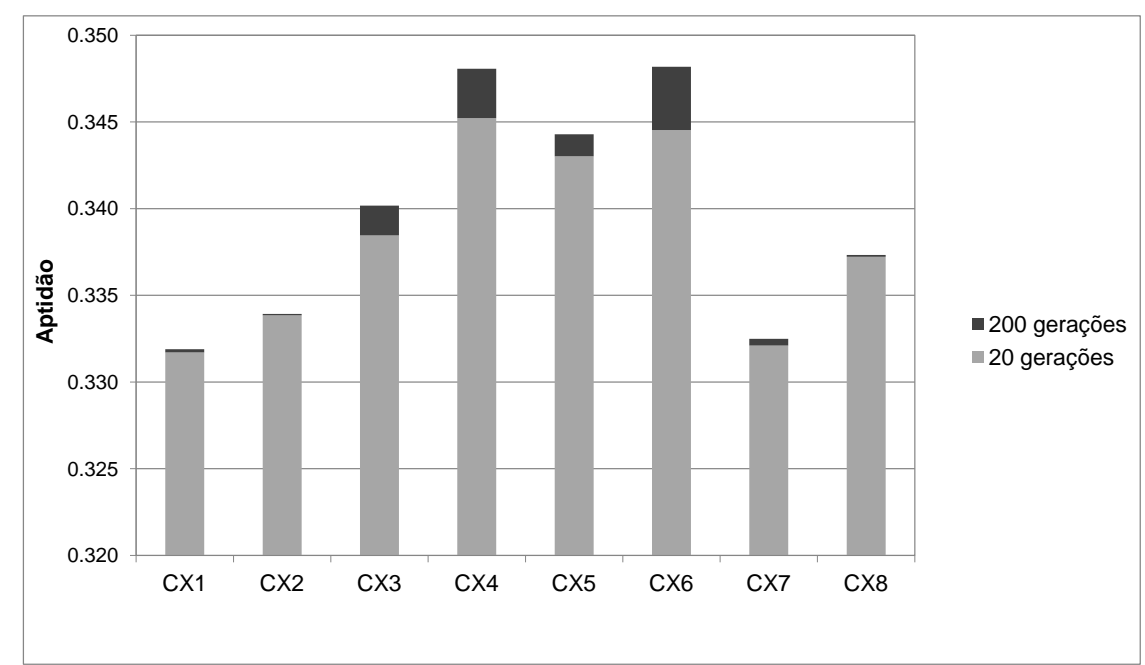

(a) Wine

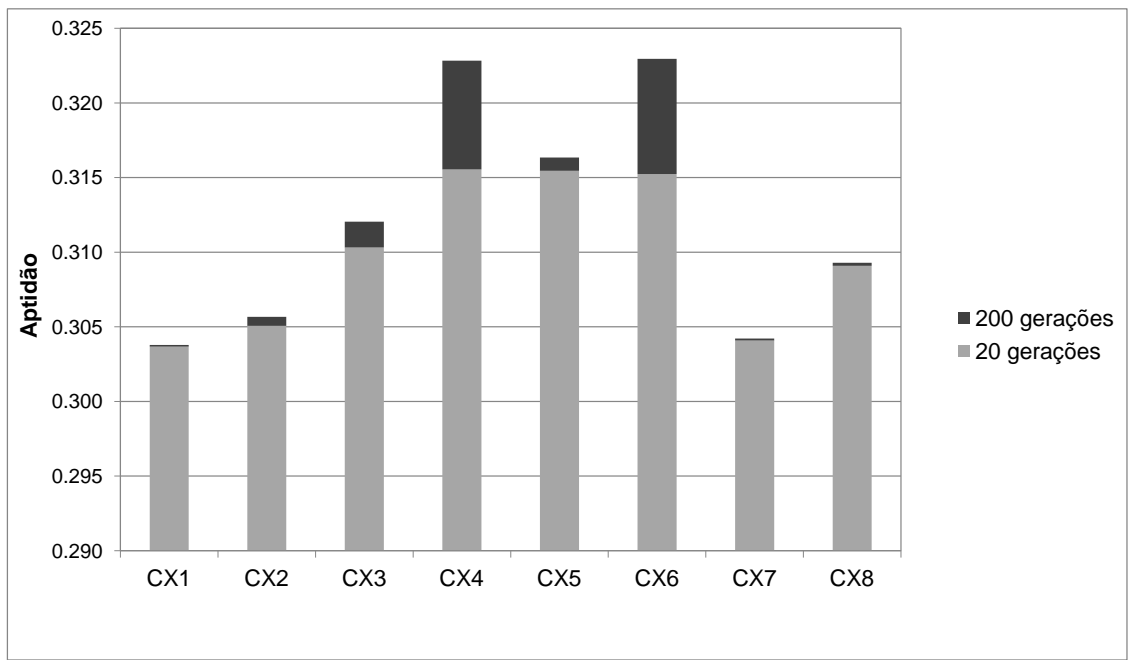

(b) WDBC

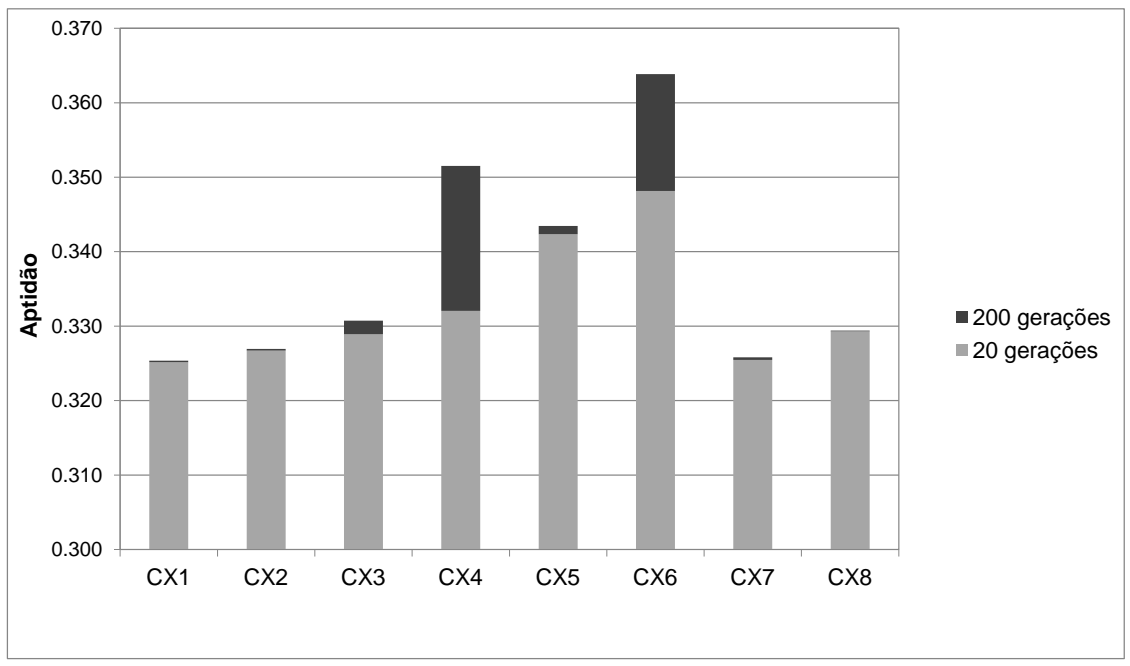

(c) Sonar 


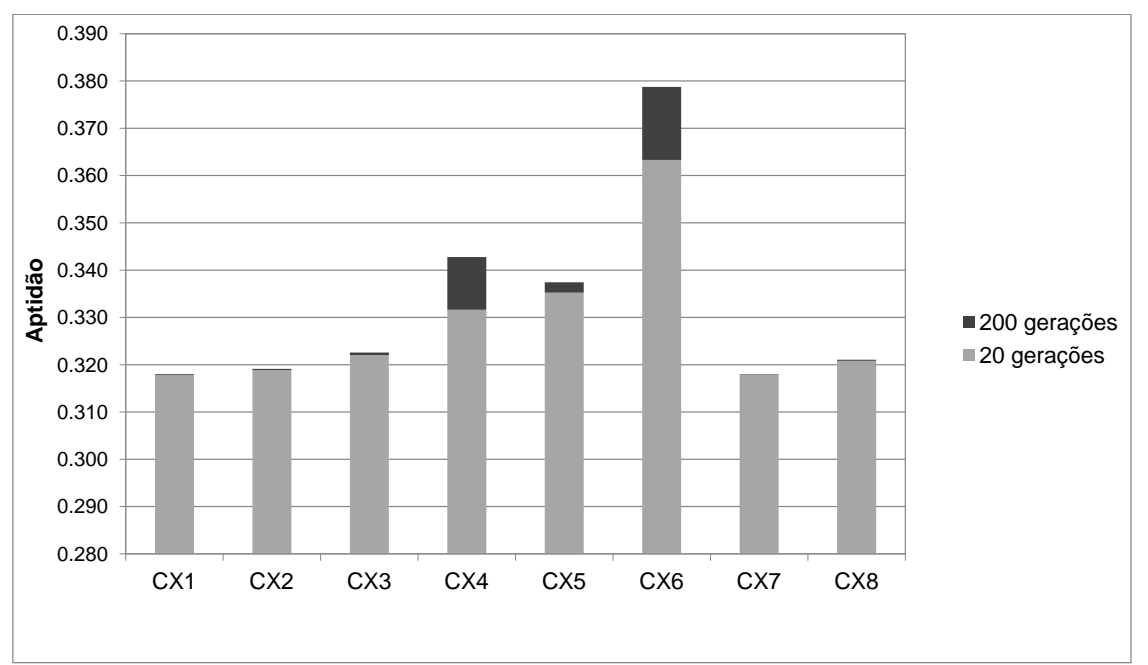

(d) Musk

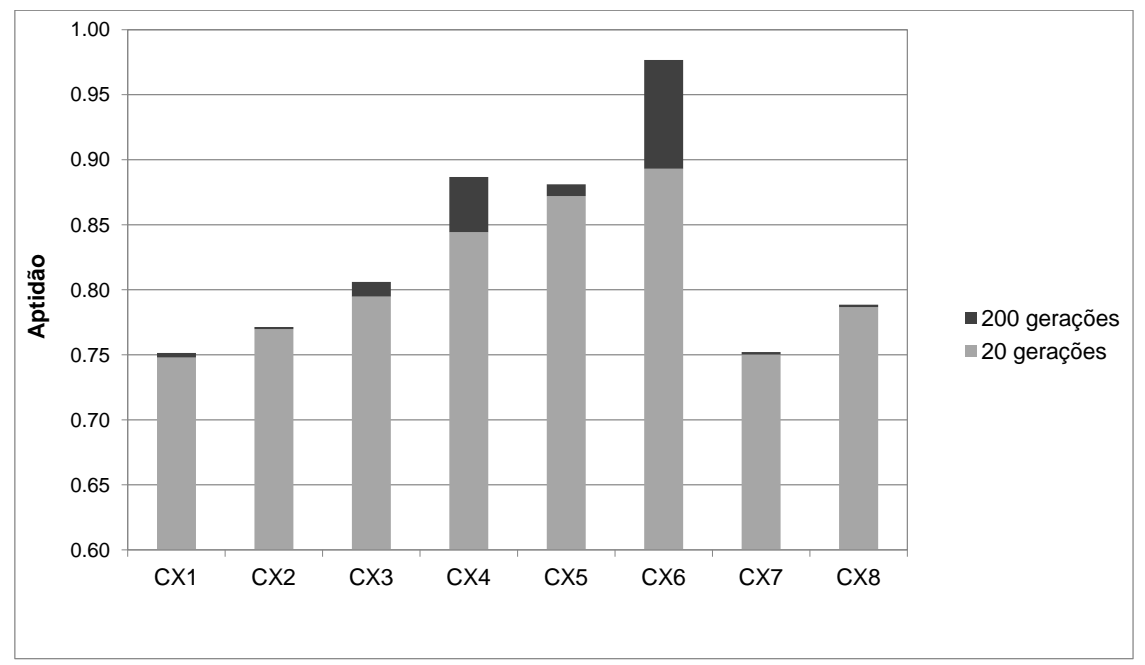

(e) Yeast

Figura 5.4: Resultados da aptidão média e da evolução da população tomada a 20 e 200 gerações (média da 300 réplicas). Cada subfigura mostra os resultados para um banco de dados diferente. A parte escura das barras representa o aumento da aptidão média que os operadores conseguem ao passar de 20 para 200 gerações. 
a diversidade). Uma desvantagem destes operadores hiper-cônicos, especialmente o operador CX6, é o elevado número de gerações que usa para convergir, o qual cresce rapidamente com a dimensão dos dados. No entanto, se o critério de convergência for um número fixo de gerações (por exemplo, 20 ou 200), o operador CX6 mostra ainda ser mais apropriado do que os outros operadores, superando consideravelmente a eles em bancos de dados com maior dimensão.

A idéia de gerar os filhos por simples recombinação das coordenadas dos pais (tal como os operadores CX3 e CX4) mostrou-se relativamente eficaz para PPGA, sendo mais apropriada a transferência de coordenadas como unidades independentes (CX4) do que a transferência de coordenadas como blocos (como no CX3). Por outro lado, ao contrário dos operadores CX5 e CX6, o desempenho dos operadores CX3 e CX4 é visivelmente diminuído com o aumento da pressão seletiva. Isto sugere que o desempenho destes operadores é fortemente dependente da diversidade da população, o qual pode ser uma limitação quando a população se aproxima da convergência.

Em relação ao número de gerações para alcançar convergência, o operador CX4 mostra um menor número para alcançar convergência do que CX6 mas ao igual que este cresce rapidamente com a dimensão dos dados. Quando as dimensões nos bancos de dados são baixas e o número de gerações é fixado (a 20 ou 200) o CX4 é tão competitivo quanto o CX6 na aptidão das soluções. No entanto, quando a dimensão dos dados é alta o desempenho de CX6 tende a se destacar sobre os outros.

A proposta de gerar filhos guiados pela aptidão dos pais (operadores CX7 e CX8) não foi tão efetiva quanto a geração dos filhos ao redor do hiper-cone dos pais. No entanto, ainda foi possível observar um pequeno ganho de aptidão desses operadores em relação a suas versões não guiadas (CX1 e CX2) com quase a mesma quantidade de gerações para convergir. Nos operadores CX1, CX2, CX7 e CX8 foi observada uma tendência por usar uma quantidade relativamente baixa de gerações para convergir em relação aos outros operadores. Este comportamento pode ser explicado pelo fato de que o espaço onde os filhos são gerados é sempre um plano (o plano dos pais), espaço que se torna muito restritivo ao aumentar a dimensão dos dados e que facilita a rápida convergência a ótimos locais de baixa qualidade. 


\subsection{Avaliação de PPGA contra outros algoritmos de otimização para SPPM}

Nesta seção é apresentado um estudo comparativo do desempenho de PPGA em relação a outros dois algoritmos de otimização que poderiam ser usados em SPPM (e que mostraram resultados positivos quando comparados com AGs canônicos): i) o Particle Swarm Optimization (PSO) utilizado recentemente em (Berro et al., 2010) no contexto de PP, e ii) o Random Scan Sampling Algorithm (RSSA) proposto por Webb-Robertson et al. (2005) para substituir o AG original de SPP. Dados os resultados satisfatórios de PPGA com o operador CX6, este último foi selecionado para realizar as presentes comparações. Os três métodos avaliados realizam a otimização de forma iterativa, mas a quantidade de cálculos realizados em cada iteração é diferente. Por este motivo, para realizar comparações justas, a avaliação foi realizada com base na quantidade de vezes que a função índice é invocada para obter a solução final. Esta medida dá uma idéia da quantidade de computação que utilizam os algoritmos para encontrar a solução. Certamente, a avaliação da função índice é o componente mais demandante computacionalmente no marco de PP e os algoritmos de otimização passam a maior parte do seu tempo de processamento realizando essas avaliações.

A avaliação consiste em executar cada método de otimização por um número máximo predefinido de chamadas à função índice (MaxPIcalls), registrando a cada certo intervalo de chamadas a aptidão da melhor solução encontrada. O tamanho da população $(w)$ foi colocado em $10 p$ para todos os métodos (em RSSA, este valor foi atribuído tanto ao tamanho da população inicial quanto ao tamanho da população de amostragem; para PSO, este número foi atribuído ao tamanho do enxame). O MaxPIcalls foi colocado em $4 \times 10^{6}$, um valor suficientemente alto para verificar a convergência de todos os algoritmos. Os intervalos para registrar a melhor aptidão foram frações de MaxPIcalls no conjunto $\{1 / 512,1 / 256, \ldots, 1 / 2,1\}$. A intenção por realizar este espaçamento (seguindo uma progressão geométrica) foi para ganhar resolução no inicio do processamento. Os parâmetros para RSSA foram iguais ao original descrito em Webb-Robertson et al. (2005), diferindo somente no critério de convergência (em que se usa MaxPIcalls para terminar). Para o PSO, foram implementadas duas versões: i) uma descrita no trabalho de Berro et al. (2010) e ii) uma modificação dessa versão, usando um ajuste dinâmico do parâmetro de inércia, o qual diminui linearmente de 0.9 para 0.4 na primeira metade da execução para depois permanecer constante, tal como descrito em (Shi e Eberhart, 2001). Em todos os experimentos, a segunda implementação de PSO superou à primeira, tanto em apti- 
dão quanto em tempo de convergência, razão pela qual os resultados apresentados nesta seção para PSO correspondem a esta segunda implementação. De forma similar à avaliação da seção anterior, o índice Holes foi usada para a presente experimentação.

A Figura 5.5 mostra o comportamento médio (sobre 100 réplicas) da aptidão das soluções geradas pelos três métodos em relação aos intervalos testados de MaxPIcalls no banco de dados Sonar. Nessa figura, mostra-se também alguns $p$-valores (em parêntesis) da significância das diferenças de aptidão entre PPGA e RSSA e entre PPGA e PSO (para isso foi usado o teste estatístico $t$-test). O comportamento dos métodos nos outros bancos de dados foi similar ao encontrado em Sonar (resultados não mostrados). Pode-se observar em todos os intervalos registrados que os resultados de RSSA e PSO são estatisticamente diferentes dos resultados de PPGA (considerando um nível de significância de 0.05). No primeiro intervalo (MaxPIcalls /512), o método RSSA consegue encontrar melhores soluções que os outros métodos. No entanto, a partir do segundo intervalo o método PPGA consegue produzir soluções com uma qualidade consideravelmente superior aos outros métodos. A melhora das soluções de PPGA com o aumento do número de chamadas à função índice continua aproximadamente até o oitavo intervalo, a partir do qual começa a se estabilizar. O método PSO produz soluções com os menores valores de aptidão nos três primeiros intervalos, mas a partir do quarto intervalo começa a superar consistentemente a RSSA. Este último é o método que apresenta o menor aproveitamento do número de avaliações do índice em favor da aptidão, estabilizando-se a partir do quinto intervalo.

\subsubsection{Discussão}

Os resultados apresentados acima evidenciam as capacidades exploratórias de PPGA com o operador CX6. Na configuração testada para PPGA não foi considerada nenhuma operação de mutação, mas os resultados mostram que essa configuração consegue superar aos outros otimizadores desde as etapas iniciais de processamento. Adicionalmente, o esquema com PPGA mostra um melhoramento quase continuo com o passar do tempo de processamento, estabilizando-se somente nos últimos estágios da evolução, o qual pode ser útil em situações onde não existem restrições de tempo para obter a resposta ou onde o é mais importante a precisão que o tempo computacional. Sempre é possível melhorar o desempenho dos outros algoritmos, realizando um adequado ajuste de seus parâmetros ou usando um esquema de auto ajuste para esse propósito. Contudo, a simplicidade, os poucos parâmetros e a boa precisão 


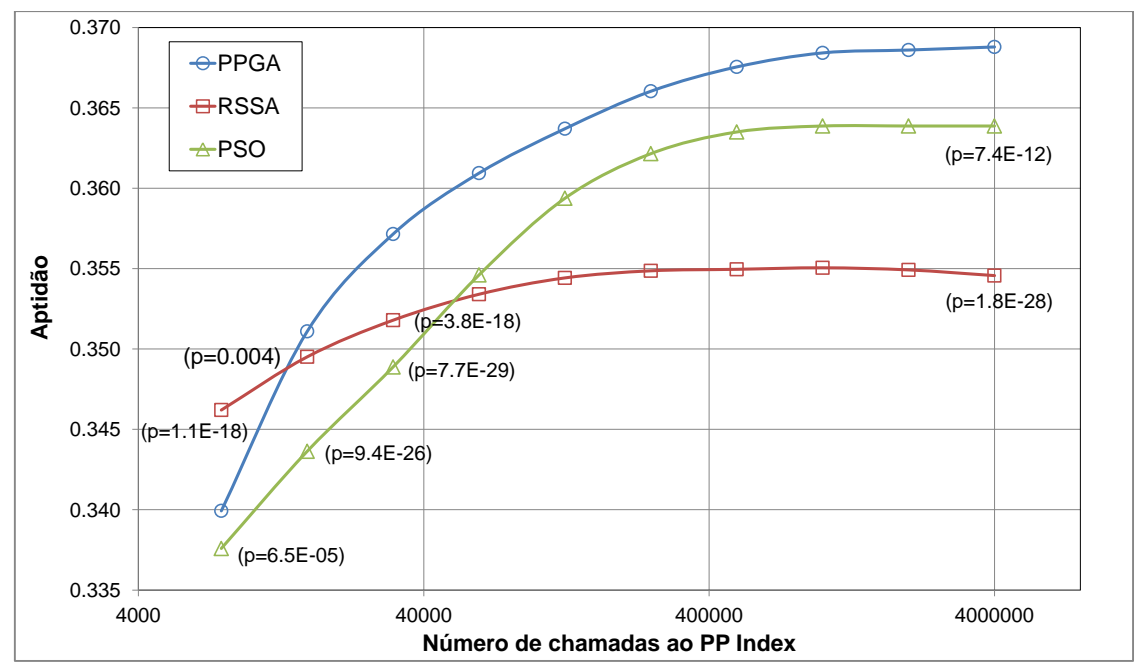

Figura 5.5: Comparação de desempenho de PPGA versus RSSA e PSO. O eixo da abscisa representa o número de avaliações da função índice e o eixo da ordenada representa o valor da aptidão média. Os valores em parêntesis nas curvas representam os p-valores resultantes de comparar (usando a estatística $t$-Test) a diferença de médias das aptidões do respectivo algoritmo em relação a PPGA.

observada de PPGA com o operador CX6 fazem que este seja uma escolha adequada como otimizador de SPPM.

\subsection{Avaliação de Block-SPPM}

Esta seção descreve uma avaliação experimental realizada a Block-SPPM em sua capacidade de reduzir a dimensão de dados de muito alta dimensão e poucas amostras para fins de classificação. Para esta finalidade, usaram-se dois métodos de classificação para avaliar a qualidade das projeções de Block-SPPM: Linear Discriminant Analysis (LDA) (Dudoit et al., 2002) e K-Nearest Neighborhood (K-NN) (Bishop, 2006). As implementações usadas para LDA e K-NN foram as disponíveis no Bioinformatics toolbox de Matlab (MATLAB, 2010). Esses métodos foram selecionados por sua popularidade, simplicidade, rapidez e também por seu comportamento determinístico (mesmos dados de treinamento geram mesmos modelos de classificação), o qual facilita a interpretação dos resultados da classificação, já que eles somente dependem da qualidade das projeções de entrada. Os bancos de dados utilizados nesta avaliação são descritos abaixo, e correspondem a bancos de dados públicos de microarranjo que representam três cenários com diferentes números de classes. 
Colon (Alon et al., 1999). Este banco de dados contém informação de expressão gênica de amostras normais e amostras com câncer de cólon. O banco é formado por 62 amostras e 2000 atributos.

MLL (Armstrong et al., 2002). Este banco contém informações de expressão gênica de amostras de três tipos de leucemia (ALL, MLL e AML). O banco é formado por 72 amostras e 8677 genes diferencialmente expressos.

SRBCT (Khan et al., 2001). Este banco de dados foi coletado para classificar células envolvidas em neoplasias malignas chamadas de round blue-cell tumors (SRBCTs). Quatro classes formam este banco de dados, as quais definem os quatro tipos de tumores desse tipo de câncer: tumores da família Ewing (EWS), linfoma non-Hodgkin (NHL), neuroblastoma (NB), rhabdomyosarcoma (RMS). O banco é formado por valores de expressão de 83 amostras distribuídas em quatro classes (EWS, NHL, NB e RMS) e 2309 genes.

Block-SPPM foi configurado com o otimizador PPGA e o operador de cruzamento hiperconico CX6, com base nos resultados satisfatórios apresentados nas seções prévias. A função de índice usada na presente avaliação foi o índice PI_lda (Equação 3.11). Junto com BlockSPPM, foram avaliados também outros sete algoritmos representativos de redução dimensional (descritos na Tabela 5.1). A seleção destes algoritmos foi motivada pelas seguintes razões: i) têm recebido uma ampla aceitação na literatura, ii) possuem implementações publicas disponíveis, iii) permitem o mapeamento out of sampling, e iv) são representativos de três grandes classes de métodos de redução dimensional: os métodos de extração supervisionada de atributos (MCML (Globerson e Roweis, 2006) e LMNN (Weinberger et al., 2006)); os métodos de extração não supervisionada de atributos (PCA (Duda et al., 2001), Isomap (Silva e Tenenbaum, 2003) e LLE (Roweis e Saul, 2000)); e os métodos filtros de seleção de atributos (ReliefF (Kononenko, 1994) e T-testM (Zhou e Wang, 2007)).

A avaliação é centrada na acurácia preditiva de classificação calculada nos dados resultantes dos diferentes métodos de redução dimensional avaliados. A estimativa da acurácia foi realizada seguindo um esquema de validação cruzada estratificada (stratified $k$-fold Crossvalidation, Kononenko e Kukar (2007)) com $K=4$ (4 folds). Nesse esquema (Figura 5.6), o banco de dados é dividido de forma aleatória em 4 partes, aproximadamente do mesmo tamanho e com a mesma distribuição das classes: Partição $_{1}, \ldots$, Partição $_{4}$. Um processo iterativo é realizado então percorrendo cada partição. Na iteração $i$, as amostras da $\operatorname{Partição~}_{i}$ são separadas para formar um conjunto de teste $T$ e as amostras das outras $K-1$ partições (denotadas 
Tabela 5.1: Algoritmos de redução dimensional avaliados junto com Block-SPPM na sua capacidade de facilitar a classificação de dados de expressão gênica. Drtoolbox (van der Maaten et al., 2008) é um toolbox gratuito para Matlab que incorpora diversos algoritmos de redução dimensional. Weka (Witten et al., 1999) é um projeto de código aberto que implementa diversas técnicas de aprendizado de máquina. SS denota método supervisionado e NS denota método não supervisionado.

\begin{tabular}{|l|l|l|l|}
\hline Algoritmo & Abreviação & Implementação & Tipo \\
\hline Maximally Collapsing Metric Learning & MCML & drtoolbox & SS \\
\hline Large Margin Nearest Neighbor & LMNN & drtoolbox & SS \\
\hline Principal Componet Analysis & PCA & drtoolbox & NS \\
\hline Isomap & Isomap & drtoolbox & NS \\
\hline Local Linear Embedding & LLE & drtoolbox & NS \\
\hline Filtro Relief Fast & ReliefF & Weka & SS \\
\hline Filtro Modified T-test & TtestM & Zhou e Wang (2007) & SS \\
\hline
\end{tabular}

como $D$ ) são utilizadas para gerar o conjunto de treinamento do classificador. Os métodos de redução dimensional são usados então sobre esse conjunto $D$ e devolvem um mapeamento para ele num espaço transformado de baixa dimensão. Foram testadas 10 dimensões para este espaço, as quais correspondem ao intervalo $[1,10]$. O conjunto de treinamento transformado, $S_{D}$, é usado seguidamente para treinar dois classificadores, $M_{1}, M_{2}$, correspondentes aos dois métodos de classificação considerados: LDA e KNN (com K=3). Após o treinamento, é determinada a acurácia da classificação sobre o conjunto transformado das amostras de teste $\left(S_{T}\right)$ para cada classificador, assim obtêm-se: Acurácia $_{i}^{M_{1}}$ e Acurácia $_{i}^{M_{2}}$. O procedimento anterior é repetido para as 4 partições $(i=1,2,3,4)$, obtendo-se ao final a estimativa da acurácia preditiva de classificação para um determinado método de redução e classificador $M_{j}$ da seguinte forma:

$$
\widehat{E}_{c v}\left(M_{j}\right)=\frac{1}{4} \sum_{i=1}^{4} \operatorname{Acurácia~}_{i}^{M_{j}},
$$




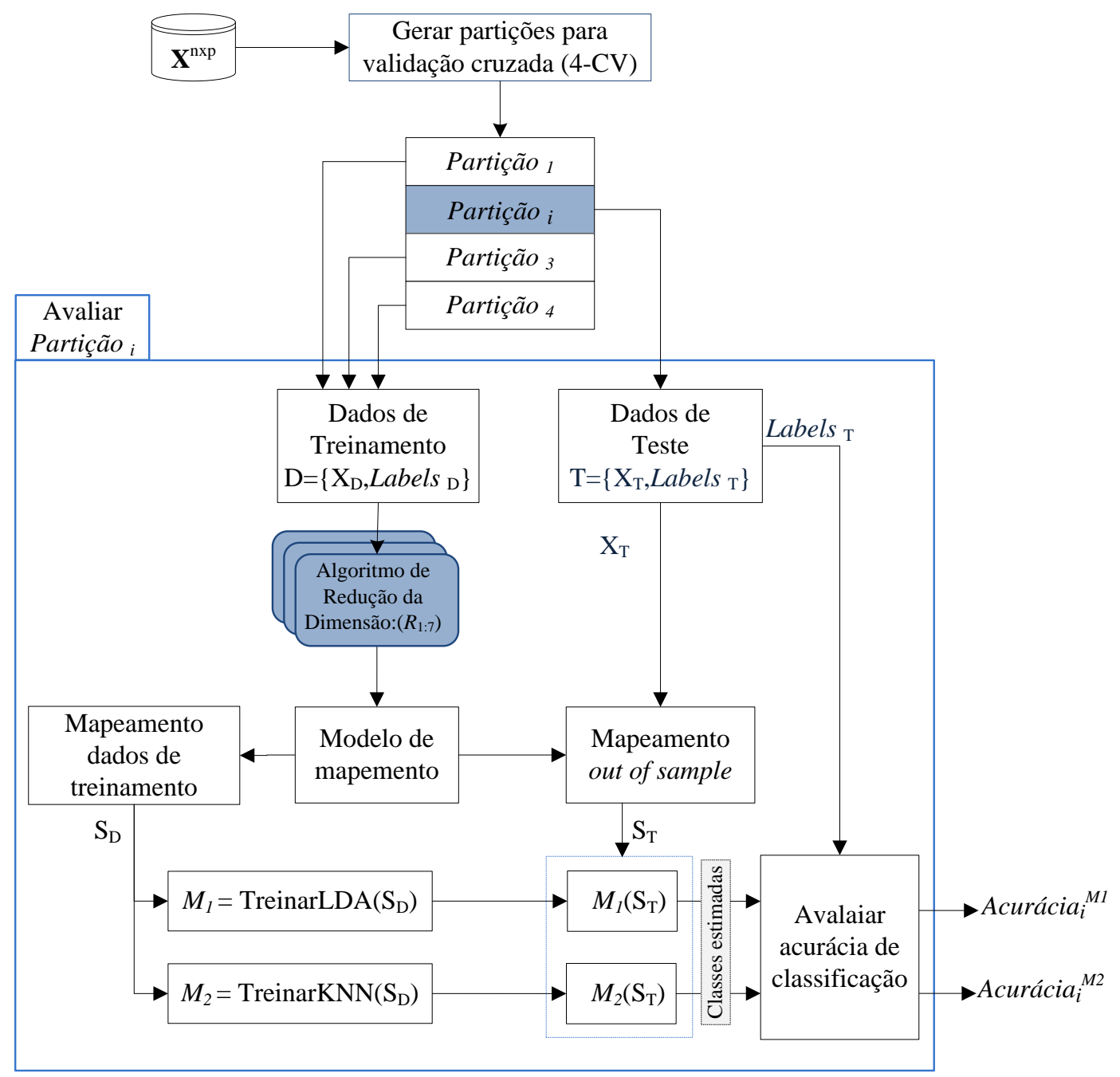

Figura 5.6: Esquema de avaliação da acurácia de classificação que os distintos algoritmos de redução dimensional induzem em dois classificadores (LDA e KNN). Para tal fim é realizada uma validação cruzada com 4 partições (folds), onde cada partição contém uma distribuição equivalente das classes. A acurácia de classificação (Acurácia ${ }_{i}^{M_{j}}$ ) de um determinado algoritmo de redução para um classificador $M_{j}$ e Partição $_{i}$ é estimado treinando o classificador com dados resultantes do mapeamento dos dados que não são da Partição $_{i}$ e testando o classificador sobre os dados mapeados da Partição ${ }_{i}$. A média dos quatro valores de Acurácia $_{i}{ }^{M_{j}}$ $(i=\{1,2,3,4\})$ é a estimativa da acurácia de classificação para o método de redução considerado e classificador $M_{j}$. 
Os resultados dos experimentos descritos acima são mostrados nas Figuras 5.7, 5.8 e 5.9. Cada figura mostra, para um determinado banco de dados e método de classificação, o comportamento da acurácia de classificação dos diferentes métodos de redução analisados como função da dimensão alvo do espaço transformado (no caso dos métodos filtro, essa dimensão corresponde à quantidade de atributos selecionados). Não foi possível obter resultados para o método LMNN no banco de dados MLL (Figura 5.8), já que ele não retornou resultados em 36 horas de processamento (máximo tempo tolerado para todos os métodos).

É possível observar uma tendência geral do método proposto Block-SPPM em induzir classificações com as taxas de classificação mais altas entre os métodos de redução dimensional avaliados para as diferentes dimensões alvo, metodologias de classificação e bancos de dados considerados. Por exemplo, no banco Colon e SRCBT, Block-SPPM consegue uma notável vantagem em acurácia de classificação em relação aos outros métodos, especialmente com o classificador 3NN. Já no banco MLL, não existe uma clara diferenciação entre métodos analisados (exceto o MCML, que tem a tendência a apresentar os menores valores de acurácia), mas Block-SPPM encontrasse frequentemente entre os mais acurados.

É importante destacar a dinâmica de Block-SPPM em relação ao aumento da dimensão alvo. Block-SPPM mostra um aumento progressivo e pouco oscilante da acurácia à medida que se aumenta a dimensão do espaço de projeção até chegar a um patamar estável. Isso implica que Block-SPPM consegue capturar em cada dimensão do espaço transformado informações relevantes e complementares que beneficiam à discriminação de classes. Já os outros métodos mostram frequentemente um comportamento mais instável, apresentando frequentes oscilações na taxa de acurácia de classificação em relação à dimensão alvo, ou inclusive, uma diminuição da acurácia com a dimensionalidade (por exemplo, MCML e Isomap no banco Colon e classificador 3NN). Provavelmente, essas oscilações podem ser ocasionadas por informações irrelevantes ou ruidosas que são eventualmente capturadas por esses métodos no processo de projeção e que, ao invés de facilitar, dificultam o processo de classificação. Já o método Block-SPPM pondera cada bloco em sua capacidade de oferecer informações (para classificação) salientes do ruído de fundo, fator que pode estar influindo positivamente na sua estabilidade. 


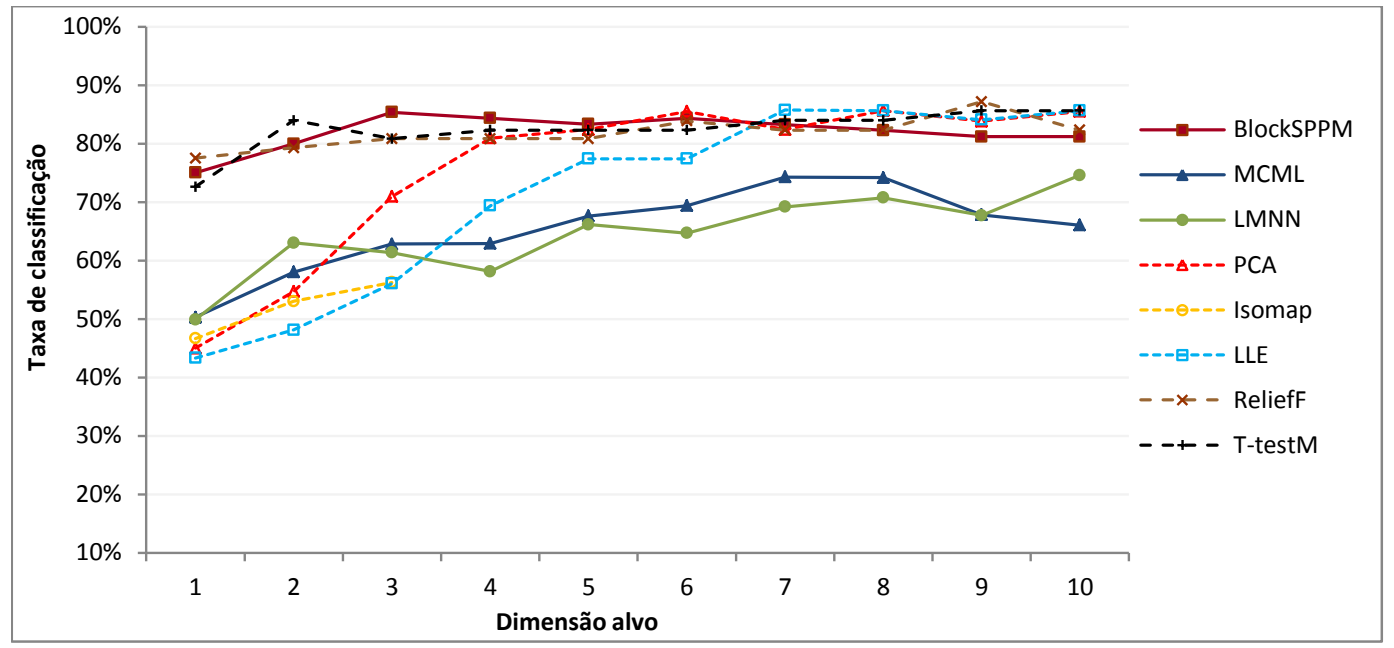

(a) Colon ( $\mathrm{n}=62, \mathrm{p}=1999, \mathrm{c}=2)$ e Classificador LDA

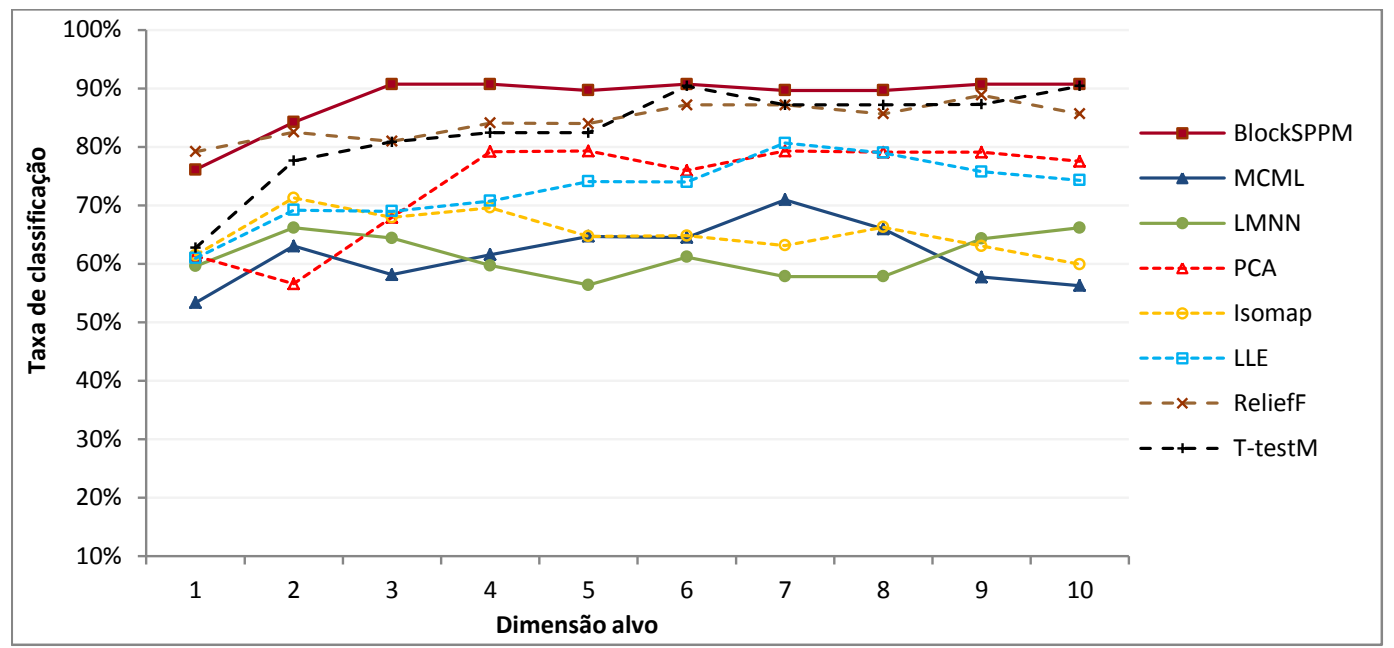

(b) Colon (n=62, p=1999, c=2) e Classificador 3NN

Figura 5.7: Resultados de classificação com Block-SPMM e classificador LDA no banco de dados Colon. 


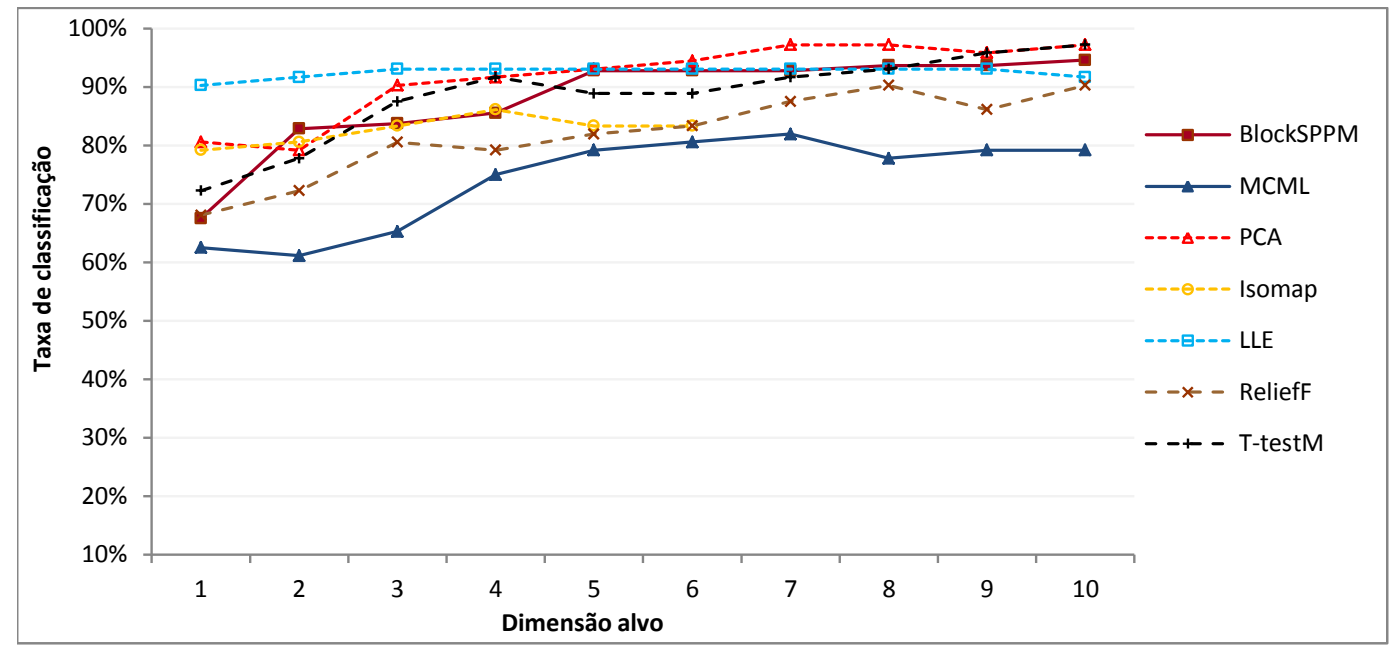

(a) MLL ( $\mathrm{n}=72, \mathrm{p}=8677, \mathrm{c}=3$ ) e Classificador LDA

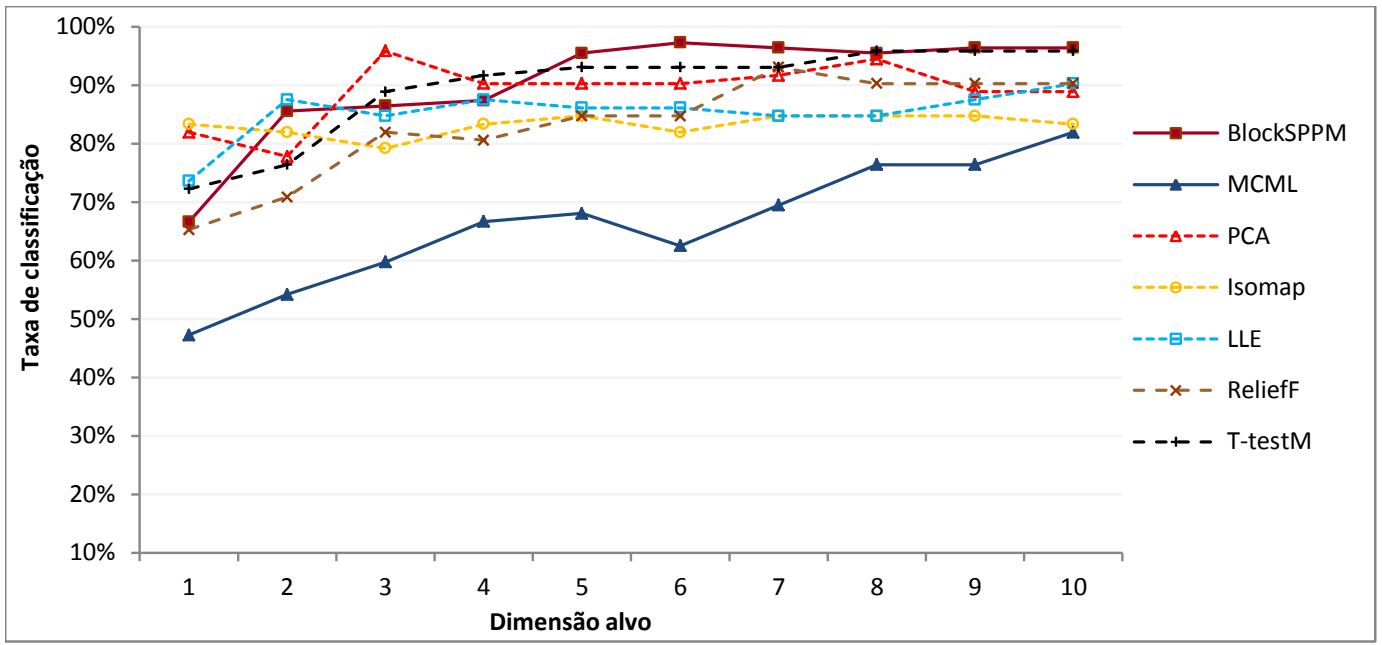

(b) MLL ( $\mathrm{n}=72, \mathrm{p}=8677, \mathrm{c}=3$ ) e Classificador 3-NN

Figura 5.8: Resultados de classificação com Block-SPMM e classificador LDA no banco de dados MLL. Não foi possível obter resultados para o método LMNN neste banco de dados, já que ele não retornou resultados em 36 horas de processamento (máximo tempo tolerado para todos os métodos). 


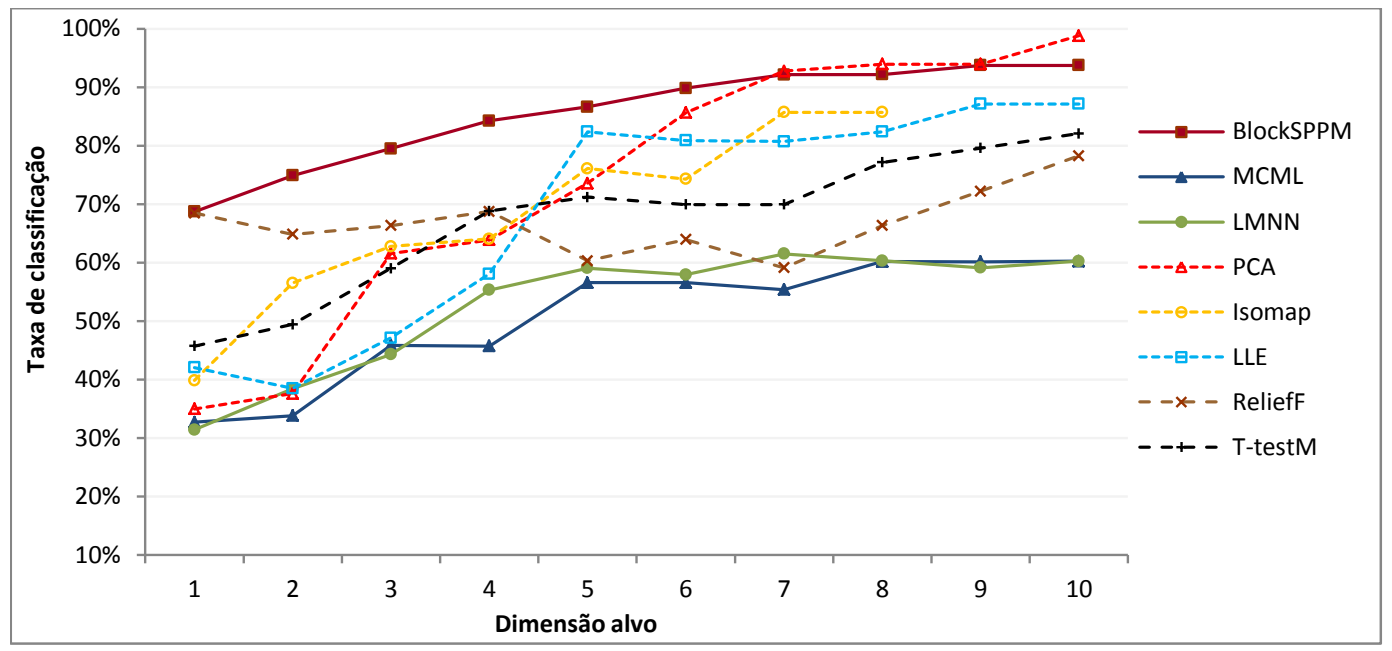

(a) SRBCT (n=83, p=2039, c=4) e Classificador LDA

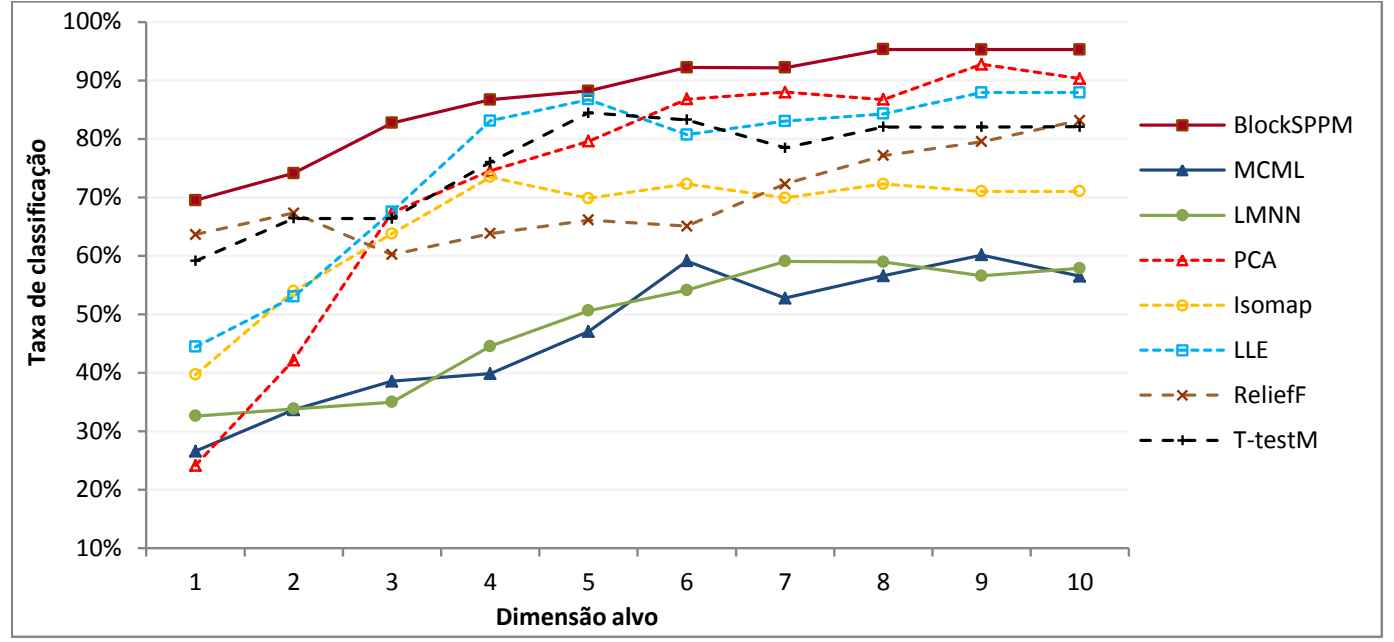

(b) SRCBT ( $\mathrm{n}=83, \mathrm{p}=2039, \mathrm{c}=4$ ) e Classificador 3-NN

Figura 5.9: Resultados de classificação com Block-SPMM e classificador LDA no banco de dados SRBCT. Note-se que no método Isomap com o classificador LDA não foi possível obter resultados em mais de 8 dimensões, isto devido a que nessas dimensões o classificador gerou erros de singularidade. 
Retirando Block-SPPM da análise, não existe uma clara evidência nos resultados obtidos sobre qual seria o método com melhor desempenho. No banco SRBCT, os métodos de extração de atributos não supervisionados (PCA, Isomap, LLE) mostram um desempenho interessante com os dois classificadores Nos bancos Colon e MLL, os métodos de seleção de atributos apresentam acurácias de classificação destacáveis, aproximando-se em alguns casos aos valores de Block-SPPM. Os métodos de redução dimensional supervisionada MCML e LMNN apresentaram uma tendência a induzir classificações com as mais baixas taxas de acurácia, o qual foi de certa forma inesperado já que eles têm a ajuda dos rótulos de classe.

Em relação ao custo computacional, a Figura 5.10 mostra os resultados dos tempos médios de execução (média de 4 repetições idênticas dos experimentos) para obter o máximo número de dimensões alvo considerado neste estudo. Os métodos de extração de atributos LMNN, MCML e Block-SPPM mostraram tempos de processamento muito maiores do que os outros métodos (especialmente o método LMNN), sendo estes na ordem de horas. Já no outro extremo estão os métodos não supervisionados de extração de atributos como PCA, LLE, os quais apresentaram tempos na ordem de segundos. Os métodos filtros de seleção de atributos mostraram também serem rápidos, estando próximos dos métodos PCA e LLE. 


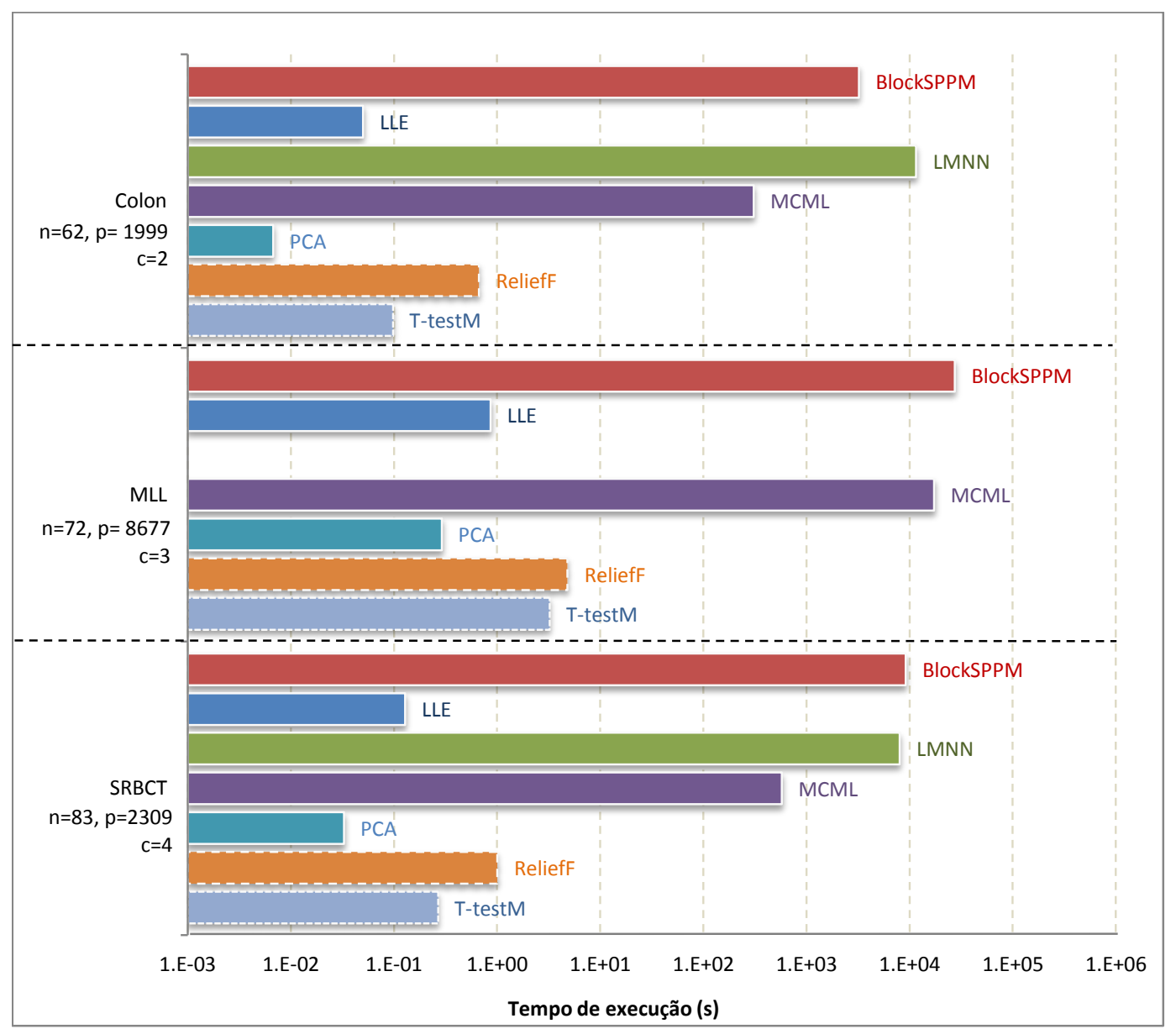

Figura 5.10: Resultados médios (sobre 4 repetições) do tempo de processamento para obter 10 dimensões alvo pelos diferentes métodos de redução dimensional estudados. O tempo é mostrado em escala logarítmica, dada as grandes diferenças observadas. Não são mostrados resultados para o método Isomap, já que ele falhou em obter mais de 8 dimensões na maioria de vezes.

\subsection{Avaliação de W-SPPM}

Esta seção apresenta uma avaliação experimental de W-SPPM. A avaliação foca-se em determinar o desempenho de W-SPPM com diversos índices de projeção na sua capacidade de reduzir a dimensão de dados de elevada dimensão e poucas amostras e facilitar a classificação. Para tal fim foram incluídos os cinco índices de tipo supervisionado descritos na Secção 3.3.2 (PI_lda, PI_nca, PI_qpc, PI_Bhattacharyya e PI_LpS) e o índice não supervisionado PI_Lp como referência para comparação com sua versão supervisionada aqui proposta. Adicionalmente foram incluídos no estudo os métodos de seleção de atributos T-testM e ReliefF, assim como o tradicional método de branqueamento como referência. Similar à avaliação da seção prévia, a dimensão alvo é variada entre 1 e 10. 
Dado que o custo computacional de W-SPPM mostrou ser bastante razoável na prática, a presente avaliação inclui 5 bancos de dados adicionais aos três da avaliação anterior. Estes bancos são derivados também de estudos com a tecnologia de microarranjo e são descritos a seguir:

Brain Tumor1 (Pomeroy et al., 2002). Este banco de dados contem informação de tumores embrionais no sistema nervoso central (CNS). O banco é formado por cinco classes de tumores (medulloblastomas, malignant gliomas, renal/extrarenal rhabdoid tumors (AT/RT), normal cerebellum e supratentorial PNETs) distribuídos em 90 amostras e 5921 atributos (genes).

Brain Tumor2 (Nutt et al., 2003). Este banco de dados contem informações de gliomas malignos. 12000 atributos (genes) e 50 amostras conformam este banco de dados. As amostras são categorizadas em quatro classes: classic glioblastomas, classic Anaplastic Oligodendrogliomas, non-classic glioblastomas e non-classic anaplastic oligodendrogliomas.

DLBCL (Shipp et al., 2002). Diffuse large B-cell lymphoma (DLBCL) é um agressivo tipo de câncer com células malignas tipo B-lymphocytes. Este banco de dados inclui dois sub-tipos clínicos de linfomas: diffuse large B-cell lymphomas and follicular lymphomas (FL) distribuídos em 96 amostras de 4026 atributos (genes).

Prostate Tumor (Singh et al., 2002). Este banco contém informação de câncer de próstata e está formado por 102 amostras e 1051 atributos. As amostras estão divididas em duas classes (tumor e normal).

TBC Berry et al. (2010). Este banco de dados possui dados sobre a identificação da assinatura de transcrição em pacientes com tuberculose ativa. 147 amostras e 48791 atributos conformam este banco. As amostras estão classificadas em três grupos (tuberculose ativa (PTB), tuberculosis latente (LTB), grupo de controle (CON)).

A Figura 5.11 mostra a estrutura de avaliação de W-SPPM. Diferentemente da avaliação de Block-SPPM, a presente avaliação realiza uma estimativa da acurácia preditiva de classificação usando um esquema Leave-One-Out (LOO) (Kononenko e Kukar, 2007). Isto foi feito dada a maior eficiência computacional de W-SPPM e a necessidade de minimizar a aleatoriedade que possa introduzir o esquema de cálculo da acurácia (de fato, LOO elimina totalmente essa 


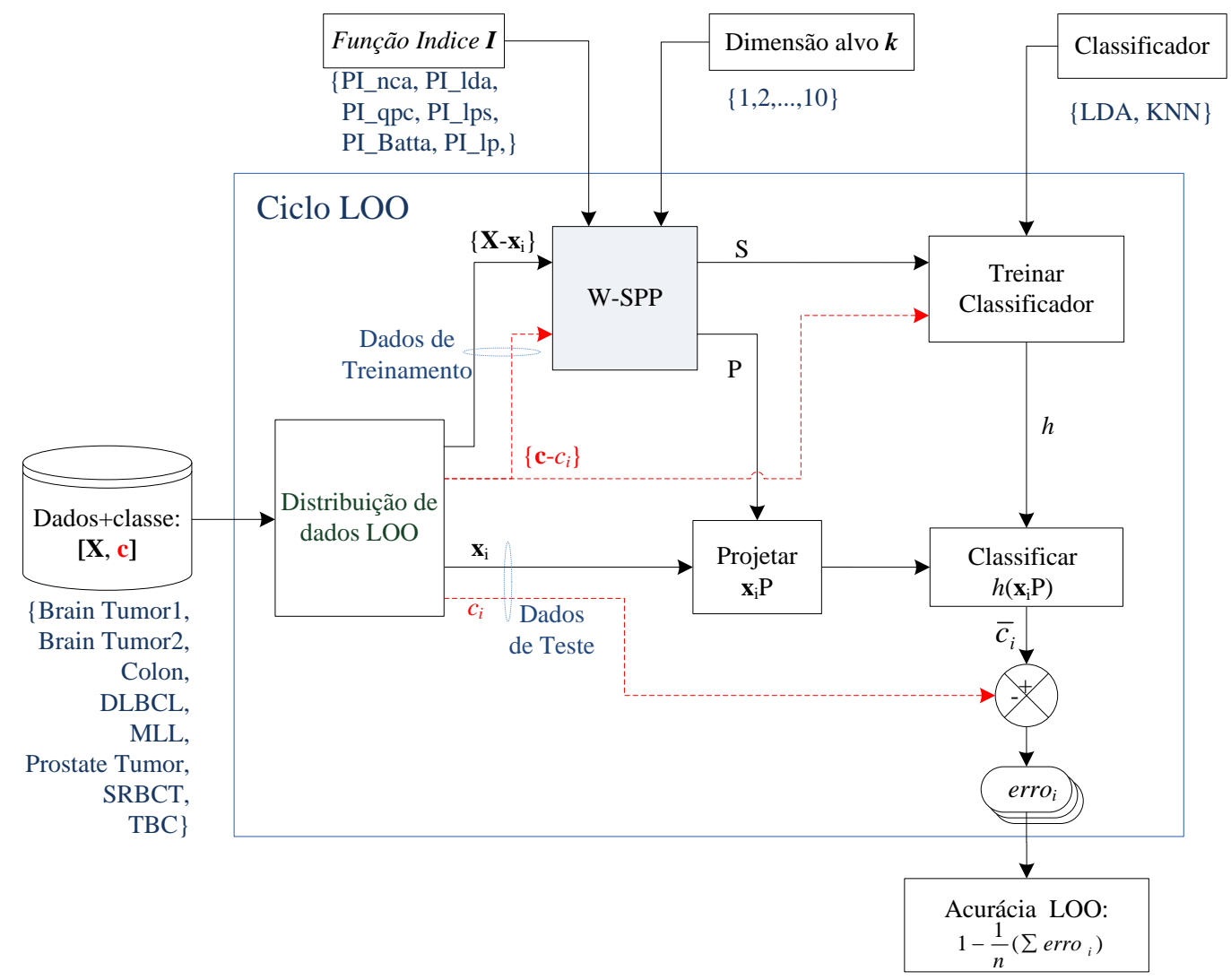

Figura 5.11: Esquema dos experimentos para avaliar o desempenho de W-SPPM para facilitar a classificação de dados.

aleatoriedade já que seu cálculo é sempre reprodutível). Para um determinado banco de dados, função índice $(I)$, dimensão alvo $(k)$ e método de classificação, o cálculo da acurácia de classificação LOO consiste de um ciclo de $n$ iterações, onde na iteração $i$ a amostra $\mathbf{x}_{i}$ é separada para teste. Os dados restantes $\mathbf{X}-\mathbf{x}_{i}$ são usados em W-SPPM para calcular as matrizes de projeção $\mathbf{P}$ e de dados reduzidos $\mathbf{S}$, a qual por sua vez é usada para treinar um classificador (LDA ou KNN). Uma vez obtida a matriz de projeção e treinado o classificador, a amostra de teste $\mathbf{x}_{i}$ é projetada usando $\mathbf{P}$ e o resultado é fornecido ao classificador treinado $h\left(\mathbf{x}_{i} \mathbf{P}\right)$. O rótulo estimado $\bar{c}_{i}$ é comparado com o verdadeiro rótulo de classe $c_{i}$ e o resultado é armazenado na variável error $_{i}$ (com 0 para rótulos iguais e 1 em caso contrario). A acurácia de classificação final LOO após as $n$ iterações é calculado como $1-(1 / n) \sum_{i=1}^{n}$ error $_{i}$. Dado que W-SPPM é estocástico (pelo otimizador PPGA), o processo de cálculo de acurácia anterior é repetido 8 vezes de forma independente, a fim de avaliar a significância estatística dos resultados.

A Figura 5.12 mostra os resultados médios de acurácia de classificação LOO (média sobre as 8 repetições) para W-SPPM e o classificador LDA nos diversos bancos de dados estudados. 
Cada figura mostra resultados para um determinado banco de dados, onde as curvas correspondem aos diferentes índices analisados como função da dimensão alvo. Incluem-se também os resultados dos métodos de seleção de atributos T-testM e Relief e o método de branqueamento (Whitened). Pode-se observar que na maioria dos casos, os resultados de W-SPPM com os índices de projeção: PI_lda, PI_LpS, PI_nca e PI_qpc tendem a ser semelhantes e superiores aos outros métodos (embora algumas diferenças sejam observadas na primeira dimensão). É possível observar um comportamento geral dos métodos em que a taxa de classificação LOO cresce com a dimensão do espaço alvo, embora os quatro índices referidos tendam a chegar à estabilidade em algumas poucas dimensões (que variam entre 2 e 4). Este é um indicativo de que W-SPPM com tais índices consegue compactar as informações mais relevantes para classificação em menos dimensões do que os outros métodos. Por exemplo, no banco de dados SRBCT (com quatro classes), esses índices induzem classificações com quase 100\% de taxa de classificação em apenas três dimensões, enquanto que os outros métodos estão bastante longe de $100 \%$ nessas dimensões. Adicionalmente, foi observado nos bancos de dados com duas classes (Figuras 5.12(c),(d),(f)) que esse grupo de índices apresentam curvas planas e sobrepostas, o qual podem estar indicando que toda a informação discriminatória é esgotada em apenas uma dimensão. É importante destacar que as classificações induzidas por W-SPPM são mais estáveis (em relação à dimensão alvo) do que os outros métodos. Particularmente, os métodos de seleção de atributos mostram oscilações frequentes, o que sugere que trabalhar sobre a representação original dos dados pode limitar a construção de classificadores acurados. 


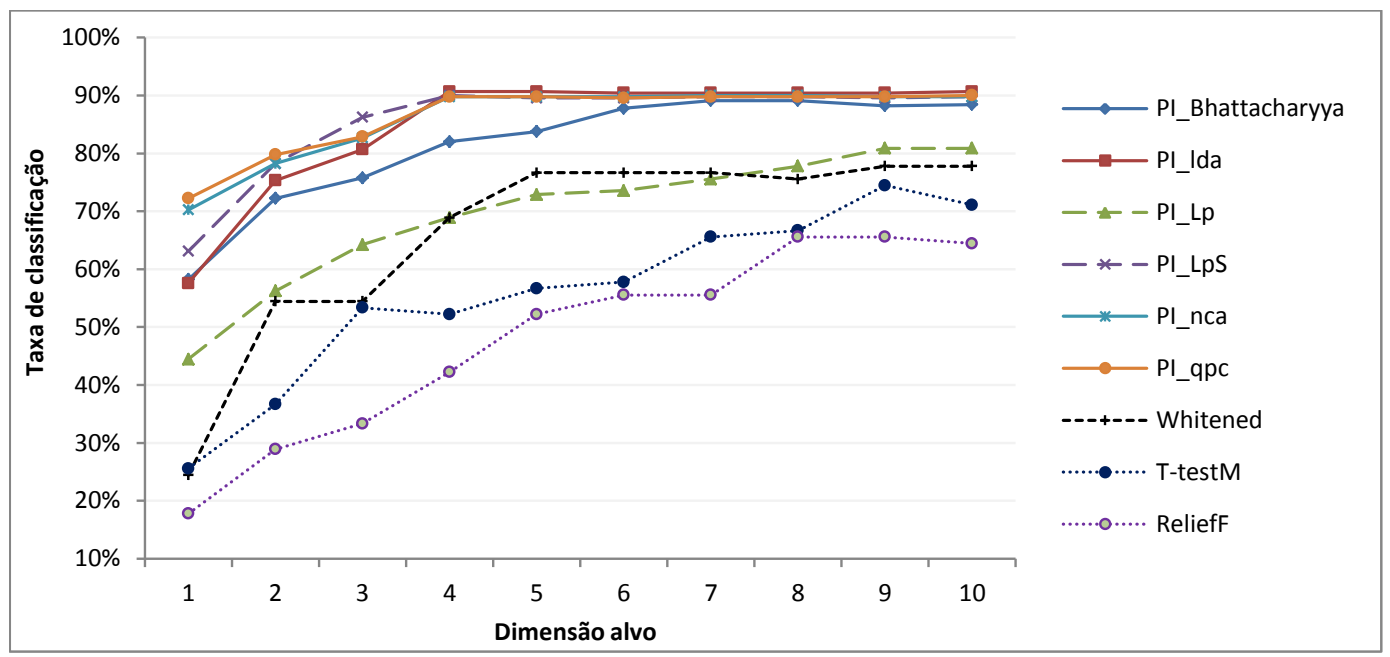

(a) Brain Tumor1 ( $\mathrm{n}=90, \mathrm{p}=5921, \mathrm{c}=5, \mathrm{q}=42)$

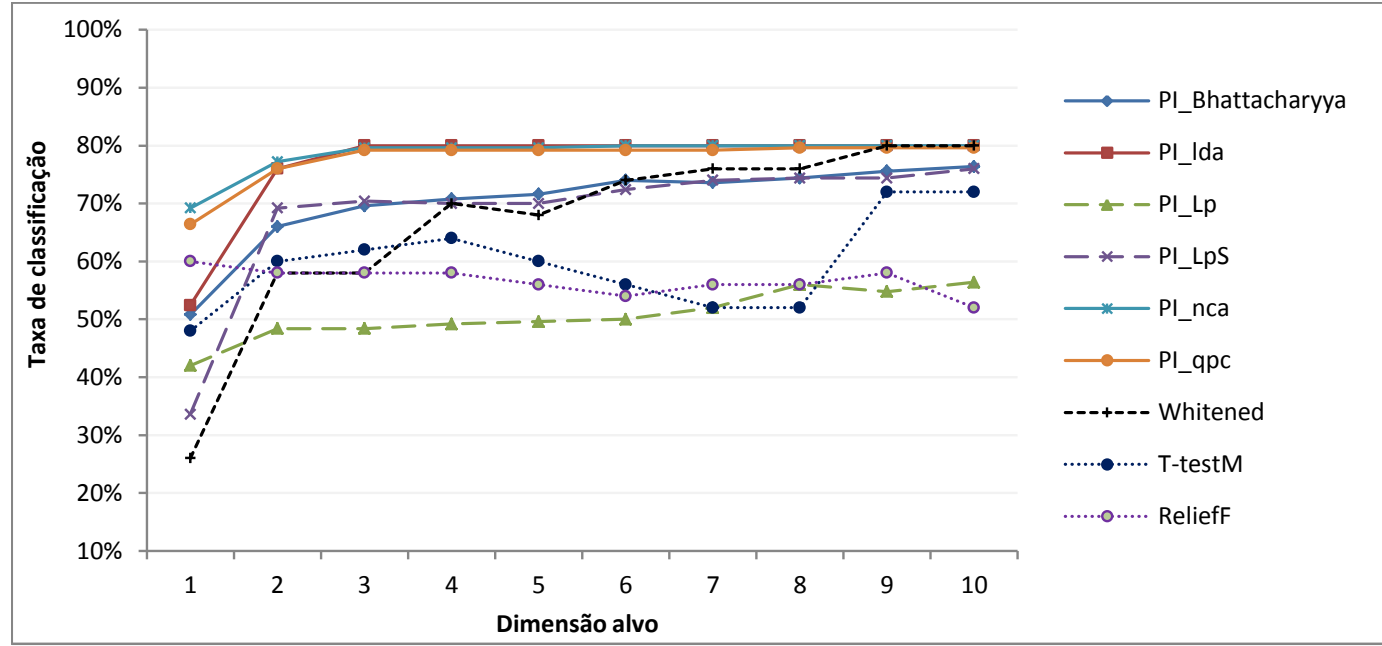

(b) Brain Tumor2 ( $\mathrm{n}=50, \mathrm{p}=10368, \mathrm{c}=4, \mathrm{q}=22)$

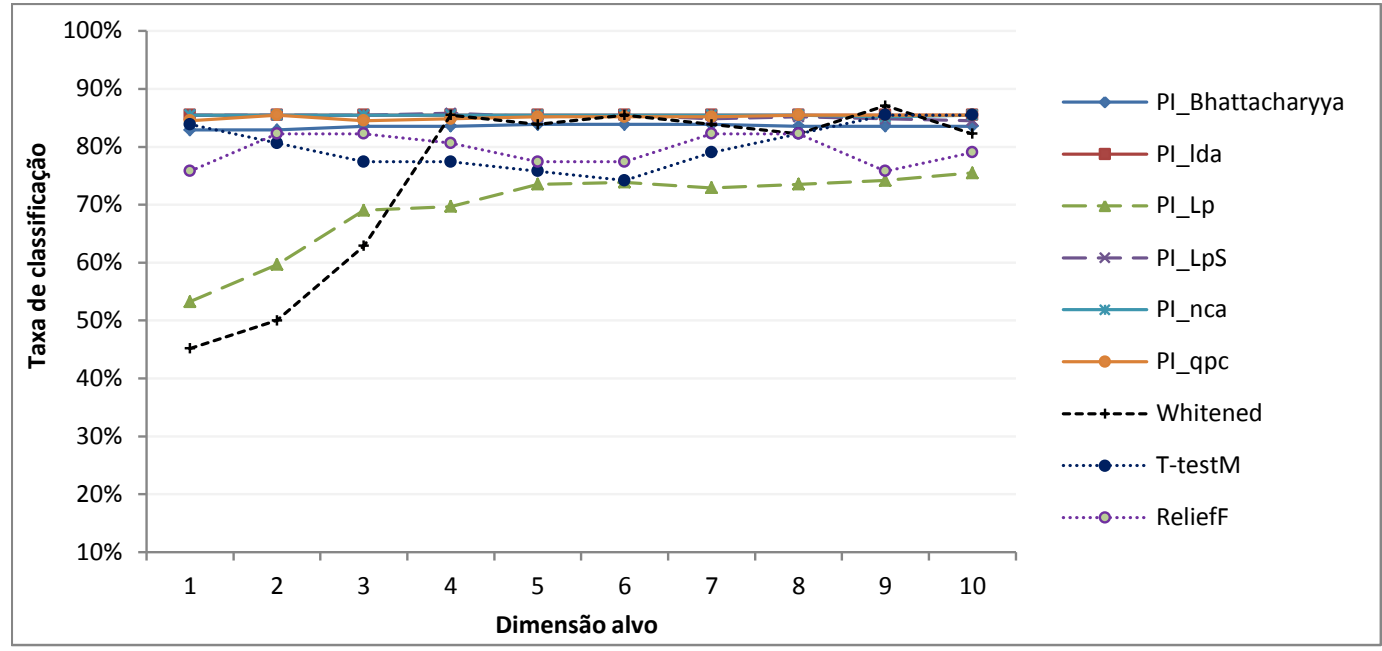

(c) Colon ( $\mathrm{n}=62, \mathrm{p}=1999, \mathrm{c}=2, \mathrm{q}=32)$ 


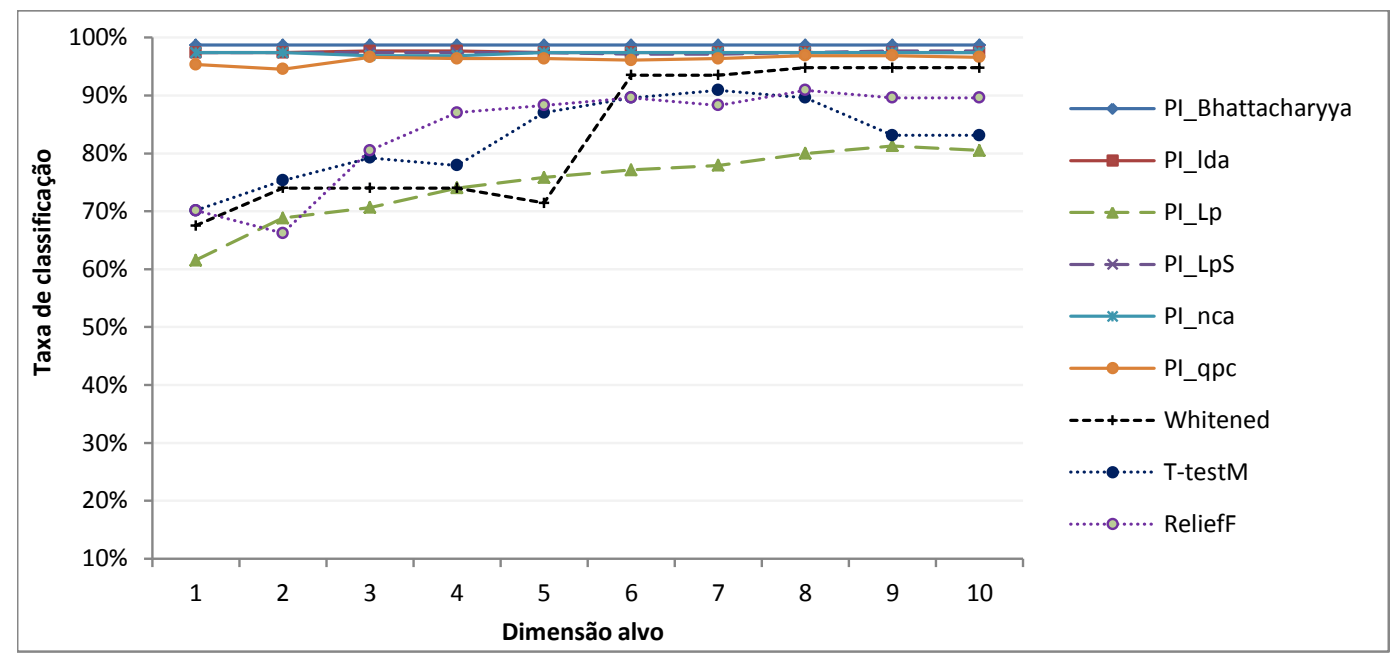

(d) DLBCL ( $\mathrm{n}=77, \mathrm{p}=5470, \mathrm{c}=2, \mathrm{q}=37$ )

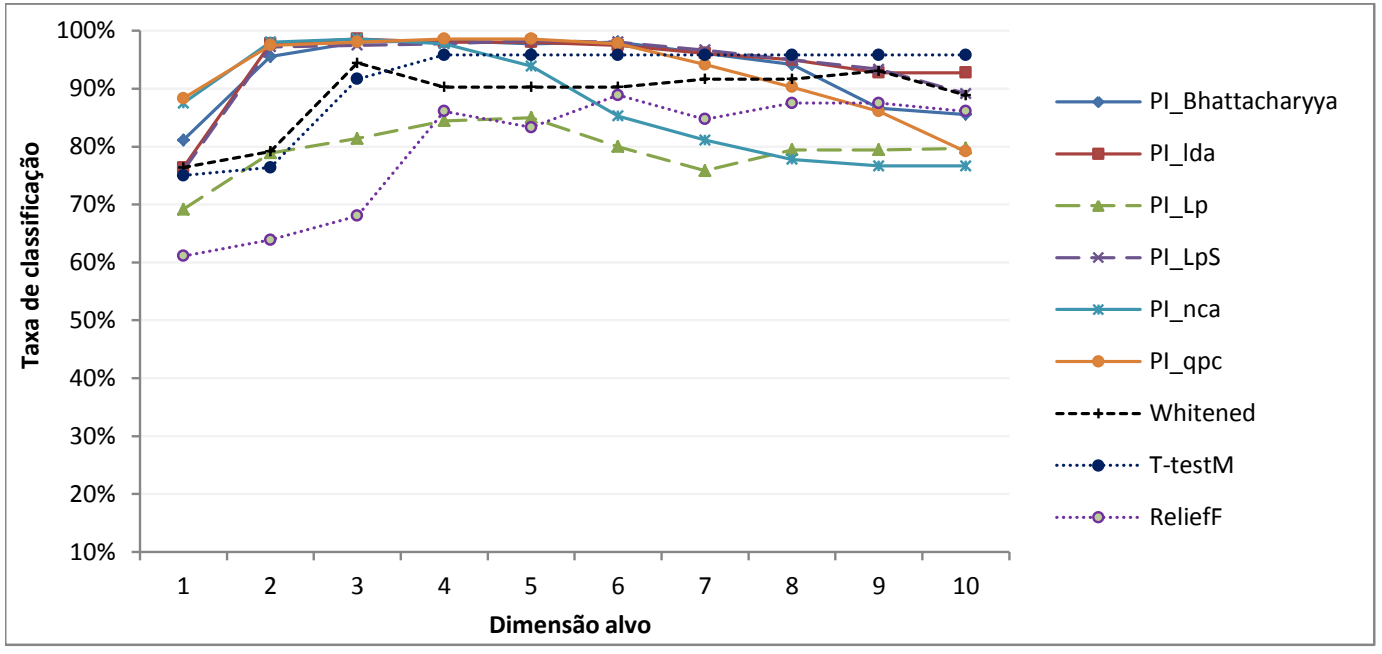

(e) MLL (n=72, p=8677, c=3, q=44)

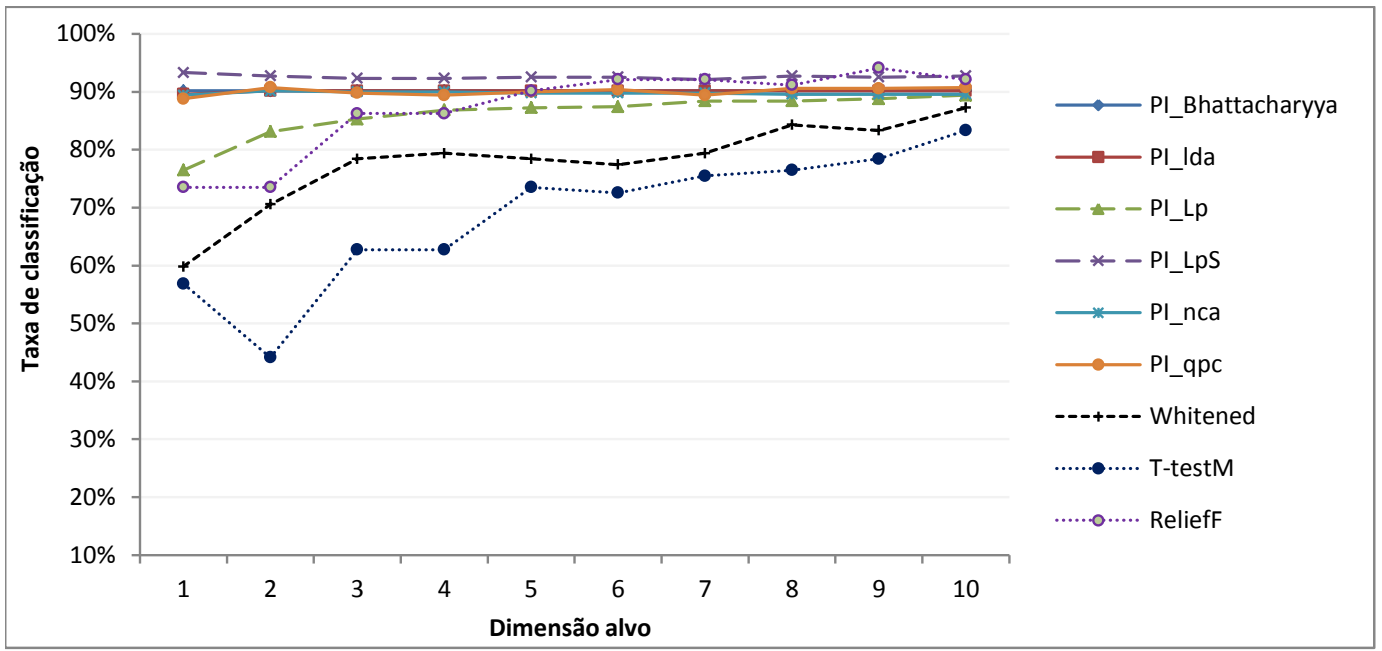

(f) Prostata Tumor $(\mathrm{n}=102, \mathrm{p}=10510, \mathrm{c}=2$, $\mathrm{q}=38)$ 


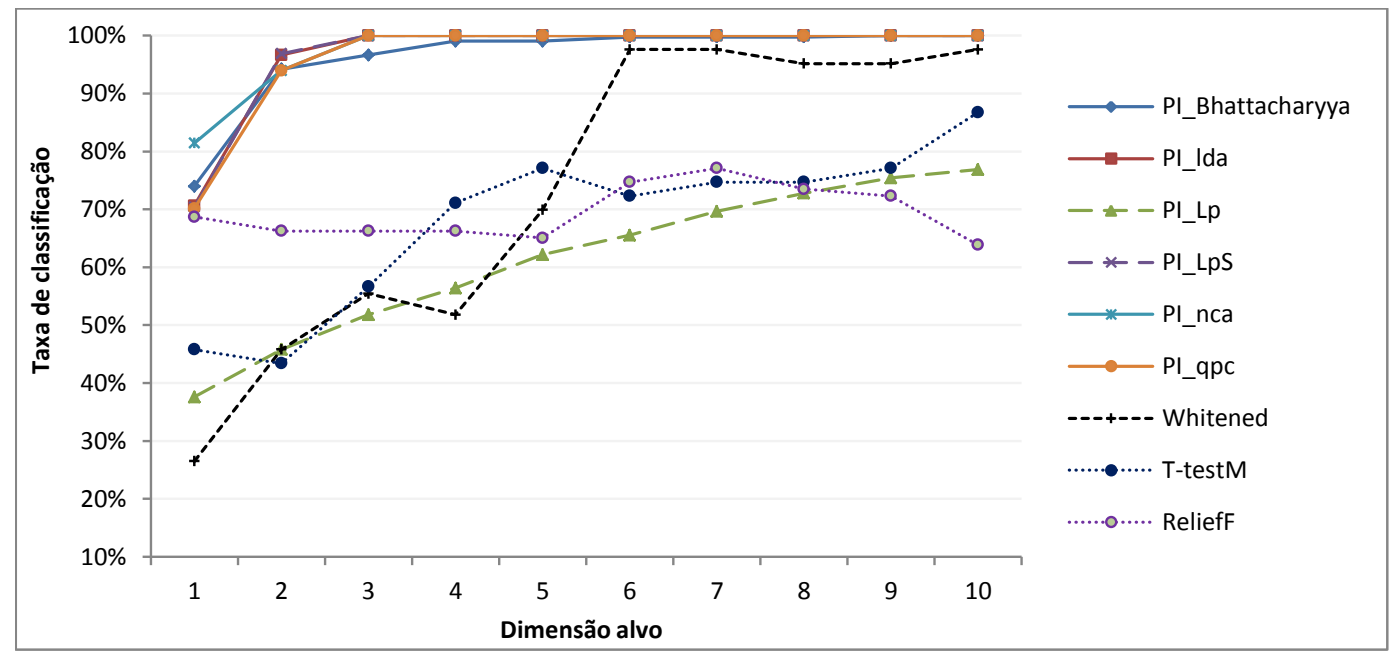

(g) SRBCT (n=83, p=2039, c=4, q=42)

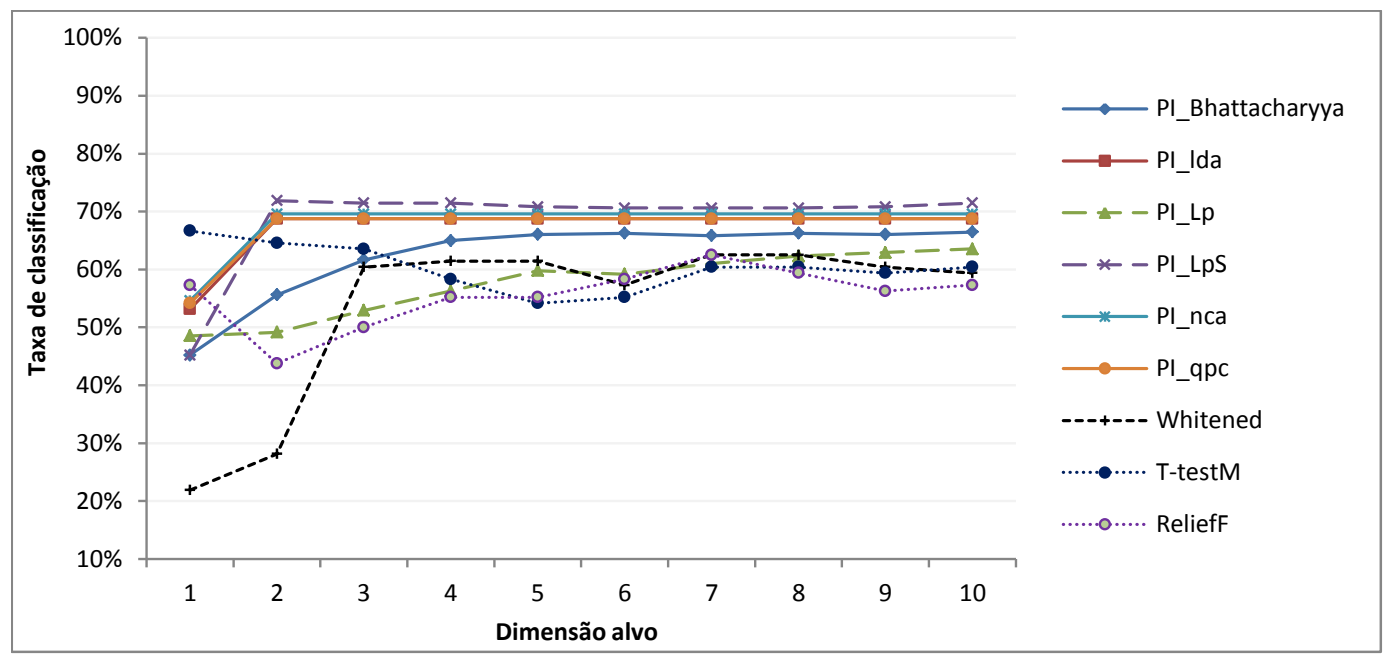

(h) TBC (n=96, p=4179, c=3, q=61)

Figura 5.12: Acurácias médias (sobre 8 repetições) obtidas com W-SPPM e o classificador LDA para 6 índices de projeção, métodos de seleção de atributos T-testM e ReliefF e o método de branqueamento (whitened). Cada figura corresponde a um banco de dados diferente. $\mathrm{O}$ eixo das abscissas representa as diferentes dimensões alvo testadas. 
A fim de ter uma visão geral do desempenho relativo dos índices de projeção e dos outros métodos testados foi realizado uma análise de ranking. Esta análise consiste em ranquear os diversos métodos de redução em relação a sua acurácia média LOO de classificação exibida para uma configuração particular de classificador, banco de dados, e dimensão alvo (os melhores métodos recebem os valores mais baixos de ranking). A Figura 5.13 mostra os resultados dos rankings médios (sobre as 8 repetições) dos métodos para os dois classificadores como função da dimensão alvo. O comportamento dos métodos com o classificador LDA (Figura 5.13(a)) pode se verificar que com duas ou mais dimensões o índice PI_lda seguido por PI_LpS, PI_nca e PI_qpc tendem a estar no topo do ranking. No entanto, na primeira dimensão os índices PI_lda e PI_LpS não são tão bons quanto PI_nca e PI_qpc. O índice PI_Bhattacharyya posiciona-se embaixo desses índices, seguido por whitened, ReliefF, T-testM e PI_Lp. No entanto, whitened apresenta um avanço mais rápido no ranking em relação à dimensão alvo. Os resultados com o classificador 3NN (Figura 5.13(b)) mostram também os índices PI_lda, PI_LpS manter uma predominância do ranking na maioria das dimensões. No entanto, o desempenho relativo dos índices PI_nca e PI_qpc mostra uma degradação acentuado a partir da quinta dimensão alvo, sendo superados por whitened e os métodos de seleção de atributos na oitava dimensão alvo. Um aspecto interessante é o desempenho do índice não supervisionado PI_Lp que é geralmente o pior posicionado no ranking, mas sua extensão supervisionada PI_LpS proposta neste trabalho mostra ser bastante competitivo em quanto acurácia de classificação.

Para determinar a significância estatística dos resultados acima, foi seguido o procedimento descrito por Brazdil et al. (2003), no qual primeiro é aplicado o teste estatístico não paramétrico de Friedman (com correção para empates, como sugerido pelos autores) para verificar a existência de diferenças nos métodos testados ${ }^{3}$. Os resultados dos testes com nível de significância 0,05 reportaram a existência de diferenças em todas as dimensões alvo para os dois classificadores. Com esta informação, determinou-se quais métodos estão gerando essas diferenças estatísticas. Para tal fim foi usada a técnica de múltipla comparação de Dunn ((Brazdil et al., 2003)), na qual são realizadas comparações pareadas entre todos os métodos, o que gerou 15 possíveis combinações para os 6 índices. Em seguida, foi realizada a correção de Bonferroni de múltiplas comparações, como sugerido também em (Brazdil et al., 2003). O nível de significância para estas comparações foi colocado em 0, 25 (indicado em (Brazdil et al., 2003)), valor

\footnotetext{
${ }^{3}$ Apenas os seis índices de projeção participaram nestes testes estatísticos, já que os outros métodos são determinísticos e, portanto, sempre estatisticamente diferentes dos outros.
} 


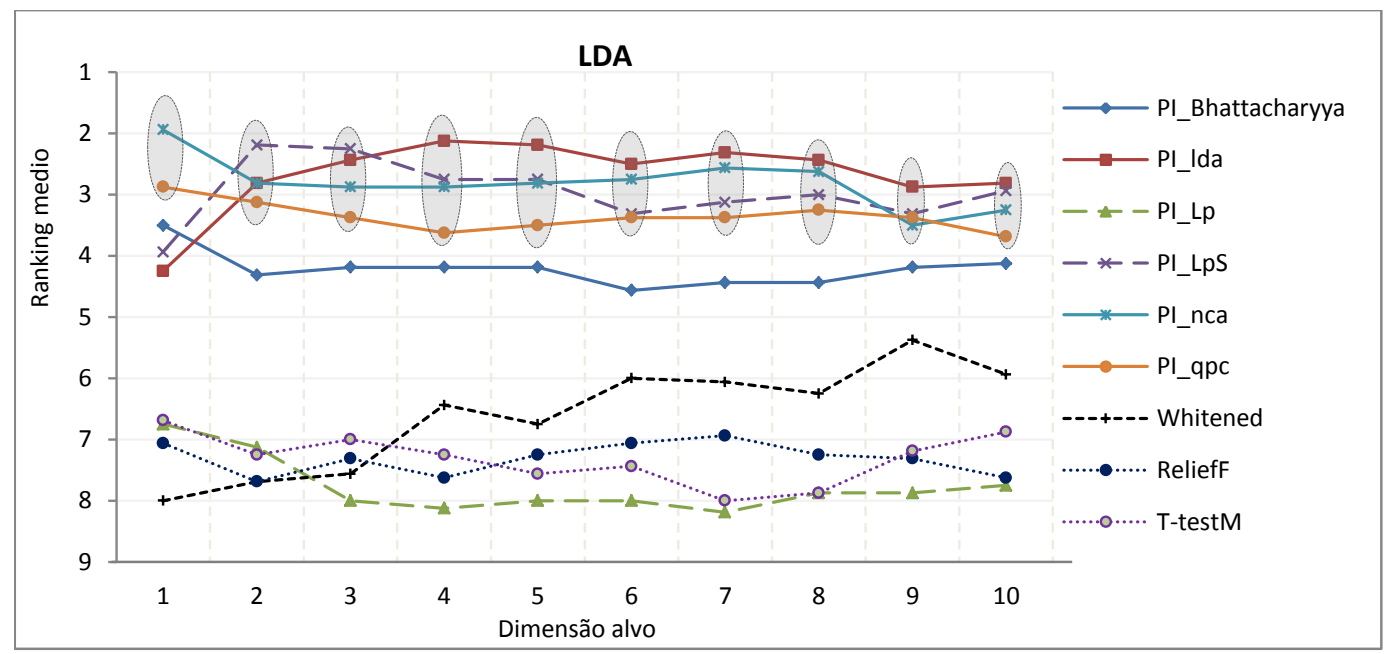

(a) Ranking LDA

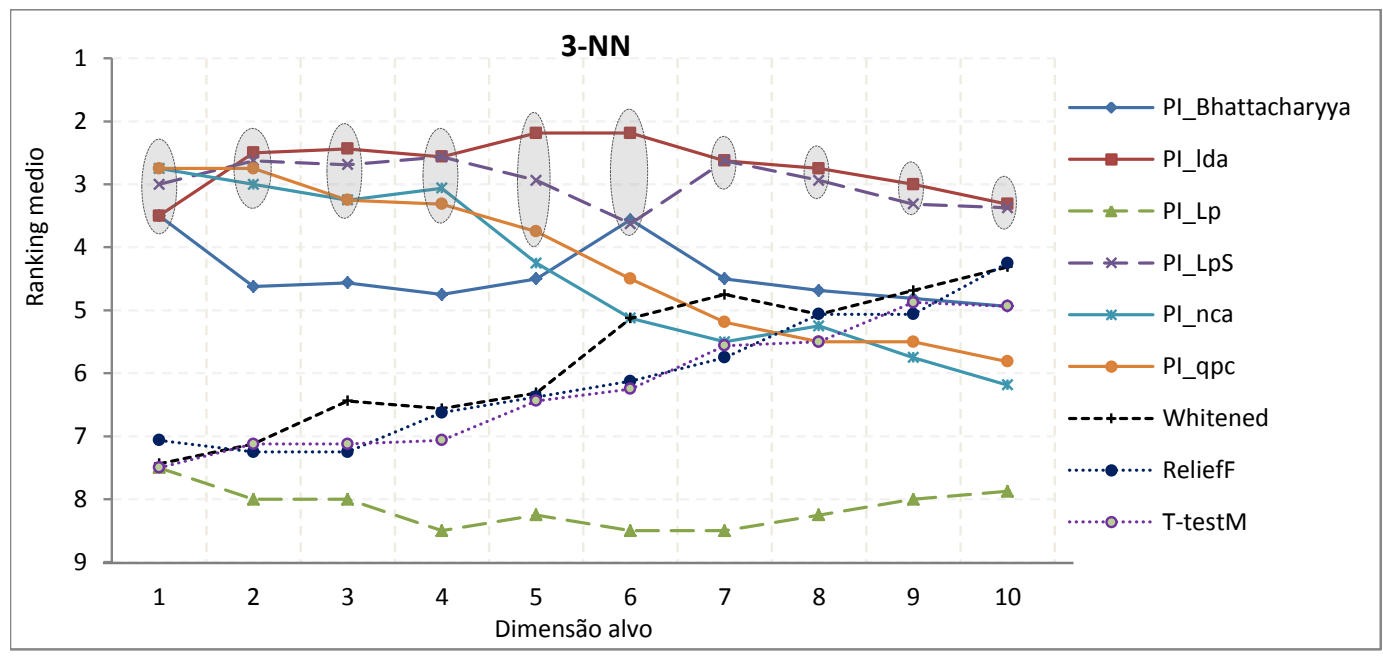

(b) Ranking 3KNN

Figura 5.13: Resultados da média dos ranking para os métodos estudados sobre dois classificadores (calculados sobre os bancos de dados e repetições dos experimentos) em função da dimensão alvo. As elipses indicam os métodos sem diferença estatística em relação ao melhor método classificado. 
intencionalmente alto já que o teste anterior acusou diferença estatística. Os resultados das comparações são indicados na Figura 5.13, a qual mostra com elipses todos os métodos que não são estatisticamente diferentes do método melhor ranqueado. Estes resultados sugerem que se fosse necessário escolher um índice para W-SPPM a fim de maximizar o desempenho de classificação com LDA, pode-se simplesmente escolher qualquer um dos índices: PI_lda, PI_LpS, PI_nca ou PI_qpc. Já para o classificador 3NN, a escolha é mais restrita entre os índices PI_lda ou PI_LpS, índices que geram resultados igualmente bons nos níveis de significância escolhidos.

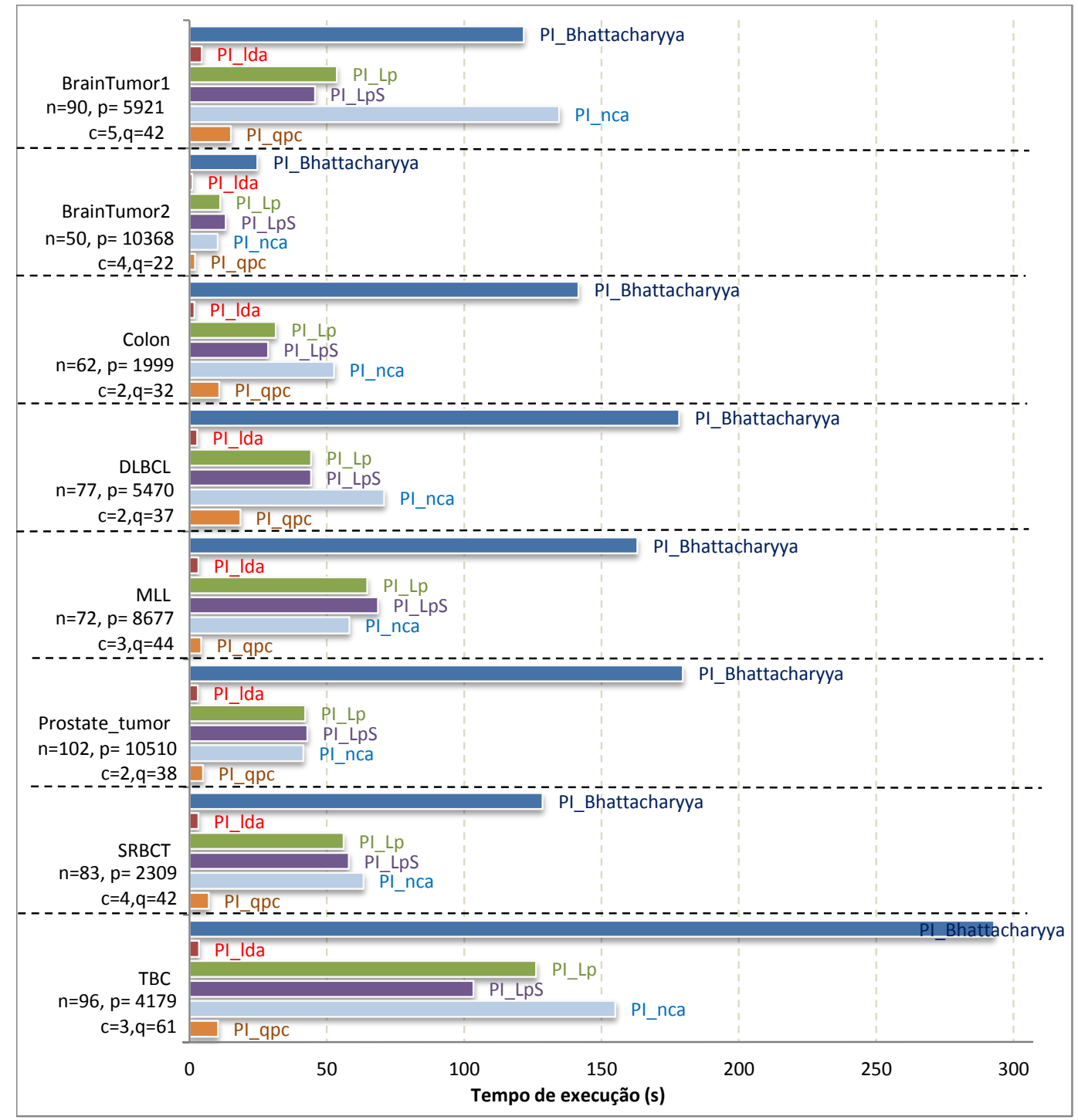

Figura 5.14: Resultados médios do tempo de processamento (média de 8 repetições) com o método W-SPPM e os diversos índices analisados para obter 10 dimensões alvo.

Em relação ao custo computacional de W-SPPM, este foi estimado através da medição do tempo de execução em obter 10 dimensões alvo (a máxima dimensão avaliada) por cada método 
em cada banco de dados. A Figura 5.14 apresenta estas medições (média das oito repetições). As seguintes observações podem ser retiradas destes resultados: i) o índice PI_Battacharya usa tempos computacionais que são significativamente maiores do que os demais índices, sendo às vezes perto do dobro do tempo do índice mais próximo. Isto pode ser explicado pela definição non-smooth deste índice (Equação 3.10) que pode estar agravando a dificultade em buscar projeções ótimas; ii) os seguintes maiores tempos de execução são apresentados pelo índice PI_nca seguido de perto pelos índices PI_Lp e PI_LpS, índices que apresentam tempos muito similares na maioria dos bancos de dados. Isto indica que a extensão para análise supervisionada do índice PI_Lp não altera o tempo de execução esperado; iv) os índices PI_qpc e PI_lda apresentam tempos de execução significativamente mais baixos do que o resto de índices, sendo PI_lda aquele que apresenta os tempos de execução mais baixos (em torno de alguns segundos). Uma explicação para isso poderia ser a simplicidade da sua definição e provavelmente a verificação dos pressupostos subjacentes (gaussianidade das classes) nos bancos de dados testados.

Outra informação importante que pode ser tirada dos resultados da Figura 5.14 é que os tempos de execução não são mais dependentes da dimensão original $p$ (como no caso da maioria de métodos de seleção de atributos) e sim da dimensão do espaço branqueado $q$. Assim, por exemplo, o banco de dados TBC com $p=4179$ e $q=61$ possui os maiores tempos de execução, enquanto que BrainTumor2 $\operatorname{com} p=10368$ e $q=22$ tem os valores mais baixos. Isso indica também que o tempo total de execução é em grande parte contribuído pela etapa SPPM dentro de W-SPPM. 


\subsection{Comparação entre Block-SPPM e W-SPPM}

Apresenta-se nesta seção uma comparação de desempenho entre Block-SPPM e W-SPPM. Não é pretendido fazer uma comparação exaustiva e aprofundada entre estes dois métodos, desde que os setups experimentais e as métricas de avaliação não foram exatamente as mesmas em ambos os casos, senão apresentar indicativos do comportamento relativo dos métodos. As figuras 5.15, 5.16 e 5.17 mostram respectivamente, para os três bancos de dados onde a avaliação de Block-SPPM e W-SPPM coincide (Colon, MLL e SRBCT), os resultados de acurácia de classificação LOO obtidos com W-SPPM e os diversos índices, métodos filtros e Whitened para o classificador LDA. As figuras incluem também a acurácia de Block-SPPM, embora esta não seja estritamente comparável à acurácia dos outros métodos, já que se trata de uma estimativa CV (de 4 folds) e não uma LOO. No entanto, esta comparação pode ajudar a ter uma idéia do comportamento relativo dos métodos.

Pode-se observar nas figuras que as acurácias de W-SPPM para os quatro índices estatisticamente indistinguíveis (PI_lda, PI_LpS, PI_nca e PI_qpc ) são frequentemente maiores do que a acurácia de Block-SPPM (o qual usa o índice PI_lda). A maior diferença encontra-se nas primeiras dimensões alvo, em que W-SPPM com qualquer dos quatro índices atinge a estabilidade em menos dimensões do que Block-SPPM (no banco Colon, W-SPPM apresenta uma acurácia estável desde a primeira dimensão, enquanto que Block-SPPM chega à estabilidade na terceira dimensão; no banco MLL, W-SPPM é estável a partir da segunda dimensão, enquanto que Block-SPPM chega à estabilidade na quinta dimensão; no banco SRBCT, W-SPPM chega à estabilidade na terceira dimensão, enquanto Block-SPPM mostra tal estabilidade na nona dimensão). Apesar de que na avaliação de Block-SPPM mostrou-se que esta abordagem consegue melhorar a acurácia de vários outros métodos representativos do estado da arte, a presente comparação indica que W-SPPM supera frequentemente a acurácia (com classificador LDA) de Block-SPPM (isto assumindo que as comparações de acurácia são válidas). Estes resultados sugerem que W-SPPM seria mais adequado em arranjar maior informação de relevância para LDA em uma menor quantidade de dimensões do que os demais métodos estudados.

Em relação aos custos computacionais, pode se observar que os tempos de processamento de Block-SPPM (Figura ??) são várias ordens de magnitude maiores do que os tempos de processamento de W-SPPM (Figura 5.14) (Block-SPPM utiliza horas para encontrar 10 dimensões alvo, enquanto que W-SPPM demora alguns poucos segundos com os índices PI_lda e PI_qpc em encontrar a mesma dimensão alvo nos mesmos bancos de dados). Estes resultados, junto 


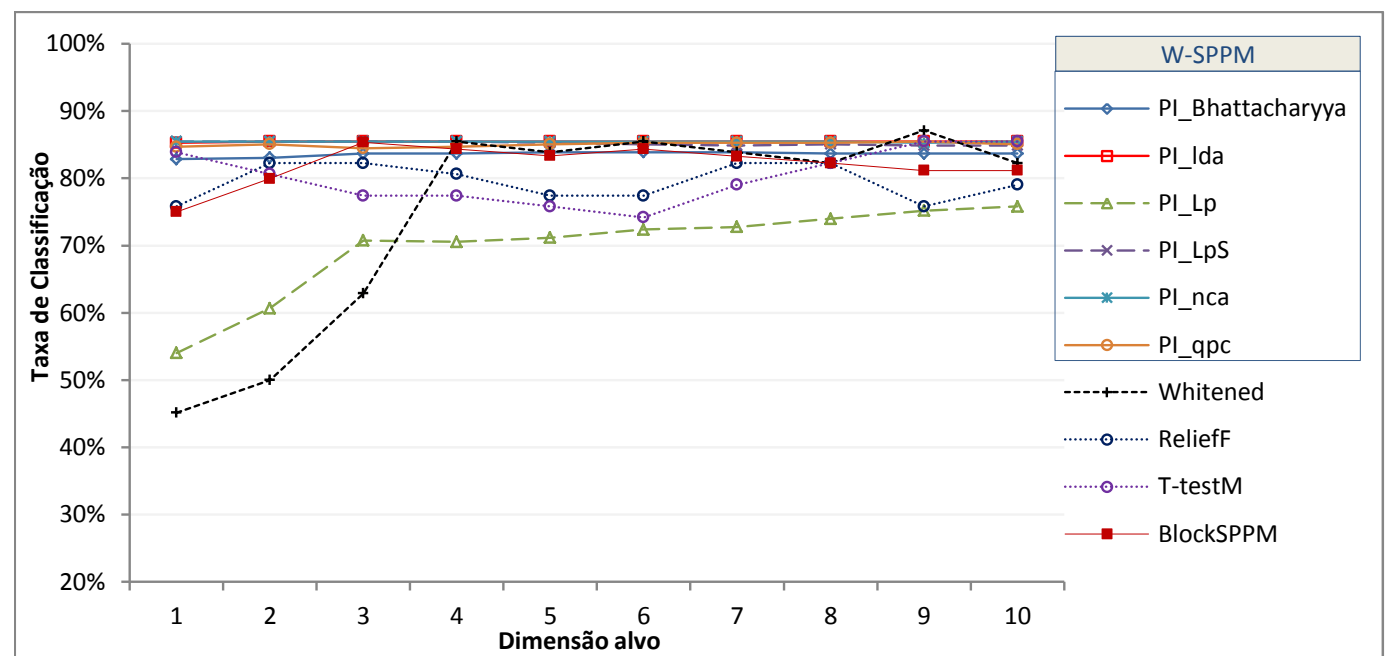

(a) Colon LDA

Figura 5.15: Comparação de acurácias de classificação dos métodos Block-SPPM e W-SPPM sobre o banco Colon. A acurácia de Block-SPPM é estimada através de 4-folds CV, enquanto que a acurácia dos outros métodos é estimada com LOO.

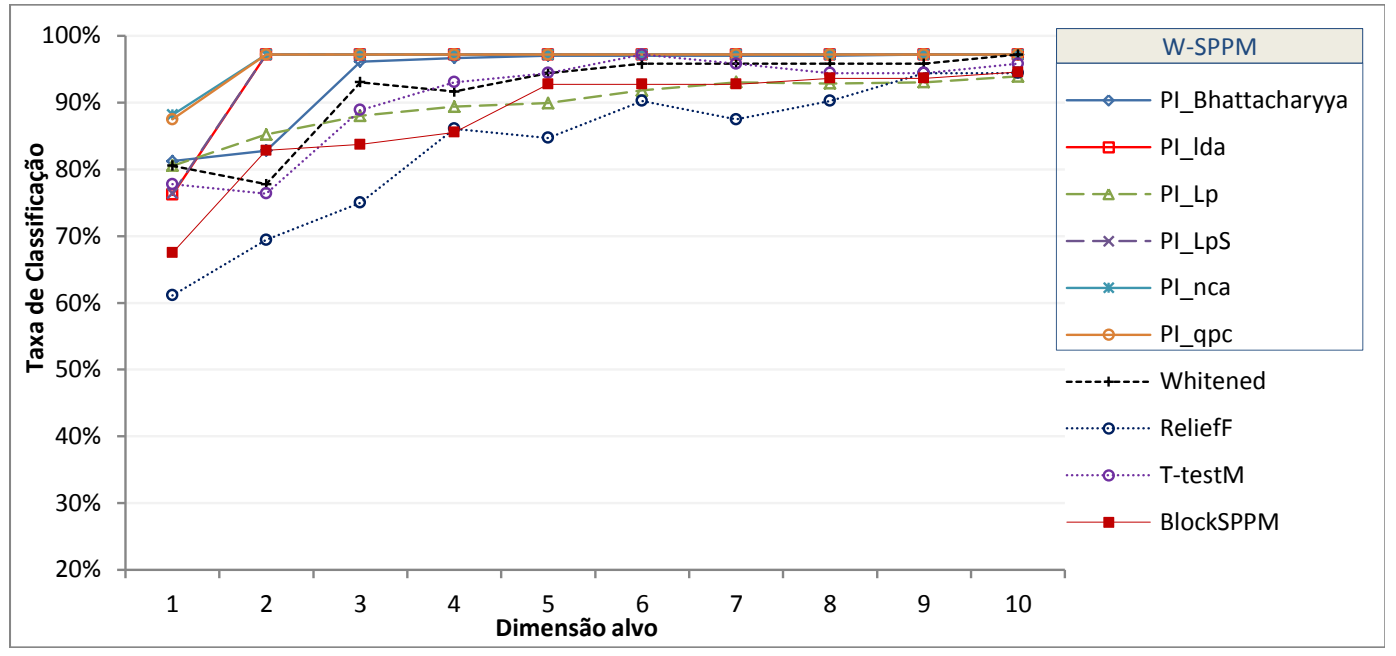

(a) MLL LDA

Figura 5.16: Comparação de acurácias de classificação dos métodos Block-SPPM e W-SPPM sobre o banco MLL. A acurácia de Block-SPPM é estimada através de 4-folds CV, enquanto que a acurácia dos outros métodos é estimada com LOO. 


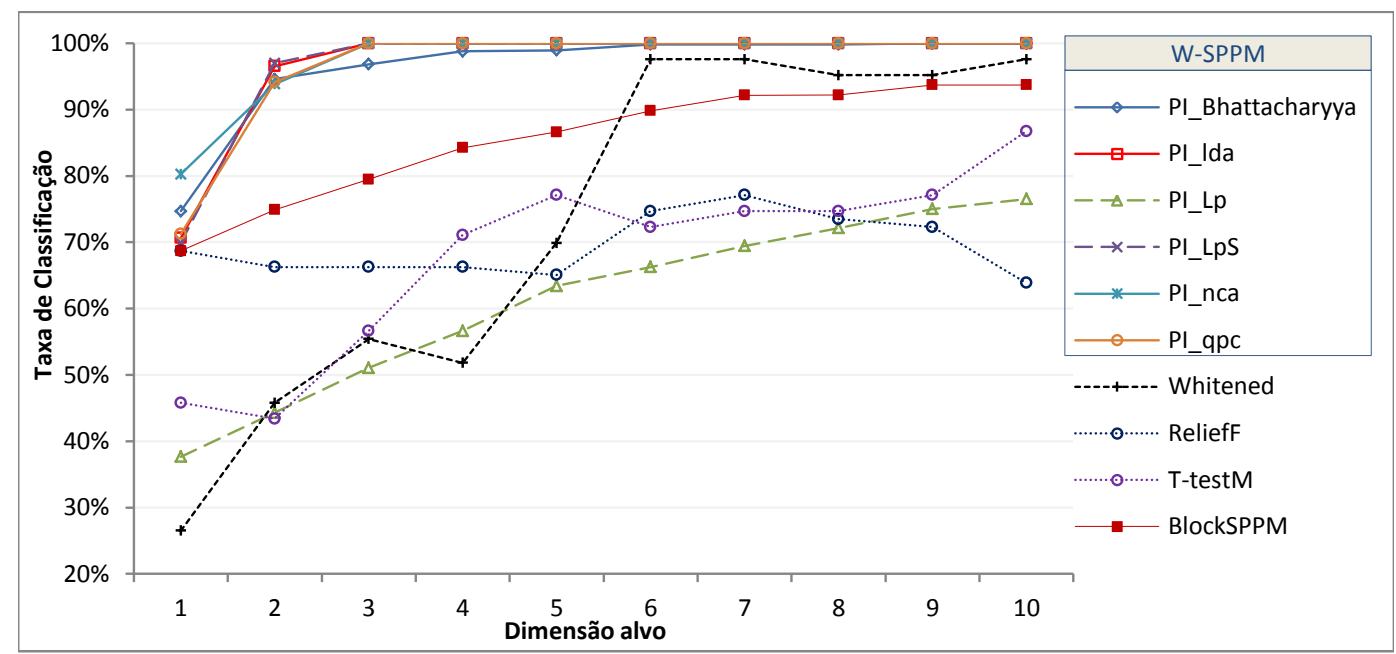

(a) SRBCT LDA

Figura 5.17: Comparação de acurácias de classificação dos métodos Block-SPPM e W-SPPM sobre o banco SRBC. A acurácia de Block-SPPM é estimada através de 4-folds CV, enquanto que a acurácia dos outros métodos é estimada com LOO.

com as comparações de acurácia sugerem que W-SPPM é uma melhor estratégia para reduzir a dimensão de dados de elevada dimensão e poucas amostras, já que tende a encontrar espaços mais discriminantes em menores tempos de processamento.

\subsection{Melhoramento do tempo de processamento de W-SPPM}

Nesta seção testa-se uma forma de melhorar ainda mais os tempos de processamento de WSPPM, a qual consiste em fornecer uma população inicial mais elaborada para PPGA do que uma simples população aleatória. A forma de obter esta população inicial é usando o recente método Candidate Projection Set (CPS) (Anexo B 4) (Su et al., 2011), o qual obtém vetores de projeção candidatos usando as informações de fronteiras entre classes. Para estimar quanto do tempo de processamento e a acurácia pode ser influenciada com a introdução desta população inicial, foram repetidos os mesmos experimentos de avaliação de W-SPPM (Seção 5.4), mas usando uma população inicial $W$ com 50\% de indivíduos gerados pelo método CPS e o restante de indivíduos gerados aleatoriamente (isto para garantir a diversidade da população). A Tabela 5.2 mostra para cada banco de dados o resultado médio (sobre 8 repetições) da razão entre o tempo de processamento usando população inicial com indivíduos CPS e o tempo de processamento sem usar CPS para obter 10 dimensões alvo com os diversos índices estudados. Da mesma forma, a Tabela 5.3 mostra a razão das acurácias com CPS e sem CPS com 10 
dimensões alvo encontradas pelos diversos índices com o classificador LDA. Observa-se uma diminuição geral do tempo de processamento na maioria de bancos de dados e índices de projeção. No entanto, a diminuição dos tempos de processamento é mais sensível em alguns índices. Por exemplo, PI_lda e PI_qpc diminuem quase à metade do tempo de processamento com população inicial CPS. Já o índice PI_Lp não apresenta quase melhoria do tempo, provavelmente porque CPS (destinada para dados rotulados) não dá nenhuma informação de relevância para esse índice não supervisionado.

Em relação às proporções de acurácia, não é evidenciada nenhuma alteração relevante das qualidades das projeções em todos os índices e bancos de dados testados (os valores estão bem próximos a 1). Isto indica que CPS é útil em acelerar a busca das projeções mas não oferece ajuda em aprofundar a busca, ou possivelmente PPGA esteja encontrando soluções próximas ao ótimo global.

Tabela 5.2: Resultados médios de W-SPPM para a razão: $\frac{t e m p o \_c o m \_C P S}{\text { tempo_sem_CPS }}$ para obter 10 dimensões alvo.

\begin{tabular}{|l|c|c|c|c|c|c|}
\hline Base de dados & PI_Bhatta & PI_lda & PI_Lp & PI_LpS & PI_nca & PI_qpc \\
\hline \hline Brain Tumor 1 & 0.73 & 0.36 & 1.08 & 0.77 & 0.84 & 0.60 \\
\hline Brain Tumor 2 & 0.81 & 0.42 & 1.12 & 0.98 & 0.79 & 0.64 \\
\hline Colon & 1.00 & 0.99 & 1.12 & 1.05 & 1.30 & 1.02 \\
\hline DLBCL & 0.99 & 0.97 & 1.15 & 1.07 & 1.19 & 1.02 \\
\hline MLL & 0.82 & 0.44 & 1.05 & 1.02 & 0.95 & 0.54 \\
\hline Prostate Tumor & 0.80 & 0.46 & 0.93 & 0.82 & 0.63 & 0.61 \\
\hline SRBCT & 0.72 & 0.34 & 1.05 & 0.86 & 0.83 & 0.57 \\
\hline TBC & 0.64 & 0.46 & 0.78 & 0.68 & 0.38 & 0.37 \\
\hline \hline Média $\pm \sigma$ & $\mathbf{0 . 8 2} \pm \mathbf{0 . 0 1}$ & $\mathbf{0 . 5 6} \pm \mathbf{0 . 0 7}$ & $\mathbf{1 . 0 3} \pm \mathbf{0 . 0 1}$ & $\mathbf{0 . 9 0} \pm \mathbf{0 . 0 2}$ & $\mathbf{0 . 8 6} \pm \mathbf{0 . 0 8}$ & $\mathbf{0 . 6 7} \pm \mathbf{0 . 0 5}$ \\
\hline
\end{tabular}

Tabela 5.3: Resultados médios de W-SPPM para a razão: $\frac{\text { acurácia_com_CPS }}{\text { acurácia_sem_CPS }}$ para obter 10 dimensões alvo e classificação LDA.

\begin{tabular}{|l|c|c|c|c|c|c|}
\hline Base de dados & PI_Bhatta & PI_lda & PI_Lp & PI_LpS & PI_nca & PI_qpc \\
\hline \hline Brain Tumorl & 0.98 & 1.00 & 1.00 & 1.00 & 0.99 & 1.01 \\
\hline Brain Tumor 2 & 0.96 & 1.00 & 1.03 & 0.98 & 0.99 & 0.98 \\
\hline Colon & 1.00 & 1.00 & 0.99 & 1.00 & 1.00 & 1.00 \\
\hline DLBCL & 1.00 & 1.00 & 1.03 & 1.00 & 1.00 & 1.01 \\
\hline MLL & 1.00 & 1.00 & 0.94 & 1.00 & 1.00 & 1.01 \\
\hline Prostate Tumor & 1.00 & 1.00 & 1.00 & 1.00 & 1.00 & 1.00 \\
\hline SRBCT & 0.99 & 1.00 & 0.95 & 1.00 & 1.00 & 1.00 \\
\hline TBC & 1.01 & 1.00 & 0.97 & 0.97 & 1.00 & 1.00 \\
\hline \hline Média $\pm \sigma$ & $\mathbf{0 . 9 9}$ & $\mathbf{1 . 0 0}$ & $\mathbf{0 . 9 9} \pm \mathbf{0 . 0 1}$ & $\mathbf{1 . 0 0}$ & $\mathbf{1 . 0 0}$ & $\mathbf{1 . 0 0}$ \\
\hline
\end{tabular}




\section{Capítulo 6}

\section{Conclusões}

A técnica de busca de projeções PP tem-se mostrado promissora em contornar o fenômeno da maldição da dimensionalidade. No entanto, sua aplicação em dados de muito alta dimensão e poucas amostras, como os gerados pela tecnologia de microarranjo, tem sido limitada pelas elevadas dificuldades computacionais em encontrar espaços de projeção ótimos. Neste trabalho foram propostas duas estratégias a fim de viabilizar a aplicação de PP na redução dimensional de dados de muito alta dimensão e poucas amostras e assim facilitar sua posterior classificação, o Block-SPPM e o W-SPPM.

Primeiramente, desenvolveu-se SPPM, uma melhora do método SPP para busca sequencial de bases de projeção, a qual constitui a base das estratégias propostas. Entre as melhoras implementadas está PPGA, um otimizador mais especializado para a busca de projeções que baseou a escolha do seu operador de cruzamento num estudo experimental de vários operadores de cruzamento: três disponíveis na literatura (cruzamento aritmético, cruzamento de um-ponto e cruzamento multiponto) e cinco novos operadores propostos neste trabalho (uma extensão do cruzamento aritmético, dois cruzamentos hiper-cônicos e dois tipos de cruzamentos guiados pela aptidão). A avaliação realizada sobre cinco conjuntos de dados públicos de variada dimensionalidade mostraram que um dos operadores hiper-cônicos propostos (CX6) tende a encontrar projeções com maior qualidade que os outros operadores, destacando-se claramente em altas dimensões. Tal comportamento foi observado tanto na população convergida quanto em diferentes estágios de evolução. O clássico operador multiponto mostrou ser também competitivo em baixas dimensões, mas mostrou uma diminuição do seu desempenho com o aumento da dimensionalidade. Os operadores baseados em recombinação aritmética mostraram um baixo desempenho, especialmente quando a dimensão é aumentada, fato que pode ser 
explicado por terem um espaço de busca muito restritivo.

Com os resultados da avaliação de desempenho dos operadores de cruzamento, foi possível ter um critério para escolher o operador mais adequado para PPGA. Em uma subsequente avaliação, foi verificado que PPGA (com o operador de cruzamento hiper-cônico CX6) consegue encontrar bases de projeção que são estatisticamente melhores (em valor de índice) em relação a bases geradas por dois otimizadores do estado da arte (RSSA e PSO) e usando similares quantidades de computação (numero de avaliações da função índice).

A primeira estratégia proposta de redução dimensional de dados de elevada dimensionalidade, Block-SPPM, foi avaliada enquanto a sua capacidade de facilitar a classificação de dados de dois métodos tradicionais de classificação: LDA e KNN. Os resultados em três bancos públicos de microarranjo mostraram que a acurácia preditiva de classificação (obtida com validação cruzada) de Block-SPPM é frequentemente superior a sete outras metodologias de redução dimensional do estado da arte. Foi notável a estabilidade apresentada por Block-SPPM em relação às outras abordagens, mostrando capturar em cada dimensão de projeção um aspecto complementário que facilita a discriminação das classes. No entanto, o custo computacional de Block-SPPM foi encontrado sendo uns dos maiores entre os métodos avaliados.

A segunda estratégia proposta de redução dimensional de dados alto-dimensionais, WSPPM, foi também avaliada enquanto a sua capacidade de produzir espaços de projeção que facilitem a classificação de LDA e KNN. A avaliação incluiu vários índices de projeção para W-SPPM e métodos de referência como T-TestM, ReliefF e a tradicional transformação de branqueamento. Os resultados em oito bancos públicos de microarranjo mostraram que WSPPM com quatro índices de projeção (PI_lda, PI_LpS, PI_nca PI_qpc) obtêm os maiores e estatisticamente indistinguíveis valores de acurácia de classificação LOO no classificador LDA em relação aos outros métodos. Já no classificador KNN, tais resultados foram observados com os índices PI_lda e PI_LpS. Um ponto interessante observado com esses índices é que eles superam a acurácia preditiva obtida isoladamente com a transformação de branqueamento, especialmente em dimensões alvo baixas, o qual confirma as considerações de W-SPPM em que o branqueamento é útil em compactar informação relevante dos dados originais, mas que se precisa de uma adequada abordagem de PP para transferir essa informação a um espaço alvo de baixa dimensão, tal como o método SPPM. O custo computacional de W-SPPM foi encontrado sendo relativamente pequeno, especialmente com os índices PI_lda e PI_qpc onde o tempo médio para conseguir dez dimensões alvo está na ordem de alguns segundos em um 
computador PC padrão.

Dos resultados das avaliações experimentais concluem-se que as duas estratégias propostas para redução dimensional de dados de muito alta dimensão conseguem facilitar a busca de projeções relevantes para classificação. No entanto, W-SPPM mostrou-se mais adequada para tal propósito, já que ela induz acurácias de classificação mais elevadas em espaços de projeção de menor dimensão e ao mesmo tempo mostra tempos computacionais marginais (na ordem dos segundos) quando comparados aos tempos de Block-SPPM (na ordem das horas).

\subsection{Trabalhos futuros}

O presente trabalho estudou seis índices de projeção, um deles (PI_LpS) proposto como uma extensão supervisionada de um índice existente não supervisionado. Tal extensão, além de simples, mostrou ser bastante efetiva enquanto a sua capacidade de induzir espaços altamente discriminativos. Nesse sentido, uma interessante linha de pesquisa seria explorar mais possibilidades de tornar "supervisionados"vários outros índices existentes descritos para análise de agrupamentos e detecção de outliers (exemplos: Holes, Entropia, etc.). Também poderia se investigar possibilidades de produzir novos índices como combinações de índices existentes, tal como proposto por Rodriguez-Martinez et al. (2010).

A avaliação experimental do presente trabalho foi realizada usando bancos de dados de expressão gênica. Apesar de que tal experimentação permitiu ter uma ideia do comportamento relativo dos métodos em cenários reais, um ponto interessante a pesquisar seria realizar uma experimentação com bancos gerados artificialmente, nos quais se varie de forma controlada a razão entre o número de atributos e o número de amostras. Isto permitiria ter uma percepção mais afinada dos limites dos diversos métodos em relação a dito ratio, o qual permitiria inferir o desempenho dos métodos em domínios variados.

Outra questão interessante que poderia ser pesquisada é buscar novas estratégias de compactação para W-SPPM, além do branqueamento. Poderia se investigar, por exemplo, o uso de PCA, PCA não linear, wavelets, entre outros, e ver se eles conseguem superar o desempenho da transformação de branqueamento.

Uma outra sugestão de trabalho futuro seria na formação de comitês de redutores dimensionais para classificação. Uma alternativa seria usar W-SPPM com vários índices para produzir diversos espaços de classificação, os quais integrariam o comitê. A hipótese é que a acurácia de 
classificação poderia melhorar, dada a diversidade dos espaços de classificação que capturam diferentes definições de "informação relevante"dos índices.

\subsection{Produção bibliográfica}

As seguintes publicações foram conseguidas como decorrência das pesquisas desenvolvidas no presente projeto de doutorado:

- Título: On the Crossover Operator for GA-based Optimizers in Sequential Projection Pursuit. Este artigo foi publicado nos proceedings do International Conference on Pattern Recognition Applications and Methods - ICPRAM 2012 (Espezua et al., 2012). O artigo propõe vários operadores de cruzamento descritos nesta tese para SPP.

- Título: Towards an efficient genetic algorithm optimizer for sequential projection pursuit. Este artigo está no prelo da revista Neurocomputing (Espezua et al., 2013). O artigo apresenta um estudo estendido do trabalho anterior sobre operadores de cruzamento para PPGA e também compara esta contra outras abordagens de otimização de SPP.

- Título: A Projection Pursuit Framework for Supervised Dimensionality Reduction of High-Dimension Small-Sample Datasets. Este artigo foi submetido na revista Neurocomputing e está na etapa de revisão. O artigo apresenta W-SPPM e um estudo com diversos índices de projeção sobre esse método. 


\section{APÊNDICE A:}

\section{Obtenção de dados de}

\section{microarranjo}

Um dos objetivos fundamentais em biologia molecular é compreender as complexas relações que governam a atividade dos genes e proteínas e suas consequências no funcionamento celular e extracelular (Hoheisel, 2006). O desenvolvimento das tecnologias de microarranjo (Russell et al., 2008; Stekel, 2003) (do inglês microarray) tem trazido grandes possibilidades para atingir esses objetivos.

Os microarranjos (também denominados DNA-chips) consistem de um arranjo pré-definido de diminutos pontos (spots) contendo moléculas de DNA (fragmentos de DNA genômico, cDNAs (DNA complementar) ou oligonucleotídeos) (Russell et al., 2008) que estão quimicamente ligadas à uma superfície sólida, usualmente membranas de nylon ou lâminas de vidrio ou silício revestidas com compostos que conferem carga elétrica positiva (dado que as moléculas de DNA possuem carga elétrica negativa conferida por seu arcabouço açúcar-fosfato) (Stekel, 2003). Em cada spot são colocadas moléculas de teste (chamadas de sondas) de um determinado transcrito (moléculas RNA mensageiras produzidas pela transcrição de um gene) que podem posteriormente ser identificadas. O princípio da técnica baseia-se na hibridização por complementaridade de bases de ácido nucleico, que ocorre entre a sonda fixada na lâmina e seu RNAm correspondente, transformado em cDNA, extraído das amostras a serem analisadas (Stekel, 2003). Antes de realizar o processo de hibridação as amostras são 'marcadas' com químicos fluorescentes (como por exemplo os fluorocromos cianina 3 (Cy3) e cianina 5 (Cy5) ou o isótopo 33-P), possibilitando assim a medida da abundância dos transcritos presentes na amostra. 
Após o processo de hibridação é gerada uma imagem da hibridação, a qual é obtida por meio de leitores (scanners) a laser (para os fluorocromos) ou leitores de fósforo (para o isótopo 33-P). A intensidade dos spots indica a quantidade relativa do transcrito e, portanto, o nível de expressão do respectivo gene. Normalmente, são empregadas técnicas de processamento de imagens e de normalização de dados após a obtenção da imagem, as quais buscam eliminar os efeitos de ruído e alguns outros problemas relativos à variabilidade experimental. No final, as intensidades medidas dos spots são transformadas em valores numéricos, gerando como resultado informações em formato matricial onde as colunas representam as amostras ou condições experimentais e as linhas representam os genes (Tarca et al., 2006).

Para a preparação dos microarranjos, utilizam-se robôs altamente precisos que aplicam as diferentes amostras de DNA nos diminutos spots. Quanto mais spots no microarranjo, mais abrangente ele será na análise do transcriptoma. Dados os constantes desenvolvimentos na robotização e miniaturização da tecnologia de microarranjo é possível a medição da expressão diferencial de milhares de genes (perfil transcriptômico) num único experimento (Tarca et al., 2006).

Os tipos de microarranjos mais difundidos são: os microarranjos de DNA complementar (Schena, 1999) e os microarranjos de oligonucleotídios (Lipshutz et al., 1999). A principal diferença entre eles é que no primeiro são utilizadas sequencias de DNAc (DNA complementar) previamente sintetizadas, compostas de algumas centenas de pares base; já no segundo são utilizadas pequenas cadeias de nucleotídeos (geralmente de 25 pares de bases), denominadas oligonucleotídios, as quais são sintetizadas diretamente nos spots do microarranjo usando técnicas baseadas na manufatura de circuitos integrados (Lodish et al., 2007).

Na Figura A.1 é ilustrado um experimento por microarranjo para geração de dados de expressão gênica, onde se compara os perfis transcriptômicos de duas amostras distintas, uma extraída de um tecido normal e outra extraída de um tecido com patologia. Inicialmente é isolado o RNAm das amostras coletadas. Em seguida, moléculas de DNAc ou oligonucleotídios são sintetizadas a partir do RNAm. Para distinguir as amostras, estas são rotuladas com tintas fluorescentes (incorporadas aos nucleotídeos) que são sensíveis à luz ou radiação. Os pigmentos Cy3 (verde) e Cy5 (vermelho) são comumente utilizados na coloração. Após a hibridação do microarranjo segue um processo de 'lavado', no qual são removidas as moléculas que não conseguiram-se ligar. Finalmente, segue o processo da 'leitura' do microarranjo, no qual é usado um scanner com um feixe de luz para iluminar os pontos da pastilha e medir a 
intensidade de fluorescência de cada pigmento hibridizado pela amostra e consequentemente a abundancia de ácidos nucleicos da amostra. É de prática comum usar o logaritmo (em base dois) da razão das intensidades de ambos os pigmentos (canais) para indicar as diferenças relativas de expressão entre ambas as amostras (Equação A.1):

$$
\text { nível_expressão }=\log _{2} \frac{\text { intensidade }(C y 5)}{\text { intensidade }(C y 3)}
$$

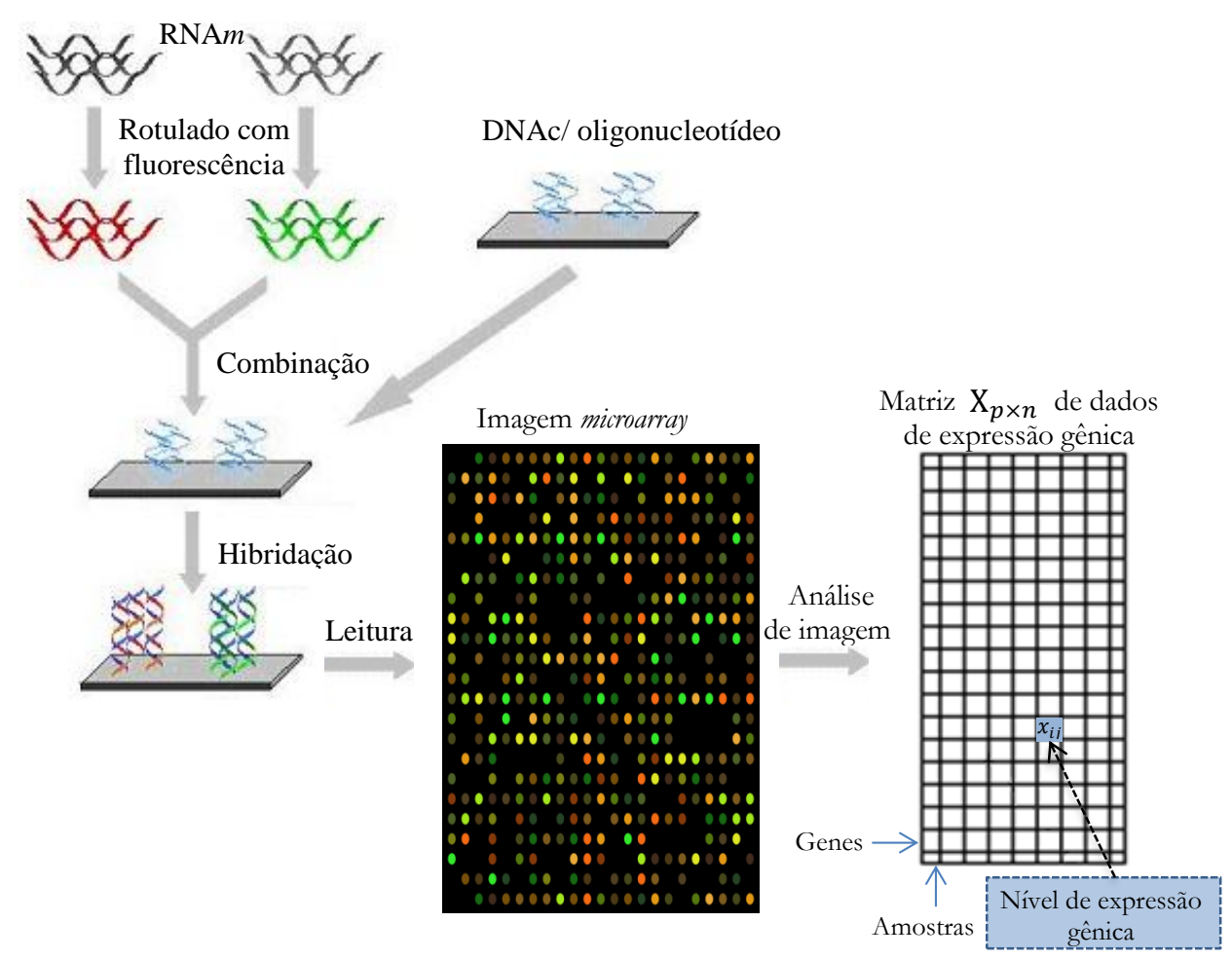

Figura A.1: Exemplo de geração de dados de expressão gênica $\left(X_{p \times n}\right)$ após uma análise de imagem, onde $x_{i ; j}$ é o valor de expressão gênica. Imagens adaptadas de (Harrington et al., 2000)

Os dados de expressão gênica apresentam algumas características que precisam ser consideradas em sua análise. Elas são as seguintes:

- quantidade de atributos (genes medidos) esta normalmente na ordem dos milhares, sobre passando largamente à quantidade de amostras que esta na ordem das dezenas ou centenas. Dados com essas característica recaem no problema conhecido em estatística como large p, small n (Cunningham, 2008); 
- natureza ruidosa dos dados, originada na aleatoriedade intrínseca dos processos biológicos e nas inevitáveis incertezas nas medições de larga escala, próprias da tecnologia de microarranjo (Tu et al., 2002); e

- complexidades das inter-relações gênicas, tendo-se atributos irrelevantes, atributos correlacionados (genes co-expressos) e atributos que mostram sua relevância na classificação somente em conjunto com outros atributos (Jaeger et al., 2003). 


\section{APÊNDICE B:}

\section{Algoritmo Candidate Projection}

\section{Set}

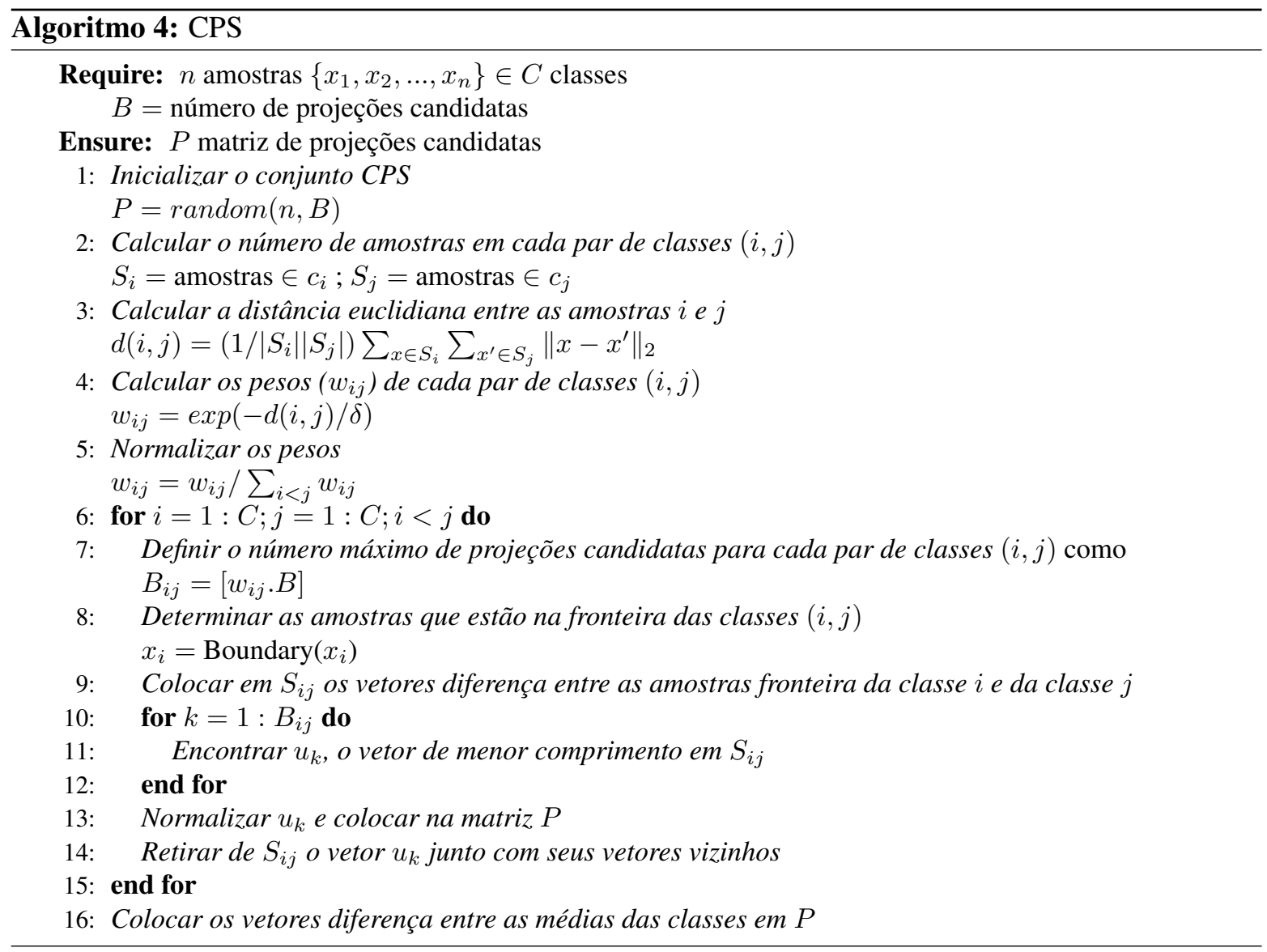




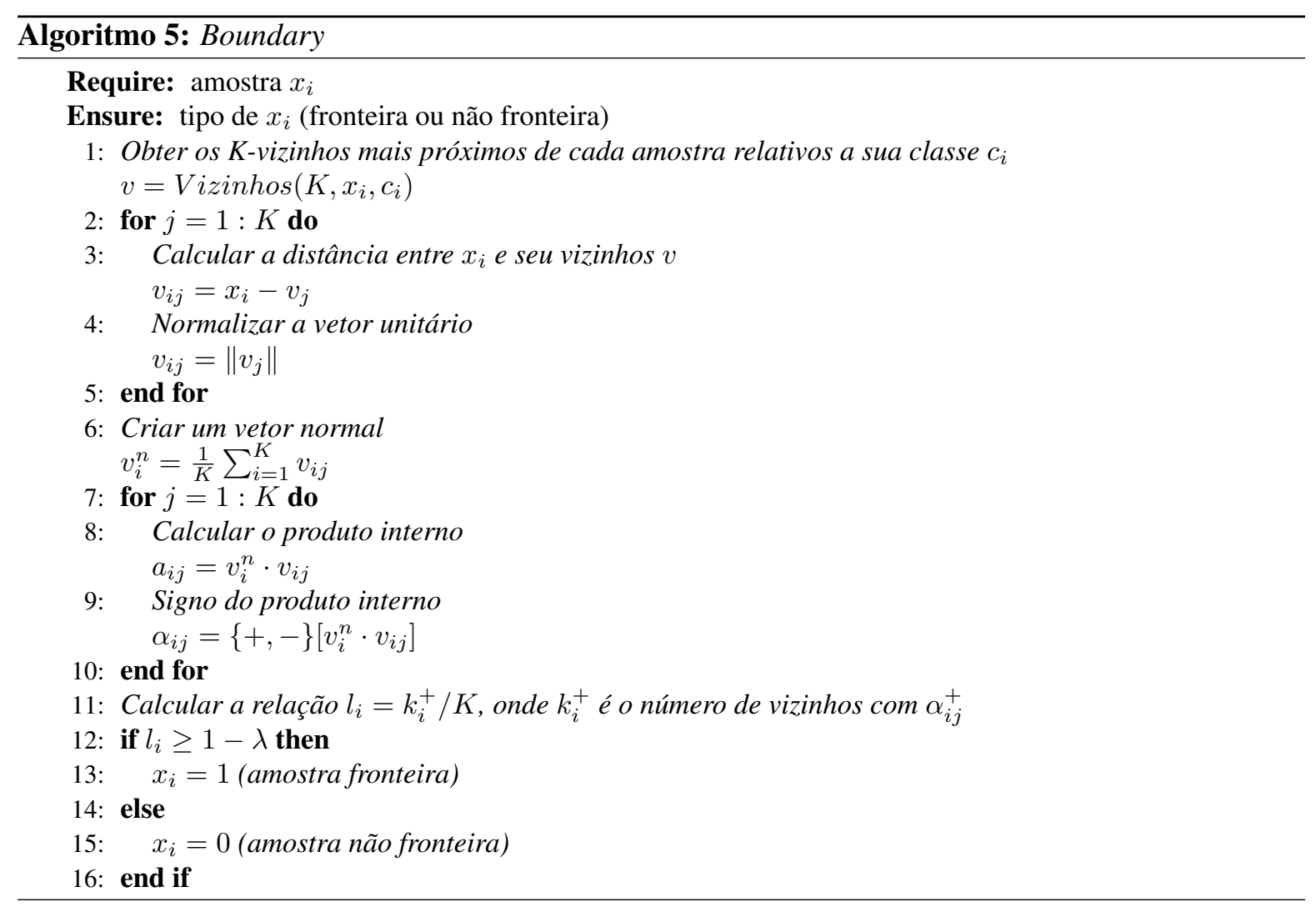




\section{Bibliografia}

Aladjem, M. (2005). Projection pursuit mixture density estimation. IEEE Transactions on Signal Processing, 53(11):4376-4383.

Alon, U., Barkai, N., Notterman, D. A., Gishdagger, K., Ybarradagger, S., Mackdagger, D., e Levine, A. J. (1999). Broad patterns of gene expression revealed by clustering analysis of tumor and normal colon tissues probed by oligonucleotide arrays. Proceedings of the National Academy of Sciences of the United States of America, 96(12):6745-6750.

Alter, O., Brown, P. O., e Botstein, D. (2000). Singular value decomposition for genome-wide expression data processing and modeling. Proceedings of the National Academy of Sciences, 97(18):10101-10106.

Alter, O., Brown, P. O., e Botstein, D. (2003). Generalized singular value decomposition for comparative analysis of genome-scale expression data sets of two different organisms. Proceeding of the National Academy of Sciences, 100(6):3351-3356.

Anton, H. e Busby., R. (2006). Algebra Linear Contemporanea. Bookman Companhia Ed.

Armstrong, S. A., Staunton, J. E., Silverman, L. B., Pieters, R., den Boer, M. L., Minden, M. D., Sallan, S. E., Lander, E. S., Golub, T. R., e Korsmeyer, S. J. (2002). MLL translocations specify a distinct gene expression profile that distinguishes a unique leukemia. Nature Genetics, 30:41-47.

Asuncion Vicente, M., Hoyer, P. O., e Hyvarinen, A. (2007). Equivalence of some common linear feature extraction techniques for appearance-based object recognition tasks. IEEE Transactions on Pattern Analysis and Machine Intelligence, 29(5):896-900.

Belkin, M. e Niyogi, P. (2002). Laplacian eigenmaps for dimensionality reduction and data representation. Neural Computation, 15:1373-1396. 
Berro, A., Marie-Sainte, S. L., e Ruiz-Gazen, A. (2010). Genetic algorithms and particle swarm optimization for exploratory projection pursuit. Annals of Mathematics and Artificial Intelligence, 60(1-2, SI):153-178.

Berry, M. P. R., Graham, C. M., McNab, F. W., Xu, Z., Bloch, S. A. A., Oni, T., Wilkinson, K. A., Banchereau, R., Skinner, J., Wilkinson, R. J., Quinn, C., Blankenship, D., Dhawan, R., Cush, J. J., Mejias, A., Ramilo, O., Kon, O. M., Pascual, V., Banchereau, J., Chaussabel, D., e O/'Garra, A. (2010). An interferon-inducible neutrophil-driven blood transcriptional signature in human tuberculosis. Nature, 466(7309):973-977.

Bishop, C. M. (2006). Pattern Recognition and Machine Learning (Information Science and Statistics). Springer-Verlag New York, Inc.

Bishop, C. M. e Williams, C. K. I. (1998). Gtm: The generative topographic mapping. Neural Computation, 10:215-234.

Biswas, S., Storey, J., e Akey, J. (2008). Mapping gene expression quantitative trait loci by singular value decomposition and independent component analysis. BMC Bioinformatics, $9(1): 244$

Bolton, R. e Krzanowski, W. (2003). Projection pursuit clustering for exploratory data analysis. Journal of Computational and Graphical Statistics, 12(1):121-142.

Borg, I. e Groenen, P. (2005). Modern Multidimensional Scaling: Theory and Applications. Springer Press, second ed.

Brazdil, P. B., Soares, C., e Da Costa, J. P. (2003). Ranking learning algorithms: Using ibl and meta-learning on accuracy and time results. Machine Learnig, 50(3):251-277.

Burges, C. J. C. (2010). Dimension Reduction: A Guided Tour. Foundations and Trends in Machine Learning, 2(4).

Carreira-Perpiñán, M. A. (2001). Continuous latent variable models for dimensionality reduction and sequential data reconstruction. Tese de Doutorado, University of Sheffeld.

Cheng, M., Fang, B., Pun, C.-M., e Yan Tang, Y. (2011). Letters: Kernel-view based discriminant approach for embedded feature extraction in high-dimensional space. Neurocomputing, 74(9):1478-1484. 
Chiang, S.-S., Chang, C.-I., e Ginsberg, I. (2001). Unsupervised target detection in hyperspectral images using projection pursuit. IEEE Transactions on Geoscience and Remote Sensing, 39(7):1380-1391.

Chuang, L.-Y., Yang, C.-H., Wu, K.-C., e Yang, C.-H. (2011). A hybrid feature selection method for DNA microarray data. Computers in Biology and Medicine, 41(4):228-237.

Clarke, R., Ressom, H. W., Wang, A., Xuan, J., Liu, M. C., Gehan, E. A., e Wang, Y. (2008). The properties of high-dimensional data spaces: implications for exploring gene and protein expression data. Nature Reviews Cancer, 8(1):37-49.

Cook, D., Buja, A., e Cabrera, J. (1993). Projection pursuit indexes based on orthonormal function expansions. Journal of Computational and Graphical Statistics, 2(3):225-250.

Cook, D., Lee, E.-K., Buja, A., e Wickham, H. (2008). Grand tours, projection pursuit guided tours and manual controls. In Chen, Chunhouh, Härdle, Wolfgang, Unwin, e Antony (Eds.), Handbook of Data Visualization, Springer Handbooks of Computational Statistics, chapter III.2, p. 295-314. Springer.

Cook, D. e Swayne, D. F. (2007). Interactive and Dynamic Graphics for Data Analysis: With $R$ and GGobi. Springer.

Crawford, S. L. (1991). Genetic Optimization for Exploratory Projection Pursuit. In Keramidas, EM (Ed.), Computing Science And Statistics, pp. 318-321. Interface Foundation North America.

Cui, X., Jin Xu, Asghar, R., Condamine, P., Svensson, J. T., Wanamaker, S., Stein, N., Roose, i., e Close, T. J. (2005). Detecting single-feature polymorphisms using oligonucleotide arrays and robustified projection pursuit. Bioinformatics, 21(20):3852-3858.

Cunningham, P. (2007). Dimension reduction. Technical report.

Cunningham, P. (2008). Dimension reduction. In Cord, M. e Cunningham, P. (Eds.), Machine Learning Techniques for Multimedia, Cognitive Technologies, pp. 91-112. Springer Berlin Heidelberg.

Dai, J. J., Lieu, L., e Rocke, D. (2006). Dimension reduction for classification with gene expression microarray data. Statistical Applications in Genetics and Molecular Biology, 5. 
Dash, M. e Liu, H. (1997). Feature selection for classification. Intelligent Data Analysis, $1: 131-156$.

Dash, M. e Liu, H. (2003). Consistency-based search in feature selection. Artificial Intelligent, 151(1-2):155-176.

Daszykowski, M., Kaczmarek, K., Heyden, Y. V., e Walczak, B. (2007). Robust statistics in data analysis - a review: Basic concepts. Chemometrics and Intelligent Laboratory Systems, 85(2):203- 219 .

Dayal, M. (2011). A new algorithm for exploratory projection pursuit. arXiv/1112.4321.

de Morais, S. R. e Aussem, A. (2010). A novel Markov boundary based feature subset selection algorithm. Neurocomputing, 73(4-6, SI):578-584. 4th French-Speaking Symposium on Bayesian Networks, Lyon, FRANCE, 2008.

Debnath, R. e Kurita, T. (2010). An evolutionary approach for gene selection and classification of microarray data based on SVM error-bound theories. Biosystems, 100(1):39-46.

Demartines, P. e Herault, J. (1997). Curvilinear component analysis: A self-organizing neural network for nonlinear mapping of data sets. IEEE Transactions on Neural Networks, 8(1):148-154.

Demirci, O., Clark, V. P., e Calhoun, V. D. (2008). A projection pursuit algorithm to classify individuals using fMRI data: Application to schizophrenia. Neuroimage, 39(4):1774-1782.

Demmel, J. W. (1997). Applied numerical linear algebra. SIAM Press.

Deng, W., Liu, Y., Hu, J., e Guo, J. (2012). The small sample size problem of ica: A comparative study and analysis. Pattern Recognition, 45(12):4438-4450.

DiPietroPaolo, D., Müller, H.-P., Nolte, G., e Erné, S. N. (2006). Noise reduction in magnetocardiography by singular value decomposition and independent component analysis. Medical and Biological Engineering and Computing, 44(6):489-499.

Duda, R. O., Hart, P. E., e Stork, D. G. (2001). Pattern Classification. A Wiley-Interscience, second ed.

Dudoit, S., Fridlyand, J., e Speed, T. P. (2002). Comparison of discrimination methods for the classification of tumors using gene expression data. Journal of the American Statistical Association, 97(457):77-87. 
Espezua, S., Villanueva, E., e Maciel, C. D. (2012). On the crossover operator for ga-based optimizers in sequential projection pursuit. In $\operatorname{ICPRAM}(1)$, pp. 93-102.

Espezua, S., Villanueva, E., e Maciel, C. D. (2013). Towards an efficient genetic algorithm optimizer for sequential projection pursuit. Neurocomputing.

Fodor, I. (2002). A survey of dimension reduction techniques. Technical report, U.S. Departament of Energy.

Frank, A. e Asuncion, A. (2010). UCI machine learning repository.

Friedman, J., Stuetzle, W., e Schroeder, A. (1984). Projection Pursuit Density-Estimation. Journal of the American Statistical Association, 79(387):599-608.

Friedman, J. H. (1987). Exploratory projection pursuit. American Statistical Association, 82(397):249-266.

Friedman, J. H. e Stuetzle, W. (1981). Projection pursuit regression. Journal of the American Statistical Association, 76:817-823.

Friedman, J. H. e Tukey, J. W. (1974). A projection pursuit algorithm for exploratory data analysis. IEEE Transaction on Computers, 23(9):881-890.

Garcia-Nieto, J. e Alba, E. (2012). Parallel multi-swarm optimizer for gene selection in DNA microarrays. Applied Intelligence, 37(2):255-266.

Globerson, A. e Roweis, S. (2006). Metric learning by collapsing classes. In Weiss, Y., Schölkopf, B., e Platt, J. (Eds.), Advances in Neural Information Processing Systems 18, pp. 451458. MIT Press.

Goldberg, D. E. (1989). Genetic Algorithms in Search, Optimization and Machine Learning. Addison-Wesley Longman Publishing.

Goldberger, J., Roweis, S., Hinton, G., e Salakhutdinov, R. (2005). Neighbourhood components analysis. Advances in Neural Information Processing Systems, 17:513-520.

Golub, T. R., Slonim, D. K., Tamayo, P., Huard, C., Gaasenbeek, M., Mesirov, J. P., Coller, H., Loh, M. L., Downing, J. R., Caligiuri, M. A., Bloomfield, C. D., e Lander, E. S. (1999). Molecular classification of cancer: Class discovery and class prediction by gene expression monitoring. Science, 286:531-537. 
Grochowski, M. e Duch, W. (2008). Projection pursuit constructive neural networks based on quality of projected clusters. In Kurkova, V and Neruda, R and Koutnik, J (Ed.), Artificial Neural Networks - ICANN 2008, PT II, vol. 5164 of Lecture Notes In Computer Science, pp. $754-762$.

Grochowski, M. e Duch, W. (2011). Fast projection pursuit based on quality of projected clusters. In Dobnikar, A., Lotric, U., e Ster, B. (Eds.), Adaptive and Natural Computing Algorithms, vol. 6594 of Lecture Notes in Computer Science, pp. 89-97. Springer Berlin / Heidelberg.

Guo, Q., Wu, W., Massart, D., Boucon, C., e de Jong, S. (2001). Feature selection in sequential projection pursuit. Analytica Chimica Acta, 446(1-2):85-96.

Guo, Q., Wu, W., Questier, F., Massart, D., Boucon, C., e de Jong, S. (2000). Sequential projection pursuit using genetic algorithms for data mining of analytical data. Analytical Chemestry, 72(13):2846-2855.

Guyon, I., Gunn, S., Nikravesh, M., e Zadeh, L. (Eds.) (2006). Feature Extraction, Foundations and Applications. Springer.

Hall, M. (1999). Correlation-based Feature Selection for Machine Learning. Tese de Doutorado, University of Waikato.

Hall, M. A. (2000). Correlation-based Feature Selection for Discrete and Numeric Class Machine Learning. In ICML '00: Proceedings of the Seventeenth International Conference on Machine Learning, pp. 359-366. Morgan Kaufmann Publishers Inc.

Hall, P. (1989). On Projection Pursuit Regression. Annals of Statistics, 17(2):573-588.

Han, B., Park, M., e Chen, X.-w. (2010). A Markov blanket-based method for detecting causal SNPs in GWAS. BMC BIOINFORMATICS, 11(3). IEEE International Conference on Bioinformatics and Biomedicine (BIBMW 2009), Washington, DC, NOV 01-04, 2009.

Harrington, C. A., Rosenow, C., e Retief, J. (2000). Monitoring gene expression using dna microarrays. Current Opinion in Microbiology, 3:285-291.

He, X., Yan, S., Hu, Y., Niyogi, P., e jiang Zhang, H. (2005). Face recognition using laplacianfaces. IEEE Transactions on Pattern Analysis and Machine Intelligence, 27:328-340. 
Hoheisel, J. D. (2006). Microarray technology: beyond transcript profiling and genotype analysis. Nature Reviews Genetics, 7(3):200-210.

Huang, H. e Feng, H. (2012). Gene classification using parameter-free semi-supervised manifold learning. IEEE/ACM Transactions on Computational Biology and Bioinformatics, 9:818-827.

Huang, W. e Zhang, X. (2011). Projection pursuit flood disaster classification assessment method based on multi-swarm cooperative particle swarm optimization. Journal of Water Resource and Protection, 3(6):415-420.

Huber, P. J. (1985). Projection pursuit. Annals of Statistics, 13(2):435-475.

Jaeger, J., Sengupta, R., e Ruzzo, W. L. (2003). Improved gene selection for classification of microarrays. In Proceedings of the Pac Symp Biocomput. 2003, pp. 53-64.

Jee, J. R. (2009). Projection pursuit. Wiley Interdisciplinary Reviews: Computational Statistics, 1(2):208-215.

Jimenez, L. e Landgrebe, D. (1999). Hyperspectral data analysis and supervised feature reduction via projection pursuit. IEEE Transactions on Geoscience and Remote Sensing, 37(6):2653-2667.

Jin, J., Zhang, Y., e Zhang, L. (2003). Flood disaster loss evaluating model based on projection pursuit. Flood Disaster Loss Evaluation, 1(2):82-85.

Johnstone, I. M. e Titterington, D. M. (2009). Statistical challenges of high-dimensional data INTRODUCTION. Philosophical Transactions of the Royal Society A-Mathematical Physical and Engineering Sciences, 367(1906):4237-4253.

Jones, M. C. e Sibson, R. (1987). What is projection pursuit? Journal of the Royal Statistical Society. Series A (General), 150(1):pp. 1-37.

Khan, J., Wei, J. S., Ringner, M., Saal, L. H., Ladanyi, M., Westermann, F., Berthold, F., Schwab, M., Antonescu, C. R., Peterson, C., e Meltzer, P. S. (2001). Classification and diagnostic prediction of cancers using gene expression profiling and artificial neural networks. Nature Medicine, 7(6):673-679. 
Khandelwal, A., Choudhury, P., Sarkar, R., Basu, S., Nasipuri, M., e Das, N. (2009). Text line segmentation for unconstrained handwritten document images using neighborhood connected component analysis. In Proceedings of the 3rd International Conference on Pattern Recognition and Machine Intelligence, PREMI 2009, pp. 369-374. Springer-Verlag.

Kohonen, T., Schroeder, M. R., e Huang, T. S. (Eds.) (2001). Self-Organizing Maps. SpringerVerlag New York, Inc., 3rd ed.

Kononenko, I. (1994). Estimating attributes: Analysis and extensions of relief. In Bergadano, F. e Raedt, L. D. (Eds.), European Conference on Machine Learning, pp. 171-182. Springer.

Kononenko, I. e Kukar, M. (2007). Machine Learning and Data Mining: Introduction to Principles and Algorithms. Horwood Publishing Limited.

Korn, F., Pagel, B., e Faloutsos, C. (2001). On the "dimensionality curse" and the "selfsimilarity blessing”. IEEE Transactions on Knowledge and Data Engineering, 13(1):96111.

Kruskal, J. (1969). Toward a practical method which helps uncover the structure of a set of multivariate observations by finding the linear transformation which optimizes a new "index of condensation". Statistical Computation, pp. 427-440.

Kulkarni, A., Kumar, B. S. C. N., Ravi, V., e Murthy, U. S. (2011). Colon cancer prediction with genetics profiles using evolutionary techniques. Expert Systems with Applications, 38(3):2752-2757.

Lee, C.-P. e Leu, Y. (2011). A novel hybrid feature selection method for microarray data analysis. Applied Soft Computing, 11(1):208-213.

Lee, E., Cook, D., Klinke, S., e Lumley, T. (2005). Projection pursuit for exploratory supervised classification. Journal of Computational and Graphical Statistics, 14(4):831-846.

Lee, E.-K. e Cook, D. (2010). A projection pursuit index for large p small $\mathrm{n}$ data. Statistics and Computing, 20(3):381-392.

Lee, G., Rodriguez, C., e Madabhushi, A. (2008). Investigating the efficacy of nonlinear dimensionality reduction schemes in classifying gene and protein expression studies. IEEE/ACM Transactions on Computational Biology and Bioinformatics, 5:368-384. 
Lee, J. A., Lendasse, A., e Verleysen, M. (2004). Nonlinear projection with curvilinear distances: Isomap versus curvilinear distance analysis. Neurocomputing, 57:49-76.

Lee, J. A. e Verleysen, M. (2002). Nonlinear projection with the isotop method. In Dorronsoro, J. R. (Ed.), Artificial Neural Networks - ICANN 2002, International Conference, Madrid, Spain, August 28-30, 2002, Proceedings, vol. 2415 of Lecture Notes in Computer Science, pp. 933-938. Springer.

Lee, J. A. e Verleysen, M. (2007). Nonlinear Dimensionality Reduction. Springer.

Li, B., Zheng, C.-H., Huang, D.-S., Zhang, L., e Han, K. (2010). Gene expression data classification using locally linear discriminant embedding. Computers in Biology and Medicine, 40(10):802-810.

Lipshutz, R. J., Fodor, S. P., Gingeras, T. R., e Lockhart, D. J. (1999). High density synthetic oligonucleotide arrays. Nature Genetics, 21:20-24.

Liu, C. e Wechsler, H. (2000). Evolutionary pursuit and its application to face recognition. IEEE Trans. Pattern Anal. Mach. Intell., 22(6):570-582.

Liu, H., Liu, L., e Zhang, H. (2010). Ensemble gene selection by grouping for microarray data classification. Journal of Biomedical Informatics, 43(1):81-87.

Liu, H. e Motoda, H. (1998). Feature Extraction, Construction and Selection: A Data Mining Perspective. Kluwer Academic Publishers.

Liu, H. e Motoda, H. (Eds.) (2007). Computational Methods of Feature Selection. Chapman and Hall CRC Data Mining and Knowledge Discovery Series.

Liu, H. e Yu, L. (2003). Feature selection for high-dimensional data: A fast correlation-based filter solution. In Correlation-Based Filter Solution". In Proceedings of The Twentieth International Conference on Machine Leaning (ICML-03), pp. 856-863. ICM.

Liu, H. e Yu, L. (2005a). Toward integrating feature selection algorithms for classification and clustering. IEEE Transactions on Knowledge and Data Engineering, 17(4):491-502.

Liu, H. e Yu, L. (2005b). Towards integrating feature selection algortihms for classification and clustering. IEEE Transactions on Knowledge and Data Engineering, 17(2):491-502. 
Lodish, H., Berk, A., Kaiser, C. A., Krieger, M., Scott, M. P., Bretscher, A., Ploegh, H., e Matsudaira, P. (2007). Molecular Cell Biology (Lodish, Molecular Cell Biology). W. H. Freeman, 6th ed.

Maimom, O. e Rokach, L. (2005). Introduction to knowledge discovery and data mining. In The Data Mining and Knowledge Discovery Handbook, pp. 1-15. Springer, second ed.

Malpica, J. A., Rejas, J. G., e Alonso, M. C. (2008). A projection pursuit algorithm for anomaly detection in hyperspectral imagery. Pattern Recognition, 41:3313-3327.

MATLAB (2010). version 7.10.0 (R2010a). The MathWorks Inc.

Nason, G. (1992). Design and Choice of Projection Indices. Tese de Doutorado, University of Bath.

Nason, G. (1995). Three-dimensional projection pursuit. Journal of the Royal Statistical Society, Series $C$, 44:411-430.

Nguyen, H. V. e Bai, L. (2010). Face verification using indirect neighbourhood components analysis. In Proceedings of the 6th international conference on Advances in visual computing - Volume Part II, ISVC'10, pp. 637-646. Springer-Verlag.

Nutt, C. L., Mani, D. R., Betensky, R. A., Tamayo, P., Cairncross, J. G., Ladd, C., Pohl, U., Hartmann, C., e Mclaughlin, M. (2003). Gene expression-based classification of malignant gliomas correlates better with survival than histological classification. Cancer Research, 63:1602-1607.

Oba, S., Sato, M., Takemasa, I., Monden, M., Matsubara, K., e Ishii, S. (2003). A Bayesian missing value estimation method for gene expression profile data. Bioinformatics, 19(16):20882096.

Pearson, K. (1901). On lines and planes of closest fit to systems of points in space. Philosophical Magazine, 27(6):559-572.

Pena, D. e Prieto, F. (2001). Cluster identification using projections. Journal of the American Statistical Association, 96(456):1433-1445.

Peng, H., Long, F., e Ding, C. (2005). Feature selection based on mutual information: criteria of max-dependency, max-relevance, and min-redundancy. IEEE Transactions on Pattern Analysis and Machine Intelligence, 27(8):1226-1238. 
Perisic, I. e Posse, C. (2005). Projection pursuit indices based on the empirical distribution function. Journal of Computational and Graphical Statistics, 14(3):700-715.

Pham, D. e Karaboga, D. (2012). Intelligent Optimisation Techniques: Genetic Algorithms, Tabu Search, Simulated Annealing and Neural Networks. Springer London, Limited.

Pires, A. M. e Branco, J. a. A. (2010). Projection-pursuit approach to robust linear discriminant analysis. Journal of Multivariate Analysis, 101(10):2464-2485.

Pomeroy, S. L., Tamayo, P., Gaasenbeek, M., Sturla, L. M., Angelo, M., Mclaughlin, M. E., Kim, J. Y. H., Goumnerova, L. C., Black, P. M., Lau, C., Allen, J. C., Zagzag, D., Olson, J. M., Curran, T., Wetmore, C., Biegel, J. A., Poggio, T., Mukherjee, S., Rifkin, R., Califano, A., Stolovitzky, G., Louis, D. N., Mesirov, J. P., Lander, E. S., e Golub, T. R. (2002). Prediction of central nervous system embryonal tumour outcome based on gene expression. Nature, 415(6870):436-442.

Posse, C. (1995a). Projection pursuit exploratory data analysis. Computational Statistics and Data Analysis, 20:669-687.

Posse, C. (1995b). Tools for two-dimensional exploratory projection pursuit. Journal of Computational and Graphical Statistics, 4(2):83-100.

Qiang, F., Tie-guang, L., e Hong, F. (2002). Applying PPP model based on RAGA to classify and evaluate soil grade. Chinese Geographical Science, 12(2):136-141.

Qu, G., Hairi, S., e Yousif, M. (2005). A new dependency and correlation analysis for features. IEEE Transactions on Knowledge and Data Engineering, 17(9):1199-1207.

Quinlan, J. R. (1992). C4.5: Programs for Machine Learning (Morgan Kaufmann Series in Machine Learning). Morgan Kaufmann, 1 ed.

Ram, R. e Chetty, M. (2011). A Markov-Blanket-Based Model for Gene Regulatory Network Inference. IEEE-ACM Transactions on Computational Biology And Bioinformatics, 8(2):353-367.

Ren, Y., Liu, H., Yao, X., e Liu, M. (2007). Prediction of ozone tropospheric degradation rate constants by projection pursuit regression. Analytica Chimica Acta, 589(1):150-158.

Rodriguez-Martinez, E., Goulermas, J. Y., Mu, T., e Ralph, J. F. (2010). Automatic induction of projection pursuit indices. IEEE Transactions on Neural Networks, 21(8):1281-1295. 
Roweis, S. T. e Saul, L. K. (2000). Nonlinear dimensionality reduction by locally linear embedding. SCIENCE, 290:2323-2326.

Russell, S., Meadows, L., e Russell, R. (2008). Microarray Technology in Practice. Academic Press, $1^{\mathrm{a}}$ edition ed.

Saeys, Y., Inza, I. n., e Larrañaga, P. (2007). A review of feature selection techniques in bioinformatics. Bioinformatics, 23(19):2507-2517.

Schena, M. (1999). DNA Microarrays: A Practical Approach. Practical Approach Series. Oxford University Press, 1 ed.

Scott, D. W. (1992). Multivariate Density Estimation: Theory, Practice, and Visualization. Probability and Mathematical Statistics.

Segal, E., Friedman, N., Kaminski, N., Regev, A., e Koller, D. (2005). From signatures to models: understanding cancer using microarrays. Nature Genetics, 37(S):S38-S45.

Sharma, A., Imoto, S., e Miyano, S. (2012). A Top-r Feature Selection Algorithm for Microarray Gene Expression Data. Computational Biology and Bioinformatics, IEEE/ACM Transactions on, 9(3):754-764.

Shen, R., Ghosh, D., Chinnaiyan, A., e Meng, Z. (2006). Eigengene-based linear discriminant model for tumor classification using gene expression microarray data. Bioinformatics, 22(21):2635-2642.

Shi, Y. e Eberhart, R. (2001). Fuzzy adaptive particle swarm optimization. In Proceedings of the 2001 Congress on Evolutionary Computation, vol. 1, pp. 101-106.

Shipp, M. A., Ross, K. N., Tamayo, P., Weng, A. P., Kutok, J. L., Aguiar, R. C., Gaasenbeek, M., Angelo, M., Reich, M., Pinkus, G. S., Ray, T. S., Koval, M. A., Last, K. W., Norton, A., Lister, T. A., Mesirov, J., Neuberg, D. S., Lander, E. S., Aster, J. C., e Golub, T. R. (2002). Diffuse large B-cell lymphoma outcome prediction by gene-expression profiling and supervised machine learning. Nature Medicine, 8(1):68-74.

Silva, V. D. e Tenenbaum, J. B. (2003). Global versus local methods in nonlinear dimensionality reduction.

Singh, D., Febbo, P. G., Ross, K., Jackson, D. G., Manola, J., Ladd, C., Tamayo, P., Renshaw, A. A., D’Amico, A. V., Richie, J. P., Lander, E. S., Loda, M., Kantoff, P. W., Golub, T. R., 
e Sellers, W. R. (2002). Gene expression correlates of clinical prostate cancer behavior. Cancer Cell, 1(2):203-209.

Spellman, P., Sherlock, G., Zhang, M., Iyer, V., Anders, K., Eisen, M., Brown, P., Botstein, D., e Futcher, B. (1998). Comprehensive identification of cell cycle-regulated genes of the yeast Saccharomyces cerevisiae by microarray hybridization. Molecular Biology of the Cell, 9(12):3273-3297.

Srinivas, M. e Patnaik, L. (1994). Genetic Algorithms - A Survey. IEEE Computer, 27(6):1726.

Stekel, D. (2003). Microarray bioinformatics. Cambridge University Press.

Su, Y., Shan, S., Chen, X., e Gao, W. (2011). Classifiability-based discriminatory projection pursuit. Transactions on Neural Network, 22(12):2050-2061.

Tan, Q., Thomassen, M., Jochumsen, K. M., Zhao, J. H., Christensen, K., e Kruse, T. A. (2008). Evolutionary algorithm for feature subset selection in predicting tumor outcomes using microarray data. In Mandoiu, I and Sunderraman, R and Zelikovsky, A (Ed.), Bioinformatics Research and Applications, vol. 4983 of Lecture Notes in Bioinformatics, pp. 426-433. Springer-Verlag Berlin. 4th International Symposium on Bioinformatics Research and Applications, Georgia State Univ, Atlanta, GA, May 06-09, 2008.

Tarca, A. L., Romero, R., e Draghici., S. (2006). Analysis of microarray experiments of gene expression profiling. American journal of obstetrics and gynecology, 195(2):373-388.

Tenenbaum, J. B., Silva, V., e Langford, J. C. (2000). A Global Geometric Framework for Nonlinear Dimensionality Reduction. Science, 290(5500):2319-2323.

Tu, J., Huang, T., Beveridge, R., e Kirby, M. (2003). Orthogonal projection pursuit using genetic optimization. In Proceedings Of The 2003 IEEE Workshop On Statistical Signal Processing, pp. 266-269.

Tu, Y., Stolovitzky, G., e Klein, U. (2002). Quantitative noise analysis for gene expression microarray experiments. Proceedings of the National Academy of Sciences U S A., 99(22):14031-6.

van der Maaten, L., Postma, E. O., e van den Herik, H. J. (2008). Dimensionality reduction: A comparative review. 
Wall, M., Rechtsteiner, A., e Rocha, L. (2003). Singular value decomposition and principal component analysis. A Practical Approach to Microarray Data Analysis, pp. 91-109.

Wang, S. e Zhang, X. (2010). Projection pursuit dynamic cluster model and its application to water resources carrying capacity evaluation. Journal of Water Resource and Protection, 2(5):2474-2482.

Webb-Robertson, B., Jarman, K., Harvey, S., Posse, C., e Wright, B. (2005). An improved optimization algorithm and bayes factor termination criterion for sequential projection pursuit. Chemometrics and Intelligent Laboratory Systems, 77(1-2):149-160.

Weinberger, K., Blitzer, J., e Saul, L. (2006). Distance metric learning for large margin nearest neighbor classification. Advances in Neural Information Processing Systems, 18:1473-1480.

West, T. R. (2006). Hyperspectral dimensionality reduction via sequential parametric projection pursuits for automated invasive species target recognition. Dissertação de Mestrado, Mississippi State University.

Witten, I. H., Frank, E., Trigg, L., Hall, M., Holmes, G., e Cunningham, S. J. (1999). Weka: Practical machine learning tools and techniques with java implementations. http://www.cs.waikato.ac.nz/ml/weka/.

Wright, A. H. (1991). Genetic algorithms for real parameter optimization. In Rawlins, G. (Ed.), Foundations of Genetic Algorithms, pp. 205-218. Morgan Kaufmann.

Yang, W., Wang, K., e Zuo, W. (2012). Fast neighborhood component analysis. Neurocomputing, 83:31-37.

Zhang, K. e Chan, L.-W. (2006). Dimension reduction as a deflation method in ica. Signal Processing Letters, IEEE, 13(1):45-48.

Zhao, L. e Zhang, Z. (2009). Supervised locally linear embedding with probability-based distance for classification. Computers and Mathematics with Applications, 57(6):919-926.

Zheng, Y. e Kwoh, C. K. (2011). A Feature Subset Selection Method Based On HighDimensional Mutual Information. Entropy, 13(4):860-901.

Zhou, N. e Wang, L. (2007). A modified t-test feature selection method and its application on the hapmap genotype data. Genomics, Proteomics and Bioinformatics, 5(3-4):242-249. 
Zhu, Z., Ong, Y.-S., e Zurada, J. M. (2010). Identification of Full and Partial Class Relevant Genes. IEEE-ACM Transactions On Computational Biology And Bioinformatics, 7(2):263277. 